\title{
4. Fluchtgrinde aus Sicht von DDR und SED: Komplexe Motive und einseitige Wahrnehmung
}

Viele hunderttausendmal trafen Menschen zwischen 1945 und 1961 die Entscheidung, die SBZ/DDR zu verlassen. Welche Gründe führten sie zu dieser nach Hirschman fast immer nprivate[n] und typischerweise stumme[n] Handlungsweise ", bei der es im Gegensatz zum öffentlichen Widerspruch „Abstimmung mit anderen, Delegierung und all die übrigen Kennzeichen kollektiven Handelns“ gewōhnlich nicht gab?' Hirschmans generelle Beobachtung über den privaten und hăufig klandestinen Charakter der Abwanderung gewinnt für die deutsch-deutsche Fluchtbewegung besondere Bedeutung, da sich die Bürger der DDR aufgrund der Diktatur in ihrer bisherigen Heimat davor hūten muBten, ihre Fluchtabsichten zu verraten, und erst recht davor, sie zu erlāutern. ${ }^{2}$ Dies wuBten auch die Behördenmitarbeiter, die für die Beobachtung und Bekämpfung der Republikflucht verantwortlich waren. So warnte ein Bezirksarzt, der das Gesundheitsministerium 1958 über die Abwanderung von Medizinern informierte, die Leser seines Berichtes vor methodischer Naivitāt, da „immer [...] damit gerechnet werden [muB], daß die vom Arzt angegebenen einzelnen Gründe nur vorgetäuscht sind." "Tatsāchlich haben sich nur sehr wenige Flūchtlinge vor ihrem Grenzübertritt zu ihrer Motivation geāußert. Dies macht die Ermittlung der individuellen Fluchtgründe schwierig. Einfacher festzustellen ist, wie die Fluchtmotive in der ostdeutschen Gesellschaft, vor allem von Seiten der Regierung, Parteien und Behörden der DDR wahrgenommen wurden. Dieser Blick unterscheidet sich von den meisten bisherigen Untersuchungen zu diesem Thema, die sich vorwiegend auf die Äußerungen der Geflüchteten nach ihrer Ankunft im Westen und auf ihre rückblickenden Betrachtungen stützen. Dies gilt nicht nur für geschichtswissenschaftliche, sondern auch für zeitgenössische Untersuchungen: Schon in den fünfziger Jahren führten Sozialwissenschaftler in der Bundesrepublik umfangreiche Erhebungen und Befragungen unter den Flūchtlingen aus der DDR über ihre Fluchtmotive durch. Einer besonderen Beliebtheit erfreuten sich dabei die gerade angekommenen Bewohner der West-Berliner und westdeutschen Aufnahmelager sowie die jugendlichen Zuwanderer, die in die Bundesrepublik kamen, ohne je zuvor in einer demokratischen Gesellschaft gelebt zu haben. ${ }^{4} \mathrm{Da}$ sie bei westdeutschen Politikern und Mitarbeitern sozialer Einrichtungen Befürchtungen vor einer integrationsresistenten Jugend auslösten, bestand ein zentrales Erkenntnisinteresse dieser Studien darin, desintegrativen Tendenzen unter den jugendlichen Zuwan-

\footnotetext{
' Hirschman, Abwanderung (1992), S. 351. Ähnliches stellt Wenzke, Fahnenflucht (1998), S. 281, über die Fahnenflucht als „Akt extremer Individualität“ fest.

2 Vgl. auch Bispinck, Flucht- und Ausreisebewegung (2004), S. 152.

* Bezirksarzt Dr. Papsdorf am 30.7.1958 an das Ministerium für Gesundheitswesen (BArch DO 1/34, Nr. 21719).

- Die beiden besten zeitgenōssischen Überblicksdarstellungen bieten Klein, Ursachen und Motive (1955), und Storbeck, Flucht oder Wanderung (1963). Vgl. auch Birkenfeld u.a., Sprung in die Freiheit (1953); von Nottbeck, Gründe und Hintergründe (1953); Ruge, Station der Flucht (1953); Berg, Notaufnahmelager (1956); Kegel, Psychische Situation (1953).
} 
derern entgegenzuwirken. ${ }^{5}$ Neben solchen vorwiegend sozialwissenschaftlich angelegten Studien gab es zahlreiche Interviews und Zeitzeugenberichte wie die von Erika von Hornstein veröffentlichten, die in ihrer politischen Aussage meistens zugleich deutlicher und zurückhaltender waren als die wissenschaftlichen Forschungen: zurückhaltender, weil sie auf große Integrationsentwürfe und Politikkonzepte verzichteten, gleichzeitig aber auch deutlicher und fordernder, weil sie die Massenflucht anhand von individuellen Schicksalen konkretisierten und mitsamt ihren zum Teil lebensbedrohlichen Ausmaßen darstellten. ${ }^{6}$

Die Reaktion auf die Flūchtlinge im Westen blieb bis zum Mauerbau 1961 zwiespältig: Zum einen bewies jeder Flüchtling in Zeiten des Kalten Krieges die Überlegenheit des Westens gegenüber der DDR; zum anderen stellten Zuwanderer für Westdeutschland in der Nachkriegszeit ebenso wie für die SBZ/DDR eine soziale Belastung dar. ${ }^{7}$ Neben den Problemen bei der Versorgung mit Nahrungsmitteln, Wohnungen und Arbeitsplātzen spielten Aspekte wie die Furcht vor einer „Entleerung “ der DDR, die unkontrollierte Einschleusung von Agenten und vor allem der Mißbrauch von Privilegien, die für politisch bedràngte Auswanderer reserviert waren, eine wichtige Rolle bei der westdeutschen Analyse der Fluchtmotive. Obwohl die bundesrepublikanischen Institutionen praktisch keinen Zuwanderer an der Grenze zurückwiesen und die DDR nicht nur in Sonntagsreden als Diktatur und Unrechtsstaat geißelten, unterschieden sie deutlich zwischen politisch bedrängten Flüchtlingen und solchen, die aufgrund familiärer, wirtschaftlicher oder anderer als vorwiegend privat eingeschätzter Gründe die DDR verließen. Eine wesentliche Rolle spielte der Zugang zu staatlicher Unterstūtzung, bei der sich die „Opferkonkurrenz" ${ }^{\text {8 }}$ der unmittelbaren Nachkriegszeit zwischen Vertriebenen und Einheimischen in den fünfziger Jahren so verschob, daß sich die seit wenigen Jahren etablierten Vertriebenen durch die Bedūrfnisse der ehemaligen DDR-Bürger bedroht zeigten. Nicht zufällig bezweifelte gerade der Bonner Vertriebenenminister Lukaschek eine tatsächliche politische Bedrohung vieler DDR-Flüchtlinge und bezeichnete diejenigen, „die glaubten, in der Bundesrepublik ein besseres Leben führen zu können“, als die größte Gruppe der Zuwanderer. ${ }^{9}$ Diese Verteilungskāmpfe wogen immerhin so schwer, daß die Bundesrepublik nur einen kleinen Teil der Zuwanderer aus dem Osten als Opfer der SED-Politik anerkannte: Den begehrten C-Ausweis, der die politische Zwangslage der Ausgewanderten anerkannte und dafür sozialstaatliche Privilegien gewāhrte, erhielten zwischen dem 1. Juli 1953 und dem 31. Dezember 1961 nur 14,2 Prorzent der aufgenommenen DDR-Flūchtlinge, ${ }^{10}$ wobei sich die Einschātzung der Fluchtmoti-

\footnotetext{
s Darin urafen sich die sozialwissenschaftlichen Interessen mit denen der westdeutschen politischen Inscitutionen, die einen großen Teil der Studien durch öffentliche Gelder finanzierten. $\mathrm{Zu}$ den desintcgrierten oder desintegrierenden Persönlichkeiten wurden etwa steuerungslose [] Intellektuelle" wic Rudi Dutschke gezāhlt, der nur einer von verschiedenen führenden Persönlichkeiten der Studentenbewegung war, die aus der DDR gekommen waren (Zitat aus Köllner, Limfang und Gründe [1961], S. 436f: vgl. auch Ackermann, Der „echte" Flüchtling [1995], S. 194).

${ }^{6}$ Gerade von Hornstein legte besonderen Wert darauf, den Blick auf die „einfachen Menschen. [...] die sonst stumm bleiben", zu lenken (von Hornstein, Die deutsche Not [1960], S. 11); vgl. auch von Kocnigswald, Der unabsehbare Strom (1957).

V Vl. Kap. 2.1, S. $24 \mathrm{f}$.

* Bade, Wege (1990), S. 7; vgl. auch Dettmer, Konflikte (1983).

9 Das Flūchtlingsproblem sehr ernst", in: FAZ Nr. 193 v. 22. 8. 1952.

10 Heidemeyer, Flucht und Zuwanderung (1994), S. 47.
} 
ve im Laufe der Jahre veränderte." Beispielsweise setzte sich in der Bundesrepublik erst Mitte der fünfziger Jahre die Erkenntnis durch, daß bei wirtschaftlichen Fluchtmotiven nicht sinnvoll zwischen politischen und unpolitischen Gründen unterschieden werden konnte, ${ }^{12}$ und erst seit 1957 wurden "schwere Gewissenskonflikte" als Zwangslage anerkannt. ${ }^{13}$ Um die Frage der berechtigten, also durch eine Zwangslage legitimierten Flucht rankten sich die langen Diskussionen über die Unterscheidung zwischen nechten " und ${ }_{n}$ unechten“"Flüchtlingen, bei denen das Fluchtmotiv das entscheidende Kriterium war.

Die enge Verbindung zwischen der Bestimmung der Fluchtmotive und der Anerkennung als „echtem" und darum privilegiertem Flüchtling führte dazu, daB sich diese „zu politischen Zwecken gestiftete Kunstfigur [...] zu verselbständigen tendierte ${ }^{\text {". }}{ }^{14}$ Jede öffentliche Analyse der Fluchtgründe hatte Auswirkungen auf die politische Debatte, die zwischen antikommunistischer Frontstellung und finanzpolitisch interessierter Sparsamkeit changierte. Dieser Kontext war nur ein Grund für die Schwierigkeiten im Westen, die Motive und Gründe systematisch zu erfassen. Verstärkt wurde sie durch die politisch überfrachtete Atmosphäre in den West-Berliner und westdeutschen Auffangstellen, in denen die $\mathrm{Zu}$ wanderer sofort von zahlreichen deutschen und westalliierten Stellen über die Situation in der DDR und über ihre persōnliche Geschichte befragt wurden. ${ }^{15}$ Diese Situation forderte hãufig Berichte zutage, die sich vorwiegend daran orientierten, was die Zuwanderer glaubten, vor den Vertretern der westlichen Staaten sagen zu müssen. Zudem schien es dank der öffentlichen Debatten im Kalten Krieg auch einfacher zu sein, von politischen Vorkommnissen als von privaten Schicksalen zu erzählen. So berichten die von Erika von Hornstein wiedergegebenen Fluchtgeschichten fast durchweg von Interventionen staatlicher Organe der DDR, namentlich der Polizei und des Staatssicherheitsdienstes. Die hãufig chaotischen privaten Lebenslagen, die bei vielen Betroffenen ebenfalls einen wichtigen Anteil an ihrem Motivbūndel ausmachten, blieben in den Berichten dagegen häufig undeutlich, schwer durchschaubar und daher weniger greifbar. ${ }^{16}$ Dabei bewegten vielfach gerade unpolitische Motive zum Weggang in den Westen, der durch familiäre, freundschaftliche und berufliche Kontakte für die meisten DDR-Bürger kein fremdes Territorium war. ${ }^{17}$

"Zur Entwicklung der juristischen Einschãtzung verschiedener Fluchtmotive in Westdeutschland vgl.: Ackermann, Der ${ }_{n}$ echte" Flüchuling (1995), S. 65-125.

${ }_{12}$ So heißt es z.B. in einem Artikel im SBZ-Archiv von 1955: „Wirtschaftliche Gründe werden von den Zonenflüchtlingen zwar oft angegeben, sie sind aber unter einem umgekehrten Vorzeichen zu verstehen. [...] Was als wirtschaftlicher Grund angeführt wird, hat in den meisten Fällen ein politisches Gepräge. [...] Der wegen eines Wirtschaftsvergehens angeklagte Zonenbewohner ist tatsächlich in der Regel das politische Opfer" (Schöller, Alarmierende Zunahme [1955], S. 311 f. Vgl. zu diesem Problem auch Ackermann, Der „echte“ Flüchtling [1995], S. 116 ff.).

13 Ackermann, Der nechte" Flüchtling (1995), S. 118.

is Ackermann, Der „echte“ Flüchtling (1995), S. 283 f.

15 Vgl. dazu Kimmel, Notaufnahmeverfahren (2005), S. 121-129; zu den Erfahrungen der Betroffenen mit den Befragungen vgl. ebd., S. $132 \mathrm{f}$.

${ }^{16}$ Schon die erste von Erika von Hornstein wiedergegebene Geschichte einer jungen Mutter macht die Schwierigkeiten drastisch deutlich: Die dramatischen persönlichen Familien-, Nachbarschafts- und Beziehungsprobleme verschwinden fast hinter den Repressionsmaßnahmen der Stasi und der Berufsbeschreibung des neuen Liebhabers, eines Volkspolizisten (von Hornstein, Die deutsche Not [1960], S. 15-29).

${ }_{17}$ Eine Folge dieser überpolitisierten, aber auch besonders unübersichtlichen Situation der Auswanderer waren - neben der antikommunistischen Rhetorik - Motivlisten, die eher einer Addition als einer Systematisierung glichen, und gleichzeitig den diktatorischen Charakter der DDR zuweilen überpointiert herausstellten. Vgl. etwa die Listen in: Bundesminister für gesamtdeutsche Fragen, Flucht aus der Sowjetzone (1961), S. 21 f.; Külz, Die Flūchllinge (1950), S. 11-14. 
Noch Ackermanns einschlägige Kapitel über die Fluchtmotive zeigen, wie schwer es fallt, die Vielfalt möglicher Motive und Gründe zur Abwanderung aus der DDR in den Westen zusammenzufassen. ${ }^{18}$ Seine Darstellung gibt zahlreiche Passagen aus verschiedenen Berichten wieder, ohne daß die disparaten Texte und Einschãtzungen zu einer schlüssigen Synthese zusammengebunden würden. Die verschiedenen, teilweise sogar gegensätzlichen Perspektiven und Interessen zwischen Ost und West, zwischen Staats- und Parteiorganen und einzelnen Betroffenen oder zwischen Sozialarbeitern und Finanzpolitikern führten bei Zeitgenossen hāufig zu einseitigen Systematisierungen. Das Zustandekommen solcher Einseitigkeit läßt sich auch an den seit 1952 wiederholt ausgegebenen Weisungen an die Volkspolizei und andere mit den Republikfluchten befaßte DDR-Organe ablesen, die besagten, daß es „in Zukunft nicht mehr vorkommen [dürfe], daß angeblich keine Gründe für die RF [Republikflucht] zu ermitteln sind. Die Einschãtzung hat ebenfalls in Zukunft einen politischen Charakter zu tragen und darf nicht formal sein. ${ }^{{ } 19}$ Nicht zuletzt solche Anweisungen verursachten auf DDR-Seite zuweilen überpolitisierte Berichte, in denen die Berichterstatter ihre Ahnungslosigkeit über individuelle Fluchtmotive hinter politischen Floskeln verbargen.

Für die westliche Wahrnehmung beispielhaft ist Heidemeyers Zusammenfassung der Fluchtmotive in sieben Gruppen: ${ }^{20}$ Neben den drei ersten Gruppen, deren Flucht durch den Krieg verursacht war (1-3), ${ }^{21}$ unterscheidet Heidemeyer je zwei Gruppen der "Zwangs-" und der "Arbeitswanderung “. Zum Zwang zāhlt er politische Gründe von Widerstand und Verfolgung bis zum Ausweichen vor Zwangsverpflichtungen etwa im Uranbergbau oder bei der Kasernierten Volkspolizei (KVP) (4) sowie wirtschaftliche Verdrāngungsprozesse beispielsweise durch Enteignung oder die Zwangsmitgliedschaft in Genossenschaften (5). Als Arbeitsmigranten schätzt Heidemeyer diejenigen ein, die aufgrund der wirtschaftlich besseren Erwartungen in den Westen kamen (6) sowie die undeutlich beschriebene Gruppe der „Asozialen, Kriminellen und Agenten“ (7). Ebenso wic die meisten der von ihm untersuchten westdeutschen Institutionen kommt auch Heidemeyer zu dem Ergebnis, daß nur eine Minderheit wegen politischer Gefahren abwanderte, die Mehrheit dagegen naus eher eigennützigen wirtschaftlichen Motiven “. ${ }^{.22}$

Aus der Sicht der Bewohner und der Institutionen der DDR stellten sich die Motive und Gründe etwas anders dar, wobei zu unterscheiden ist zwischen denen, die die DDR verließen, und denen, die ihren Sozialismus gegen die Fluchtbewegung verteidigen wollten und die Flūchtlinge als Verrãter oder Feinde brandmarkten. Die Perspektiven der DDRGesellschaft sind bislang wenig bekannt, zumal die offiziellen Analysen ostdeutscher Institutionen entweder unzugānglich oder ebenso unerträglich ideologisiert waren wie die

\footnotetext{
17 Ackermann, Der „echte" Flüchtling (1995), Kapitel 3.1 und 3.3. Vgl. auch die Statistik in: Eberle, Gegnerschaft (1996), S. 454 f., deren zusammengetragene „Begründungen“ zu einem betrāchulichen Teil keine Gründe und Motive nennen, sondern vor allem wiedergeben, wie die Parteikontrollkommission die (ieflohenen einschätzte: AJkoholismus“, „Schulden“, „moralisch verkommen“", masozial und arbeitsscheu“"

${ }^{19}$ SPK, Chemiekaderkommission, am 28. 7. 1960 (BArch DO 1/34, Nr. 21725).

20 Heidemeyer, Flucht und Zuwanderung (1994), S. 54-58. Vgl. auch die prinzipiell āhnlichen Svstematisierungen bei Klein, Ursachen und Motive (1955), S. 370 f., und Storbeck, Flucht oder Wanderung (1963), S. 158-163.

21 Die Flucht vor sowjetischen Truppen (1), die Rückkehr der im Krieg evakuierten Stadthevölkerung (2) und die Weiterwanderung der Vertriebenen aus den ehemals ostdeutschen Gebieten (3).

$x^{2}$ Heidemeyer. Flucht und Zuwanderung (1994), S. 57.
} 
Verlautbarungen in den DDR-Medien. Stārker wahrgenommen wurden literarische Verarbeitungen wie die 1963 erschienenen Būcher „Der geteilte Himmel“ von Christa Wolf und "Die Aula" von Hermann Kant, die allerdings weniger als Information über ostdeutsche Sichten auf die - inzwischen weitgehend unterbundene - Republikflucht, denn als Seismographen für die allgemeinpolitische Stimmungslage nach dem Mauerbau befragt wurden. ${ }^{3}$

Im folgenden wird vorwiegend aus offiziellen Berichten zitiert, in denen sich Staatsund SED-Funktionäre direkt oder indirekt über die Fluchtmotive äußerten. Dadurch bevorzugt auch diese Untersuchung nur eine von verschiedenen möglichen Perspektiven, nämlich die der SED und ihres Staates. Sofern die Flüchtlinge selbst zu Wort kommen, verdankt sich die Überlieferung der betreffenden Quellen zumeist der Polizei oder der Staatssicherheit, die Abschiedsbriefe aus dem regulären Postverkehr abfingen und sammelten. Noch deutlicher als bei den westlichen Texten ist bei den in der DDR abgefaBten Analysen zu erkennen, daB sie in einem interessegeleiteten politischen Umfeld entstanden sind. Thre Verfasser verfolgten vor allem die beiden Ziele, Fluchten zu vermeiden und das Thema politisch zu bagatellisieren. Bagatellisiert wurde der Massenexodus, weil er ganz offensichtlich eine „Abstimmung mit den Füßen “ gegen die DDR darstellte, letztich also eine Kritik an der SED-Herrschaft, ohne die der ganze ostdeutsche Staat nicht denkbar war.

Die Berichterstatter in der DDR zāhlten viele Fluchtgründe auf, die man in westlichen Analysen fast identisch wiederfindet. So sandte Maron in Folge der sowjetischen Kritik an den Zwangsaussiedlungen an der Westgrenze der DDR eine Liste von Fluchtgründen an die SKK, in der er zwar zuerst die ${ }_{n}$ gegnerische Beeinflussung " und die " negative Einstellung zur DDR" nannte, dann aber auch die kritische Einstellung der Bevölkerung zu den Genossenschaften, die Angst vor weiteren staatlichen ZwangsmaBnahmen und die allgemeinen wirtschaftlichen Schwierigkeiten aufzählte. ${ }^{24}$ Solche vorwiegend in Polizeibehörden und in der ZK-Abteilung für Staat und Recht verfaßten Berichte über die Flucht und Abwanderung entwickelten sich schnell zu detailfreudigen Spiegeln der gesellschaftlichen Mängel und Unzufriedenheiten, die fast alle wirtschaftlichen, politischen und kulturellen Problembereiche berührten, letztlich aber immer im dichotomen System der kommunistischen Weltdeutung verfangen blieben. Durch die reflexhaft anmutende Einordnung aller Phänomene in die Schwarz-Weiß-Muster von internationalem Systemgegensatz und Kaltem Krieg wurden selbst konkret beschriebene DDR-interne Fehlentwicklungen zu Folgen feindlicher Einflußnahme externalisiert oder als individuelle Fehler einzelner Funktionäre individualisiert.

Die Ursachen, die zur Flucht führten, waren fast immer komplexer, als es die bipolaren Interpretationen nahelegten, denn jeder einzelnen Flucht lag eine eigene Mischung verschiedener Gründe und Motive zugrunde. ${ }^{25}$ So bot die Auswanderung hãufig die Möglichkeit, persōnliche Probleme zu lōsen, die nichts mit dem internationalen Systemgegensatz zu tun hatten, die man aber dank der politisch-geographischen Grenze einfach hinter sich lassen konnte. Außerdem zāhlte die Attraktivitāt der Bundesrepublik zu den wichtig-

${ }^{23}$ Zur Thematisierung der Flucht in den beiden Romanen vgl. Müller-Toovey, Flucht und Ausreise im Spiegel der Kunst (2005), S. 174 f.

24 BArch DO 1/11, Nr. 961 Bl. $104 \mathrm{f}$.

25. Patrick Major spricht von einem "complex cocktail of motives“. Vgl. Major, Going West (2002), S. 202. 
sten Fluchtgrūnden, was die DDR-Berichterstatter selbstverstāndlich nicht oder nur in demagogisch abwertender Form notierten. Westdeutschland bewies vor allem in der zweiten Hälfte der fünfziger Jahre seine wirtschaftliche Überlegenheit, als die Mehrheit der Bevölkerung materiell unter weit besseren Bedingungen lebte als die Menschen in der DDR.

Herrschte im Westen die Frage nach der politischen Zwangslage als Motiv für die $\mathrm{Zu}$ wanderung vor, konzentrierten sich die meisten der in der DDR verfaßten Berichte auf die Arbeitswelt, auf einzelne Betriebe, Betriebsteile oder Berufsgruppen und stellten die Flüchtlinge in erster Linie als Mitglieder ihrer beruflichen oder sozialen Gruppe dar, wodurch zahlreiche Mißstande in der DDR und auch private Themen nur nachgeordnet behandelt wurden. Die Unterscheidung zwischen beruflichen, privaten und sonstigen Fluchtgründen war angesichts der gesellschaftspolitischen Wirklichkeit in der DDR allerdings nur schwer vorzunehmen. Neben der bereits erwähnten jeweils individuellen Mischung verschiedener Gründe lag dies vor allem an der beschränkten Gültigkeit der Grenzen zwischen privater und beruflicher Lebenswelt in einer Gesellschaft, die von der politischen Führung unter dem extrem weitreichenden Primat der Politik umgestaltet wurde, denn in der Perspektive dieser Machthaber blieben die beruflichen, die privaten und alle sonstigen Fluchtgründe letztlich nur Ausdruck einer richtigen oder falschen, also SED-loyalen oder illoyalen Haltung.

\subsection{Berufsspezifische Fluchtgrunde}

$\mathrm{DaB}$ sich die meisten offiziellen Berichte an einzelnen Berufsgruppen oder bestimmten Arbeitsplätzen orientierten, lag an der überragenden Bedeutung von Beruf und Arbeit in allen modernen Gesellschaften, die in der DDR noch dadurch gesteigert war, daß die SED ,ihr' Land in erster Linie als Arbeitsgesellschaft verstand. Obwohl diese Perspektive den Blick auf zahlreiche Fluchtgründe verstellte, fokussierte sie doch eines der wichtigsten Motivfelder der deutsch-deutschen Fluchtbewegung, nämlich die Behandlung vieler Menschen aufgrund ihrer beruflichen Qualifikation und Tãtigkeit. ${ }^{3 * 1}$ Schon in den ersten Jahren der SBZ/DDR zeigte sich das Phănomen der Vertreibung zahlreicher Menschen, die zu den alten, angeblich dem Untergang geweihten Eliten gezählt wurden oder wirtschaftlich selbstāndig waren. Die anfangs bewußt initiierte oder in Kauf genommene Vertreibung als gewaltfreie ,Lōsung' sozialer oder politischer Konflikte nahm zwar ab, als zu Beginn der fünfziger Jahre das bedrohliche Ausmaß der Abwanderung ins allgemeine Bewußtsein rũckte. Restriktive Maßnahmen gegen einzelne Bevölkerungsgruppen seuten sich aber in den fünfziger und sechziger Jahren fort und gaben immer wieder Anlaß zur Flucht. Dies betraf vorwiegend Bauern, Handwerker sowie Angehörige akademischer Berufe und Selbstāndige. Ihre Auswanderung hatten die Staats- und Parteifunktionäre meistens keineswegs geplant oder gewūnscht, aber sie wurde in Kauf genommen, weil das Erreichen von allgemein beschlossenen Planzielen Vorrang hatte. Die Analyse der Flucht-

${ }^{26}$ Dies zeigt sich auch am überdurchschnitulich hohen Anteil der ,arbeitsunfähige[n] Personen" an den erteilten Genehmigungen zur Übersiedlung in den Westen, die im Februar 1959 76,0 Prozent, im Oktober sogar 80,2 Prozent betrugen ( $\overline{\mathrm{C}}$ bersicht über den Innerdeutschen Reiseverkehr vom 17.3. 1959 und weiter unten vom Oktober 1958, und ofters in: BArch DO 1/34, Nr. 21727; 6. 10.1958, BArch DO $1 / 11$, Nr. 79, B1. 154). 
gründe anhand der Großgruppen Bauern, Handwerker, Akademiker und andere Spezialisten sowie Arbeiter orientiert sich an den zugrunde gelegten Quellen. Zahlreiche gruppenunspezifische Motive zeigen, daB die Einteilung unzureichend ist. Dennoch erlaubt diese Perspektive einen genaueren Blick auf die Wahrnehmung der Fluchtmotive durch SED und Staatsapparat und auf ihre Wertschātzung der verschiedenen Auswanderer.

Die SBZ/DDR verlor jedes Jahr mehrere tausend Bauern, die es vorzogen, im Westen zu leben. Schwerpunkte dieser Fluchtbewegung waren - nach den Enteignungen und Ausweisungen im Zuge der Bodenreform Mitte der vierziger Jahre - die Jahre 1952/53 und 1960/61: Im Jahr 1953 zählte die Zentralverwaltung für Statistik insgesamt 11613 und in den beiden letzten Jahren vor dem Mauerbau 6283 bzw. 5257 geflohene Bauern; zu keiner anderen Zeit gab es vergleichbar hohe Zahlen. ${ }^{\text {g7 }}$ FluchtanlaB in diesen Jahren war fast immer die Kollektivierungspolitik, die die SED in diesen Zeiten besonders vorantrieb. Der erste Zeitraum stimmt mit der allgemeinen Fluchtwelle in Folge der Zweiten Parteikonferenz der SED vom 9. bis 12. Juli 1952 überein und endet mit der Verkündung des Neuen Kurses im Sommer 1953.28 In diesen Monaten forcierte die SED ihre Politik vor allem gegen die noch verbliebenen Großbauern, ${ }^{29}$ die nach der Enteignung und Vertreibung der Großgrundbesitzer hāufig im Verdacht standen, die informellen Macht- und Informationszentren auf dem Land zu bilden. Viele von ihnen gerieten durch die seit 1950 sukzessive erhöhten Ablieferungsanforderungen in Schwierigkeiten, zumal auch die Beschaffung von Saatgut, Düngemitteln, Maschinenersatzteilen und anderen Dingen, die zur landwirtschaftlichen Standardausrüstung gehörten, für sie zunehmend schwieriger wurde. Auch Ernteausfälle aufgrund von Unwettern wurden bei der Festlegung des Solls bei Großbauern kaum berūcksichtigt. So konnte eine Mecklenburger Landwirtin ihr Soll nicht erfüllen, weil ein schwerer Hagelsturm ihre Ernte im Sommer 1950 fast vollstāndig vernichtet hatte. Sie wurde daraufhin eines Wirtschaftsverbrechens angeklagt. Zwar sprach das Landgericht Güstrow die GroBbāuerin frei, doch sollte sie 1951 die Ablieferungsrūckstānde des Vorjahres ausgleichen, wozu die Erträge bei weitem nicht ausreichten. Daraufhin wurden sämtliche Vorrāte auf ihrem Hof beschlagnahmt. Einer drohenden erneuten Verhaftung entzog sie sich durch die Flucht in den Westen. ${ }^{30}$ Die politischen Probleme verschärften sich 1952 noch durch eine verhāltnismāßig schlechte Ernte, die zu allgemeinen Versorgungsengpässen führte. ${ }^{31}$ Hatten SED und Staatsapparat zuerst die Großbauern als Hauptverantwortliche für alle Probleme ausgemacht, richteten sich ihre Vorwürfe seit Beginn der Vergenossenschaftlichung gegen die selbstândigen Bauern, da die eigene Landwirtschaftspolitik und die LPG-Gründungen per se als, fortschrittlich

\footnotetext{
${ }^{27} \mathrm{Vgl}$. Tabelle 3. Die Zahlen gehen auf eine umfangreichere Statistik zurück, in der in einzelnen Jahren Großbauern, LPG-Mitglieder und andere Sondergruppen aus- und wieder eingegliedert wurden. Da diese Differenzierungen vor allem für die konflikthaften Jahren der Vergenossenschafulichung ungenau sind - zahlreiche Bauern flohen wenige Stunden oder Tage, nachdem sie einen Vertrag zum Beitritt in die LPG unterschrieben hatten - werden die Zahlen hier zusammengezählt. Die westdeutsche Notaufnahmestatistik bestātig diesen Trend: hier war der Anteil der Berufsgruppe "Pflanzenbau/Tierwirtschaft" an den Aufgenommen in den Jahren 1952, 1953 und 1960 am höchsten; vgl. die Tabelle bei Heidemeyer, Flucht und Zuwanderung (1994), S. 51.

28 Vgl. oben Kap. 3.2, S. 49-54.

29 Vgl. dazu Bauerkämper, Ländliche Gesellschaft (2002), S. 288-300.

so Vgl. dazu Bispinck, Motive (2005), S. 57; Nieske, Republikflucht (2001), S. 82-85; Nieske, Vom Land (1997), S. 330-336.

"Vgl. Baring, Der 17. Juni (1983), S. 34 ff.
} 
galten und damit grundsätzlicher Kritik entzogen waren. Die angeblich ungenügende Produktivitât selbstãndiger Bauern wurde in erster Linie mit politischen und strafrechtlichen Mitteln beantwortet. Viele Bauern gerieten so ins Visier der Sicherheitsorgane und der Staatsanwaltschaften oder wurden aufgefordert, ihre Höfe in die neuen Produktionsgenossenschaften einzubringen. ${ }^{52}$ Die Folge war wenig überraschend: Nachdem Ende der vierziger und Anfang der fünfziger Jahre viele Neubauern die ihnen während der Bodenreform zugeteilten unrentablen Kleinparzellen aufgegeben hatten, 3 flohen seit 1952 auch viele alteingesessene Bauern, weil sie ihr Ablieferungssoll nicht erfüllen konnten oder sich nicht in die LPG integrieren wollten. ${ }^{\text {s4 }}$

Auch die zweite Fluchtwelle spiegelte eine Verschärfung sowohl der allgemeinpolitischen Lage als auch der Landwirtschaftspolitik wieder. Seit 1960 forcierte die SED die zwischenzeitlich zurückgestellte Vergenossenschaftlichung wieder. Die Gründung der LPG wurde dazu genutzt, den EinfluB und hãufig auch die Anwesenheit alteingesessener Bauern und ihrer Familien zu beseitigen, nicht zuletzt weil das Kompetenzgefälle zwischen ihnen und vielen der aus Gründen politischer Opportunitāt eingesetzten Funktionstrāger der LPG die Autoritāt von Staat und SED und den Glauben an die Überlegenheit der sozialistischen Wirtschaft unterminierte. ${ }^{35} \mathrm{Am}$ 14. April 1960 erklärte die Regierung auch die letzte Gemeinde der DDR zum nvollgenossenschaftlichen Dorf", aber der Unmut darüber war groB: „Das flache Land wurde in den năchsten Monaten ununterbrochen von Protesten, Gewalt, Brandstiftung, Selbstmord, Republikflucht und der Auflösung vieler LPG heimgesucht. Erst mit dem Mauerbau kam die Ruhe. ${ }^{.96}$ Die Flucht von einigen tausend Bauern überraschte niemanden ${ }^{37}$ und wurde auch nicht zum Anlaß für Kurskorrekturen genommen.

Den Zusammenhang zwischen forcierter Landwirtschaftspolitik und verstärkter Auswanderung erkannten auch HVDVP und SED in ihren Analysen. Immer wieder wiesen sie auf die Flucht von Bauern hin, „die erst 2 Tage Mitglied der L.PG waren. " ${ }^{\text {sk }}$ Die Hauptabteilung Innere Angelegenheiten des Innenministeriums wuBte in einer vertraulichen Dienstsache vom 12. Mai 1960 zu berichten, da „der überwiegende Teil“ der geflohenen Bauern nerst vor kurzem der Genossenschaft beigetreten [sei]. Ein Mangel ist, daß die po-

\footnotetext{
32 Zur "Politik gegen Bauern“ in der SBZ/DDR vgl. Mitter, Die Bauern und der Sozialismus (1995) (Zitat S. 83); „Verordnung üher devastierte landwirtschaftliche Betricbe“ vom 20. 3. 1952, GBI. Nr. 38, 27. 3. 1952, S. 226 f.; Ulbricht, Gegenwärtige Lage (1952), S. 102-114; Bauerkämper, Ländliche Gesellschaft (2002), S. 159 ff.; Bauer, Blockpartei (2003), S. 335 ff:; Bell. Enteignungen (1992); Nehrig, Bauern (1993); Schulz, Ruhe im Dorf? (1990); Werkentin, Politische Strafjustiz (1995). S. 52-112.

"s Osmond, Kontinuitāt (1996), S. 147 f.

4 Nach Kramer, Landwirtschaft (1957). S. 25, sollen bis zum 31. 10. 1953 ca. 14000 selbstāudige Bauern geflohen sein. Zur Bauernflucht vgl. auch die von Nieske. Republikflucht (2001), gesammelten Erinnerungsberichte.

${ }^{35} \mathrm{Vgl}$. einen anschaulichen Bericht dazu in: von Hornstein, Die deutsche Not (1960), S. 30-42.

${ }^{36}$ Osmond, Kontinuitāt (1996), S. 159. Nach einem Bericht über die Lage in der Landwirtschaft von 3. 3. 1961 stiegen die Fälle vorsätzlicher Brandstiftung von 1959 auf 1960 um 56 Prozent. Als Hauptursache wurde zutreffend „Haß gegen die LPG“ ausgemacht. BStL: ZA, MfS-BdI. Nr. 005157, BI. 28.

37 Karl Schirdewan hatte Anfang Januar 1958 kurz vor seinem AusschluB aus dem ZK darauf hingewiesen: „Mit der Beschleunigung des Aufbaus des Sozialismus auf dem Lande müssen wir auch [damit] rechnen, daß in größerer Zahl werktātige Einzelbauern republikflüchtig werden." (Schirdewan, Aufstand [1994], S. 207); zur zweiten Fluchtwelle der Bauern vgl. Major, Torschlußpanik (2000), S. 226 f.

*6 HVDVP, Generalmajor der VP Dombrowsky am 30.9.1958 an die HA Innere Angelegenheiten über Genossen Staatssekretār Grūnstein (BArch DO 1/34. Nr. 21725).
} 
litische Massenarbeit bei der Werbung oftmals nicht genügend differenziert durchgeführt wurde." Ein Beispiel aus der Gemeinde Glindow (Potsdam-Land) beschrieb den offensichtlichen Einfluß des politischen Stils der SED: „Das Gerūcht, daß die Obstbauern ihre Hãuser los werden, bekam noch mehr Nahrung durch das von der dort tãtigen Brigade herausgegebene Flugblatt. Darin stand, daß die Bankkonten, Kraftfahrzeuge und Möbel als persönliches Eigentum den Bauern verbleiben, von Haus, Grund und Boden wurde nichts erwāhnt. Die Agitatoren brachten gegenüber alten Bauern zum Ausdruck, daB [sie], wenn sie zum Eintritt in die Genossenschaft zu alt sind, in ein Altersheim kommen und in ihrem Haus arbeitsfahige Menschen untergebracht werden (es bedurfte längerer Aussprache, um die Menschen von dieser falschen Auffassung zu befreien). ${ }^{49}$ Ebenso bekannt wie solche häufig wiederkehrenden Einzelfalle waren strukturelle Probleme wie das des Ablieferungssolls, das zu zahlreichen Fluchten führte. ${ }^{40}$

Die Bildung der LPG führte zur Zuspitzung von Konfliktlagen, die die ländliche Gesellschaft der DDR auch zu anderen Zeiten prägten. Das Verhāltnis zwischen den politischen Institutionen und einem großen Teil der ländlichen Bevölkerung, vor allem der noch selbständigen Bauern, war von erheblichem MiBtrauen geprägt. Den allgemeinen Hintergrund bildete die seit 1945 auf dem Land erst langsam gefestigte Erkenntnis, daB die SED den seit Jahrhunderten überkommene[n] und scheinbar festgefügte[n] Begriff vom Eigentum am Boden [...] mehr und mehr gelockert" hatte, und daB die Eigentumsverhältnisse dadurch „äußerst labil geworden" waren."1 Konkret erwuchs das Mißtrauen nicht nur aus der Berliner Landwirtschaftspolitik, sondern eher noch aus kleinen Vorfällen vor Ort, etwa wenn die Polizei nicht einmal den Genossenschaftsbauern vertraute und ihrem gerade 24 Stunden zuvor gewāhlten LPG-Vorsitzenden wegen angeblicher Republikfluchtpläne den Personalausweis abnahm. ${ }^{42}$ Vor allem die alteingesessene ländliche Bevölkerung hielt die SED für bauernfeindlich und inkompetent. Schon die Bodenreform war bei vielen Bauern nicht auf Gegenliebe gestoßen, weil sie mit einer Bevorzugung von Neubauern einhergegangen war, die in vielen Fällen fachlich ungeeignet waren. Die radikale Wendung der Landwirtschaftspolitik 1952/53 verstärkte die Aversionen, denn allein schon das Tempo der gesellschaftlichen Veränderungen widersprach der von Regelmäßigkeit und Kontinuitāt geprägten und abhängigen Lebensweise und Mentalitāt der lāndlichen Gesellschaft. Obwohl Regierung und SED mit dem Neuen Kurs im Sommer 1953 zahlreiche der abgelehnten Maßnahmen zurücknahmen, mußten sie weiterhin mit der ${ }_{n}$ grūnen Front ${ }^{443}$ der Bauern rechnen. Auch ohne die forcierte Enteignungs- oder Vergenossenschaftlichungspolitik flohen jāhrlich mehrere Tausend Bauern in den Westen, denn die generelle Einschãtzung der SED als bauernfeindliche Partei verstärkte sich im Laufe der Jahre noch durch ihre offensichtliche Inkompetenz. Oft war nicht die LPGGrũndung selbst, sondern die damit verbundene Personalpolitik der Anlaß für die Republikflucht. Im Notaufnahmelager Marienfelde in West-Berlin gaben Bauern als Fluchtmotiv die Befürchtung an, neinem jungen, nur politischen Mann ausgeliefert zu werden, der

\footnotetext{
${ }^{39}$ Analyse der Republikfluchten in der Landwirtschaft, BArch DO 1/34, Nr. 21718.

40 Dombrowsky, Generalmajor der Volkspolizei, HVDVP, Der Leiter, am 10.9.1958 an die HA Innere

Angelegenheiten über Gen. Staatssekretär Grūnstein (BArch DO 1/34, Nr. 21725).

11 Bohne, Die Dritte Welle (1953), S. 283.

42 Vertrauliche Dienstsache 12.5. 1960, BArch DO 1/34, Nr. 21718.

4s Brant, Der Aufstand (1954), S. 256.
} 
nicht aus dem Dorfe stammt und von der Landwirtschaft wenig oder keine Ahnung " hat. Wörtlich äußerte ein Bauer: „Ich hatte eigentlich gar keinen wirtschaftlichen Grund. Ich hatte Angst vor mir selber, daB ich unserem Vorsitzenden nicht einmal die Mistgabel ins Kreuz jage. Ein junger Schnösel war das, vom Tuten und Blasen nicht die geringste Ahnung, nur dauernd politische Phrasen im Kopf. Das Transparent an der Scheunentūr wurde wichtiger als die Arbeit im Stall. ${ }^{44}$ Angesichts der negativen Folgen der politischen und administrativen Einflußnahme und Regelungskompetenz glaubten die wenigsten alteingesessenen Bauern - trotz aller Propaganda - an die immer wieder öffentlich behauptete Überlegenheit der Genossenschaften.

Dazu trug bei, daB sich viele SED-Funktionäre tatsāchlich nicht um eine bessere Verständigung zwischen ihnen und der Landbevölkerung bemühten, sondern ihre arrogante Grundeinstellung gegenüber der dōrflichen und kleinstädtischen Bevölkerung geradezu pflegten. Nie sahen sie den Grund für ein Problem bei Regierung und Partei, sondern immer nur bei den ,unaufgeklärten' Landwirten: „Bei der Analysierung der Abwanderungsgründe der Bauern sticht besonders hervor, daß alle Gesetze und Maßnahmen unserer Regierung auf vōlliges Unverständnis bei den Bauern stoßen. ${ }^{\text {"45 }} \mathrm{Da}$ die Kritik der Bauern aber nicht immer von der Hand zu weisen war und die Berichte der Dramatik der Fluchtwellen wenigstens ansatzweise gerecht werden mußten, fanden die Genossen mit der Zeit auch andere Ursachen für die Probleme, ohne damit allerdings die von ihrer Partei- und Staatsspitze entschiedene Politik zu kritisieren oder zu belasten. Zur Zielscheibe der Kritik machten sie daher zum einen die bereits erwāhnten unfāhigen Bürokraten, zum anderen den Westen. Den Bürokraten wurde unterstellt, einzelne Fehler zu machen, die mit ihrer fachlichen Unterqualifizierung oder ihrem politischen Übereifer erklärt wurden und durch Schulung und größere politische Linientreue abgestellt werden sollten. Der Westen

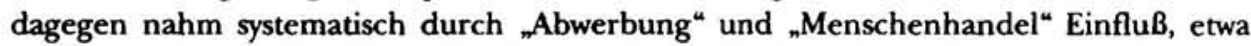
wenn DDR-Bürger die "Grüne Woche“ in West-Berlin besuchten oder wenn in der DDR Gerüchte kursierten, daß es westdeutsche Bestimmungen zur Unterstützung der Überseeauswanderung etwa nach Kanada gebe oder daß Bauern im Westen für ihr Land entschādigt würden. ${ }^{46}$

In einem ähnlichen Rahmen beurteilten die Berichterstatter die Republikflucht von Handwerkern $^{47}$, die ebenfalls häufig von politischen Maßnahmen gegen selbstāndige Betriebe veranlaßt wurde. Nie waren selbstāndige Betriebe in der SBZ/DDR wohl gelitten ge-

4 Dok. 21.

45 Dok. 15.

${ }^{46}$ BArch DO 1/34, Nr. 21724: „Methoden der Abwerbung von Bürgern der DDR“, o.D. (1960/61), S. 14; MdI HA Innere Angelegenheiten, Analyse der Republikfluchten in der Landwirtschaft, 12.5.1960 (BArch DO 1/ 34, Nr. 21718).

47 Zum Handwerk in der DDR vgl. die wirtschaftswissenschafuliche Studie von Büter, Handwerk (1997); Buck, Formen (1995), S. 1130 ff., 1163-1168; für die SBZ Großbölting, Zwischen ökonomischer Marginalisierung (2000) sowie für die Phase bis 1953 Owzar, Sozialistische Būndnispolitik (2001). S. 339-444. Owzars Studie, die sich auf Thüringen konzentriert, geht von einer im Vergleich zu anderen Sozial- und Berufsgruppen deutlich geringeren Auswanderungsquote bei Handwerkern aus. Bei ihm finden sich auch interessante Hinweise auf die Gründe, die Handwerker zum Verbleib in der DDR veranlaßten (S. 451-455). Einzelne Hinweise zu republikflüchtigen Handwerkern finden sich auch bei Scheybani, Handwerk (1996), S. 173 ff.; in ãlteren, vom Bundesministerium für Gesamtdeutsche Fragen (Plönies/Schōnwalder, Sowjetisierung [1951]) und der Friedrich-Ebert-Stiftung herausgegebenen Broschūren (Friedrich-Ebert-Stiftung, Handwerk und Gewerbe [1976]) sowie für die SBZ-Phase bei Schmidt, Gewerblicher Mittelstand (2000), S. 239 f. 
wesen, und jedes Jahr waren zahlreiche ihrer Eigentümer in den Westen gegangen. Infolge des fünften Parteitages 1958 richtete sich ein verstärkter Druck zur Eingliederung in Genossenschaftsbetriebe auch auf Handwerksbetriebe. Mit der bereits bei den Bauern angewandten Mischung aus Propaganda, Versprechungen und Zwang schafften es Regierung und SED, die Zahl der selbstāndigen Betriebe stark zu dezimieren. Viele Handwerker gewann man damit aber nicht für die neuen Produktionsgenossenschaften, sondern vertrieb sie außer Landes. Die staatlichen Behörden nahmen diesen Exodus nicht erheblich anders wahr als den der Bauern. Im Vordergrund stand die Verantwortung der Handwerker selbst, die zwar kein staatlich festgelegtes Ablieferungssoll zu erfullen hatten, dafür aber - neben den alltäglichen Problemen etwa bei der Materialbeschaffung - nicht unerheblich unter der Steuerpolitik und den 1949/50 einsetzenden Steuerüberprüfungen litten. ${ }^{48}$ Die daraus resultierenden wirtschaftlichen Schwierigkeiten nahmen die staatlichen Behörden nur achselzuckend zur Kenntnis: Aus Frankfurt flohen drei „Schneidermeister bzw. Schneiderinnen [...]. Sie hatten angeblich wirtschaftliche Schwierigkeiten, lehnten es aber $\mathrm{ab}$, einer Produktionsgenossenschaft beizutreten. ${ }^{49}$ Einem selbständigen Tischler, der den Eintritt in eine Genossenschaft hartnāckig verweigert hatte, wurde, nachdem man bei einer Hausdurchsuchung Konsumgüter aus West-Berlin gefunden hatte, ein Strafverfahren sowie die SchlieBung seines Betriebes angedroht, woraufhin er mit seiner Frau flūchtete. ${ }^{50}$ Diese Politik gegen Handwerker veranlaBte den Leiter der Hauptabteilung Innere Angelegenheiten im Innenministerium, Bergmann, im Oktober 1958 immerhin zu einem kritischen Vorsto $B$ gegenüber der Staatlichen Plankommission, ohne $\mathrm{da} B$ er allerdings auf die politisch opportune antiwestliche Rhetorik verzichtete: Die ansteigende Tendenz in der Republikflucht der Handwerker zeige, ${ }_{n}$ daB der Klassengegner die Abwerbung verstärkt auch auf diesen Personenkreis konzentriert und dadurch versucht, die weitere Einbeziehung dieser Bevölkerungsschichten in den sozialistischen Aufbau zu hemmen." Trotzdem schlug er vor, prüfen zu lassen, „ob nicht die in einzelnen Bezirken der DDR in letzter Zeit aufgetretenen Entstellungen in Durchführung des Beschlusses des V. Parteitages EinfluB auf diese Entwicklung haben. ${ }^{451}$ Obwohl ihre Folgen also bekannt waren und wirksam blieben, änderte sich die Politik gegenüber den Handwerkern nicht nennenswert. Noch im Februar 1961 bemängelte die Polizei, daß Parteigruppen in verschiedenen Kreisen mit aller Gewalt versuchten, alle Handwerker zu Produktionsgenossenschaften des Handwerks zusammenzuschließen. Es bedurfte mehre-

48 Vgl. dazu Buck, Formen (1995), S. 1163-1168; Owzar, Sozialistische Bündnispolitik, S. 309 f.; Tatzkow, Gehen oder bleiben (1993), S. 208 f.

49 Dombrowsky, Generalmajor der Volkspolizei, HVDVP, Der Leiter, am 30.9. 1958 an die HA Innere Angelegenheiten über Gen. Staatssekretär Grünstein (BArch DO 1/34, Nr. 21725).

30 Der Leiter des Bundes-Notaufnahmeverfahrens in Berlin, Begründung für Erteilung der Aufenthaltserlaubnis, 26. 6. 1959 (BStU ZA, MfS-AS, Nr. 231/63, Bd. II, Bl 5 f.). Ein weiteres Beispiel hat von Hornstein, Die deutsche Not (1960), S. 115-119, aufgezeichnet.

51 BArch DO 1/34, Nr. 21725. Tatsāchlich ist der im selben Dokument angeführten Statistik kein Anstieg, sondern ein leichter Rückgang der republikflüchtigen Handwerker zu entnehmen: 1957 flohen im Monat durchschnittlich 141, von Januar bis August 1958 durchschnittlich 130 Handwerker. Den Angaben der ZV für Statistik ist sogar ein deutlicher Rūckgang von 2494 (1957) auf 1814 (1958) zu entnehmen, der aufgrund der insgesamt stark zurückgegangenen Fluchtbewegung jedoch einen leichten prozentualen Anstieg von 0,71 Prozent auf 0,85 Prozent bedeutet. Daß die Zahlen der ZV für Statistik deutlich über denen des MdI liegen, zeigt einmal mehr, mit welcher Vorsicht solche Angaben zu genießen sind. 
rer Hinweise der Bezirksleitung, bis diese falsche Arbeit korrigiert wurde. ${ }^{452}$ Solche Mahnungen und Vorschläge zu mehr Zurückhaltung blieben aber Einzelfälle. Im Vordergrund der Ursachenforschung stand die angebliche Abwerbung durch die Bundesrepublik. Als Beleg dafür wurden beispielsweise Berichte in westdeutschen Medien angeführt, nach denen als politische Flüchtlinge anerkannten Handwerkern, Gewerbetreibenden und Unternehmern in der Bundesrepublik Aufbaukredite von bis zu 35000 DM, in Ausnahmefallen sogar bis zu 50000 DM gewährt würden. Diese Berufsgruppen seien zudem „auf Grund ihrer teilweise abwartenden Haltung für die Beeinflussung durch den Gegner besonders empfänglich". ${ }^{53}$ Insgesamt wurde der Republikflucht von Handwerkern weniger Aufmerksamkeit geschenkt als der anderer Berufsgruppen, und das obwohl es schon 1952 aufgrund der Republikflucht im Gefolge der Zwangsaussiedlungen Schwierigkeiten bei der (Neu-)Besetzung der Handwerksbetriebe gegeben hatte. ${ }^{54}$ Unternehmer, die über größere Betriebe verfügten, gingen zum großen Teil bereits in den ersten Jahren nach Kriegsende in den Westen. Sie werden in den offiziellen Berichten jedoch in erster Linie nicht als Flüchtlinge, sondern - hãufig nicht zu unrecht - als Abwerber erwāhnt. ${ }^{55}$

Die führende Partei der DDR verstand sich als Arbeiterpartei, in deren Tradition Bauern und Handwerker nur von nachgeordneter politischer Bedeutung waren. Daraus erklärt sich auch ihr im ganzen recht geringes Interesse für die Abwanderung aus diesen Bevōlkerungs- und Berufsgruppen. Der Weggang von Arbeitern mußte sie dagegen mehr beunruhigen, da sie ihren Staat als Verwirklichung der im Marxismus-Leninismus beschriebenen historischen Aufgabe der Arbeiterklasse verstand. Deren Angehörige sollten die ersten und wesentlichen Profiteure der Veränderungen sein. Gegen Arbeiter konnte es zudem keine wirtschaftlich existenzgefāhrdenden Eingriffe wie Enteignung oder zwangsweise Vergenossenschaftlichung geben, und auch das soziokulturelle Verhalten dieser Bevōlkerungsgruppe enthielt keine von der SED als ,reaktionār' oder ,klassenfeindlich denunzierten Elemente. Doch trotz dieser klassenspezifischen Privilegierung ${ }^{56}$ flohen auch zahlreiche Arbeiter aus der DDR in den Westen. Bezogen auf ihren prozentualen Anteil an der gesamten Bevölkerung wanderten zwar weniger Arbeiter als Batern oder Akademiker ab, absolut gesehen lag ihre Zahl aber immer um ein vielfaches über der der anderen Berufsgruppen. Vermutlich flohen Arbeiter und andere niedrig qualifizierte Arbeitnehmer daher seltener wegen akuter Gefahr oder einzelner Maßnahmen, als aufgrund alltäglicher Sorgen und Probleme in der DDR, die sie mit der Mehrheit der Bevölkerung teilten und die längerfristig bestanden. Diese Unzufriedenheit paßte nicht in das Bild von der DDR-Gesellschaft, das Regierung und SED für allgemeingültig ausgaben und in dem gesellschaftliche Probleme als Folge des Kapitalismus und der NS-Diktatur dargestellt wurden, deren ,Korrekturen' aber zu Lasten der ehemals sozial, ōkonomisch oder kulturell Privilegierten gehen sollten. In den ersten Jahren der SBZ und DDR konn-

\footnotetext{
${ }^{32}$ Bericht vom 13.2. 1961 (BArch DO 1/11, Nr. 967, Bl. 37-60, hier Bl. 38).

53 „Methoden der Abwerbung von Bürgern der DDR*, o.V., o.D. [1960], BArch DO 1/34, Nr. 21724 , hier S. 12.

it Bericht der operativen Kommission aus dem Kreis Eisenach, 16. 6. 1952 (SAPMO-BArch DY 30/IV 2/ $13 / 11, \mathrm{Bl} .62)$.

3s Vgl. dazu Hefele, Die Verlagerung (1998).

s6 Von einer Privilegierung kann nur im Verhãltnis zu anderen Bevölkerungsgruppen gesprochen werden; auch die Arbeiter hatten an den Kriegsfolgen und dem Aufbau des Sozialismus schwer zu tragen. Dic starke Beteiligung von Arbeitern an den Unruhen um den 17.6. 1953 machte dies besonders deutlich.
} 
te dieses Bild noch eine gewisse Plausibilitāt für sich reklamieren, spātestens Mitte der fünfziger Jahre wurde aber angesichts der Vollbeschäftigung und des breiten Konsumanstiegs in Westdeutschland deutlich, daß der Aufbau im Westen fast allen Bevölkerungsgruppen zugute kam und auch den meisten Arbeitern und Angestellten einen weit über dem DDR-Durchschnitt liegenden Lebensstandard ermöglichte.

Vor dem Widerspruch zwischen politischem Anspruch und gesellschaftlicher Wirklichkeit in Ost- und Westdeutschland kapitulierten die meisten Berichterstatter in den Reihen der Polizei und des ZK: Bei der Suche nach den Ursachen für die Westabwanderung von Arbeitern und Angestellten kamen sie zu noch weniger konkreten und problemorientierten Ergebnissen als bei den anderen Berufsgruppen. Ideologische Formeln über ,falsches BewuBtsein' waren die einfachste Form, mit der Abwanderung von Arbeitern - und von SED-Mitgliedern - umzugehen: „Es gibt solche Erscheinungen, wo Genossen mit langjähriger Parteizugehōrigkeit nach ihrem Besuch in Westdeutschland die Lage falsch einschätzen und die Konjunktur in Westdeutschland verherrlichen." Neben dem Verdacht, $\mathrm{da} ß$ das Ostbüro der SPD seinen Einfluß geltend gemacht hatte, hieß die Diagnose gewōhnlich in erster Linie politische Unklarheiten ${ }^{477}$ und „Unaufgeklärtheit ${ }^{48}$. Die Flucht von Arbeitern und Angestellten wurde in den Berichten über einzelne Betriebe und Branchen zwar erwähnt, in den Mittelpunkt rückten aber immer Akademiker und hochspezialisierte Fachleute, deren Weggang jeden Betrieb entscheidender prägte als der Verlust von Arbeitern. Dennoch scheinen auch einige der berufsspezifischen Gründe durch, die Arbeiter und Angestellte mit ihren Familien aus der DDR wegführten. Zwei Problemfelder standen dabei im Vordergrund: die Folgen der mangelhaften betriebsinternen Arbeitsorganisation und der zu geringe Verdienst.

In keinem Bericht wurde daran gezweifelt, daß zahlreiche Republikfluchten ,auf innerbetriebliche Măngel ${ }^{4}, 59$ also auf das schlechte Management in der volkseigenen Wirtschaft zurückgingen. Eine wichtige Folge des MiBmanagements war ein zuweilen eklatanter Mangel an Rohstoffen, Vorprodukten und Ersatzteilen, der vor allem die industriell organisierte Arbeit erschwerte, lāhmte und zwischenzeitlich auch ganz unterbrach. Dies führte bei fast allen Mitarbeitern zu Frustration, langen Wartezeiten und häufig auch zu Verdienstausfällen. ${ }^{60}$ "Begünstigend für Republikfluchten wirkt sich der in vielen volkseigenen Betrieben vorhandene unkontinuierliche Arbeitsablauf aus, durch den Wartezeiten entstehen, artfremder Einsatz von Fachkräften erfolgt und die materielle Interessiertheit der Werktātigen nicht gefördert wird. Diese Mängel in der ökonomischen Leitung der Betriebe hemmen die politische Arbeit, wirken sich demoralisierend auf die Arbeiter aus und rufen Unglauben an die Überlegenheit der sozialistischen Wirtschaft hervor." 461 Nur in Ausnahmefāllen richtete sich direkte Kritik gegen Leitungsfunktionäre wie im VEB Nordthūringisches Textilkombinat Bleicherode (Betriebsstătte Gernrode), wo die Ursa-

\footnotetext{
57 Bericht über die Verbesserung der Arbeit mit den Menschen und der Parteierziehung im Bezirk Halle und die Lehren des Kampfes gegen die Republikflucht Jugendlicher, Lehrer, Ärzte, Facharbeiter im Sekretariat des ZK vom 31.5. 1961 (SAPMO-BArch DY 30/J IV 2/3-740, BI. 4-82, hier BI. 73 f.).

si Dok. 15.

59 Dombrowsky HVDVP, Leiter der HA K am 13. 7. 1955: „Kriminalpolizeiliche Analyse über Republikfluchten, Rūckkehrer und Neuzugänge“, hier über das Werk für Fernmeldewesen in Berlin-Oberschōneweide (BArch DO 1/11, Nr. 708, Bl. 18-34, hier Bl. 18).

60 Vgl. z.B. Dok 14.

61 Bericht vom 13.2. 1961 (BArch DO 1/11, Nr. 967, Bl. 37-60, hier Bl. $42 \mathrm{ff}$.).
} 
che der stark ansteigenden Republikfluchten nach Meinung der Kollegen [...] im unkollegialen Verhalten des Betriebsstāttenleiters R. begründet [ist]. Derselbe kann mit den Menschen nicht umgehen, will jemand eine Beschwerde vortragen, so läßt er diese Person einfach stehen. ${ }^{42}$ Trotz der weithin zurückhaltenden Kritik an Genossen in betrieblich leitenden Funktionen war offensichtlich, daB die Produktion hảufig unter Problemen litt, die auf die ungenūgende Wahrnehmung von Leitungsāmtern zurūckzufūhren war, daß akute Fehlplanungen hãufig den $A n s t o B$ gaben, nach einer Arbeit im Westen zu suchen: "In der Kesselschmiede des Karl-Marx-Werkes in Potsdam-Babelsberg wußte z. B. keiner der Arbeiter, was er nach der Umstellung machen soll und die Absicht, Grenzgānger zu werden, wurde diskutiert. "6s

Als wohl ärgerlichste Folge der mangelhaften Leitungskompetenz mußten viele vor allem jüngere Arbeiter häufig ihren Arbeitsplatz wechseln und unterhalb der eigenen Qualifikation arbeiten. 64 Damit kam man aber nicht dem Arbeitsalltag ohne feste Arbeitsplatzbeschreibung nāher, wie ihn Marx für den Kommunismus verheißen hatte, in dem es möglich sein sollte, „heute dies, morgen jenes zu tun, morgens zu jagen, nachmittags zu fischen, abends Viehzucht zu treiben, nach dem Essen zu kritisieren, wie ich gerade Lust habe ".65 Den vorkommunistischen Alltag in der DDR nahmen die Betroffenen eher als Willkür wahr, durch die sie ihre Fāhigkeiten gerade nicht entfalten konnten; ein junger Schaltmechaniker des VEB Elektro-Projekt Berlin beschrieb ihn in seinem Kündigungsschreiben: „Dauernde Wartezeiten, in welchen ich vom Lagerarbeiter, Kartoffeltrāger, Beifahrer, Versandarbeiter, Kohlenträger, Mōbelträger, Transportarbeiter über Tiefbauarbeiter beinahe alle Arbeiten eines Hilfsarbeiters mitgemacht habe. ${ }^{466}$ Das Elektro-Motoren-Werk Wernigerode setzte gegen Ende 195570 Prozent aller ehemaligen Lehrlinge berufsfremd ein. Āhnliches galt für den VEB Stern-Radio und das Kali Werk in Staßfurt, die 17 Mechaniker und acht Rundfunkmechaniker bzw. 25 Junghāuer und Lehrhāuer „nicht im erlernten Beruf, sondern mit allen vorkommenden Arbeiten beschäftigt [en]“. Solche Fälle waren keine Ausnahmen: „Ähnliche Erscheinungen" gab es in vielen Betrieben, wobei die Abteilung für Innere Angelegenheiten im Bezirk Magdeburg darauf hinwies, da $B$ die Abteilung Arbeit und Berufsausbildung darüber nicht einmal im einzelnen informiert war. Obwohl solche Probleme mit der Arbeitskräftelenkung individuellen Unmut hervorriefen und erhebliche Verluste bedeuteten, schafften die staatlichen Planungsinstanzen keine Abhilfe. ${ }^{67}$

62 Die Meldung dieses Falles an die Hauptabteilung Kader fiel Hauptabteilungsleiter Bergmann aus dem Innenministerium sicherlich nicht schwer, weil er damit die antiwestlichen Ressentiments gegen zurückkehrende Republikflüchtige und andere Zugezogene aus dem Westen verstārkte: Der Betriebsstãttenleiter habe bis Anfang der fünfziger Jahre an der Textilfachschule in Mũnchberg/Bayern studiert, wo sich auch eine Niederlassung der Firma befand, zu der dieser VEB frūher gehört hatte. „Außerdem ist er mit der Tochter des verstorbenen früheren Werkdirektors Busch verheiratet". Darüber hinaus hätten sich SED und FDGB im Betrieb ja auch schon gegen R. geãußert (MdI Hauptabteilungsleiter Bergmann [HA Innere Angelegenheiten] am 21.1. 1958 an HA Kader (BArch DO 1/34, Nr. 21725]).

6s Bericht vom 13.2.1961 (BArch DO 1/11, Nr. 967, Bl. 37-60, hier Bl. 42 ff.).

*t Z.B. die ausgebildete Weberin, die infolge akuten Arbeitsmangels aus der VEB Woll- und Seidenspinnerei Gera entlassen wurde, keine ihrer Fähigkeit entsprechende Arbeit fand und daraufhin republikflüchtig wurde (BArch DO 1/11, Nr. 963, Bl. 53 ff.).

${ }^{65}$ Marx/Engels, Ideologie (1983), S. 33; vgl. auch Marx, Kapital (1983), S. 512.

${ }^{66}$ Bericht vom 13. 2. 1961 (BArch DO 1/11, Nr.967, Bl. 37-60, hier Bl. 43).

67 An die Regierung der DDR, MdI, Staatssekretariat für Innere Angelegenheiten am 12.12. 1955 (BArch DO 1/34, Nr. 11803). Über eine Beschäftigung unter ihrer Qualifikation beschwerten sich auch viele Zugezogene aus der Bundesrepublik (Schmelz, West-Ost-Migranten [1999], S. 96 ff.) und zahlrci- 
Dem berufsfremden Einsatz vorwiegend jugendlicher Arbeiter entsprach die Arbeitsplatzunsicherheit in verschiedenen Betrieben. Arbeiter fürchteten angebliche SchlieBungsabsichten für bestimmte Werke, ${ }^{68}$ ältere Kollegen die Ablösung durch Hochschulabsolventen. So wußte das Innenministerium im Herbst 1957 von Gerüchten im Stahl- und Walzenwerk Brandenburg, "daB alle Dispatcher und Abteilungsleiter durch Jungingenieure abgelöst werden sollen. "In gewohnter Manier tat der ministeriale Verfasser die Ge rüchte als feindliche Desinformation ab, durch die "Unsicherheit hervorgerufen werden [sollte], damit dieser Personenkreis veranlaßt wird, sich nach Möglichkeit einen anderen Arbeitsplatz und zwar nach [!] Westberlin zu suchen. ${ }^{40}$ Bereits wenige Monate spāter aber hatten sich die Gerūchte bestätigt, wie Innenstaatssekretär Grünstein den Minister für Berg- und Hüttenwesen in einem Schreiben über die stark gestiegenen Republikfluchten aus diesem Stahl- und Walzwerk informierte. ${ }^{70}$ Zuerst führte er die Abwanderung zwar auf Abwerbungsversuche der im Aufbau befindlichen Stahl- und Walzwerke in Bremen und Berlin-Tegel zurück, , in denen die westliche Lebensart sowie die Verdienstmöglichkeiten [...] in den rosigsten Farben gepriesen werden. " Danach aber verheimlichte auch er nicht die eklatanten "Mängel im Produktionsablauf", die zu "Verärgerungen" führten, "die teilweise die Abwerbung erleichtern “. Und tatsächlich wurden die Dispatcher und Abteilungsleiter inzwischen durch Jung-Ingenieure ersetzt: „Hierbei ist man an einen Abteilungsleiter herangetreten und hat ihn gefragt, ob er im Lok-Dienst arbeiten würde. Dieser Kollege soll ein alter erfahrener Facharbeiter sein, der geäuBert hat: ,Wenn sie mich versetzen, dann gehe ich nach Bremen!' Unter den Schichtleitern besteht die Meinung: ,Wir haben unsere Schuldigkeit beim Aufbau getan, jetzt können wir gehen! ‘ “

Schon früh hatten sich Arbeiter dem von starken politischen Eingriffen geprägten Arbeitsalltag durch einen Umzug nach Westdeutschland entzogen. So stellte der brandenburgische Minister für Arbeit und Sozialwesen, Schwob, bereits 1947 fest, daß „viele junge Leute unser Gebiet [verlassen], um sich vor einer Arbeitseinweisung zu drücken ", ${ }^{11}$ und einige Gerichtsurteile gegen "Arbeitsbummelanten“ konnten nicht vollstreckt werden, weil sich die betroffenen Personen in den Westen abgesetzt hatten. ${ }^{72}$ Aus ähnlichen

che Akademiker und Spezialisten, die „von ihrer gesamten Leitungstātigkeit abgehalten werden, indem sie zu zweckfremder Arbeit herangezogen werden“. (SPK, Chemiekaderkommission, am 28. 7. 1960, BArch DO 1/34, Nr. 21725); zur Arbeitskräftelenkung vgl. generell Hoffmann, Aufbau und Krise (2002). 68 So etwa ein Oberingenieur und ein Elektromonteur aus dem RFT-Werk Leipzig (HVDVP, Seifert an MdI, Oktober 1955, BArch DO 1/11, Nr. 963, Bl. 53 ff.).

69 Mdl, HA Innere Angelegenheiten, Abt. 1 am 4.11.1957 an HVDVP HA PM (BArch DO 1/34, Nr. 21725).

70 Grünstein am 5. 3. 1958 an Steinwand (BArch DO 1/34, Nr. 21725).

" BArch DQ 2/2030, Protokoll über die Amtsleitertagung im Landesarbeitsamt Potsdam am 15.7. 1947, zitiert nach Hoffmann, Aufbau und Krise (2002), S. 55. In Sachsen-Anhalt verließen allein in den Monaten Januar und Februar 1948 „350 mānnliche Arbeitskräfte wegen Verpflichtung zum Bergbau durch das dortige Arbeitsamt" die SBZ (Statistische Erfassung der aus der Ostzone nach dem Westen geflüchteten Personen, 7.4. 1948, BStU ZA, MfS-AS, Nr. 224/66, Bd. II, Bl. 321); in Mecklenburg und Thüringen waren am 15.3. 1948 jeweils ein Viertel der seit Kriegsende in den Westen gegangenen Personen, bei denen das Fluchtmotiv ermittelt werden konnte, wegen "Entziehung der Dienstverpflichtung ${ }^{*}$ abgewandert (ebd., Bl. $324 \mathrm{ff}$.).

72 Amtliches Mitteilungsblatt für den Kreis Haldensleben vom 14.2.1948 enthält „Liste von Personen, die in Schnellgerichtsverfahren zu Gefängnisstrafen zwischen sechs und elf Wochen verurteilt worden waren; 18 namentlich genannte Personen hatten sich der Aburteilung durch Flucht entzogen." (Hoffmann, Aufbau und Krise [2002], S. 60, Anm. 74: BArch DQ2/137, Bl. 274). 
Gründen wurde auf einer Tagung von Volkpolizeileitern im Januar 1950 mehr Rũcksicht gegenüber Arbeitern empfohlen, die in der britischen Zone lebten, aber im Elektrizitätswerk Harbke in Sachsen-Anhalt arbeiteten, „damit uns diese Arbeiter nicht verlorengehen. ${ }^{\text {"73 }}$ Eine Berechnung über die Abwanderung aus staatlichem Sektor und aus Privatbetrieben in Karl-Marx-Stadt bestãtigte 1958 diese Aversionen: „In den staatlichen Institutionen wie Verwaltungen, Banken usw. sind vom 1. Januar 1957 bis 31. Mārz 19582684 Personen illegal abgewandert. Das sind gleich 8,65 Prozent der dort beschäftigten Personen. In dem privaten Sektor wo zum überwiegenden Teil die Lōhne, die sozialen Belange und der EinfluB der Parteien und Massenorganisationen sich noch nicht so stark wie in unserer volkseigenen Industrie auswirkt, wanderten im gleichen Zeitraum 6382 Personen illegal ab. Das sind gleich 1,56 Prozent der dort beschãftigten Personen. ${ }^{474}$

In einer bemerkenswerten interpretativen Freiheit aber sahen die Autoren der Vorlage selbst in diesen eindeutigen Zahlen keinen AnlaB zu einer gründlichen Kritik der Fehler in den VEB und den staatlichen Behörden. Vielmehr wiesen sie die Ratsmitglieder darauf hin, daB die Zahlen "die Meinung [widerlegen], die von einem Teil unserer Bevölkerung in Versammlungen und Aussprachen vertreten wird, daß wirtschaftliche Schwierigkeiten zur Republikflucht führen", womit sie die Kritik am unbefriedigenden Lohn- und Konsumniveau in der DDR bagatellisieren wollten. Sie sahen den entscheidenden Grund für die Abwanderung nicht in den materiellen Lebensbedingungen und der volkseigenen Wirtschaft, sondern in der mangelhaften Erkenntnis der Betroffenen, nāmlich „im Nichterkennen der Perspektiven beider deutscher Staaten ". Daß ihr konkretes Leben für viele Arbeiter aber wichtiger war als derartige Floskeln, zeigen die zahlreichen Hinweise auf das unterschiedliche Lohnniveau in beiden deutschen Staaten. Fast alle Berichte hielten fest, daß die Arbeiter im Westen einen erheblichen finanziellen Zugewinn erwarten konnten, egal ob es sich um Berg- ${ }^{75}$ Bau-,${ }^{76}$ Textil- ${ }^{77}$ oder Metallarbeiter ${ }^{78}$ oder um Fachverkāuferinnen $^{79}$ und Handelsorganisation (HO)- und Konsumangestellte handelte. ${ }^{n n}$ Verschãrfend kam hinzu, daß die schlechte Betriebsorganisation zu Wartezeiten und damit auch zu Verdienstausfällen der leistungsabhängig Bezahlten und zu Einbußen im Prāmiensystem führte, so daß beispielsweise Facharbeiter aus dem VEB Rheinmetall Sömmerda zur westdeutschen Rheinmetall AG in Düsseldorf überwechselten, weil sie am Monatsende weniger verdient hatten als ihre ungelernten, aber fest bezahlten Kollegen. ${ }^{.1}$ In den Bezirken nahe West-Berlin führte das Lohngefälle dazu, daß zahireiche Menschen von ihren Wohnsitzen in Ost-Berlin oder in den Kreisen Potsdam und Frankfurt in West-Berliner Betriebe pendelten und sich bis zu 125 Mark, seit Ende November 275 Mark monatlich in der ,harten' Westwãhrung auszahlen lassen durften. Ein einfaches Rechenbeispiel des Innenmi-

\footnotetext{
73 BArch DO 1/07, Nr. 567, Bl. $21 \mathrm{ff}$.

74 "Ratsvorlage zum Tagesordnungspunkt 4 der Ratssitzung vom 4.6. 1958" (S. 6) (BArch DO 1/34, Nr. 21725).

75 HA PM am 4. 10. 1957 an ZK der SED, Abt. Sicherheitsfragen. BArch DO 1/11, Nr. 964, BI. 174 f.

76 Seifert am 16.9.1957 an ZKSicherheitsabteilung, die Abt. VE in Hause und die HA PM (B.Arch DO 1/11, Nr. 964, Bl. 161).

77 HA Innere Angelegenheiten, Abt. I am 19.11.1957 an BA Betriebsschut?. (BArch DO 1/34, Nr. 21725).

78 Dok. 14.

79 HVDVP an ZK, MfS u.a. am 7. 2. 1958 (BArch DO 1/11, Nr. 965, Bl. 37-40, hier Bl. 40).

so Dombrowsky am 2.11. 1957 (BArch DO 1/11, Nr. 964, BI. 193-201, hier BI. 197).

RI Dok. 14; āhnlich: Dok. 15 und Augustine, Frustrierte Technokraten (1996), S. 67.
} 


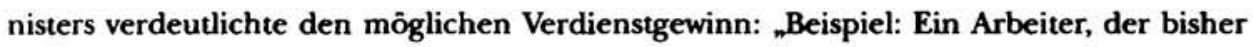
in einem VEB angenommen 600 DM brutto erhielt, verdient jetzt in Westberlin $400 \mathrm{WM}$. 35 Prozent des Lohnanteils $=140 \mathrm{WM}$. Ausgezahlt erhālt er 125 Westmark. In der Wechselstube umgetauscht: $125 \times 4,75=$ DM 593,75. Rest der Lohnsumme in DM der DNB [Deutsche Notenbank]: DM 275,00. Gesamtverdienst: DM 868,75.

Die offiziellen Stellen der DDR nahmen solche Angelegenheiten in erster Linie als wirtschafts- und sicherheitspolitische Probleme wahr, da sie die ostdeutsche Wirtschaft schwächten und das Sicherheitsbedürfnis nach einer möglichst umfassenden Abschottung vom Westen unterminierten. Selbst in der Einführung von Autos durch zurūckgekehrte Republikflūchtige sahen sie große[] Schwierigkeiten in den Kreisen“, weil die Rückkehrer mit ihren PKW indirekt für die Republikflucht werben würden, besonders wenn sie sich das Geld dafür während eines kurzen Aufenthaltes in der Bundesrepublik verdient hätten. ${ }^{83}$

Die Republikfluchtberichte über Arbeiter, Bauern und Handwerker wirken im Vergleich zu denen über Akademiker und Spezialisten blaB. Trotz der Versorgungsengpāsse, die durch die Flucht von Bauern und Handwerkern verstärkt wurden, und trotz der religiös anmutenden Verehrung der, Arbeiterklasse` und ihrer vorgeblich welthistorisch zentralen Rolle richtete sich die Aufmerksamkeit in den Büros des Arbeiter- und Bauernstaates und der Arbeiterpartei hinsichtlich der Republikflucht in erster Linie auf den Akademikerschwund und seine Ursachen und Umstände. Den Weggang dieser Fachleute schildern die offiziellen Berichte mit zahlreichen Details, so daB die privaten Bedingungen genauer ausgeleuchtet werden, mehr Rücksicht auf kulturelle Eigenheiten genommen wird und auch Fragen wie Sozialprestige und informelle Netzwerke ernsthaft behandelt werden. Neben der - teilweise nur indirekt geãußerten - Arroganz gegenūber Handwerkern und Bauern und der vermeintlichen Sicherheit der kommunistischen Funktionāre beim Umgang mit Problemen aus der Welt der Arbeiter lag dies wohl vor allem daran, daß die Akademiker einige kulturelle und professionelle Fāhigkeiten wie selbstverständlich beherrschten, die sich viele Funktionäre des neuen Staates häufig erst im Laufe der Nachkriegszeit angeeignet hatten. Außerdem war der gesellschaftliche Wert eines Mediziners, Lehrers und Ingenieurs - ebenso wie der eines spezialisierten Facharbeiters - plastisch vorstellbar und jeder einzelne Verlust daher konkret zu bestimmen. Viele Bauern, Handwerker, Arbeiter und Angestellte rissen demgegenüber nur kleinere Lücken in die Berufswelt der DDR, da sie häufig schnell durch Nachrücker ersetzt werden konnten. Darüber hinaus konnten die Berichterstatter auf zahlreiche - hãufig wohl formulierte Stellungnahmen geflūchteter Akademiker zurückgreifen, die im Nachhinein etwa bei Kollegen und Nachbarn abgefragt oder von den Sicherheitsorganen abgefangenen Abschiedsbriefen entnommen wurden; solche Selbstzeugnisse und Erklärungen finden sich bei Arbeitern, Angestellten, Bauern oder Nichtberufstātigen deutlich seltener.

\footnotetext{
"22 Anschreiben und Bericht von Maron vom 30.11. 1955 an Gen. Generaloberst, Stellvertreter des Vorsizzenden des Ministerrates der DDR, Stoph, und in Abschrift an Minister Wollweber (MIS), Gen. Roebelen (ZK der SED) und Mdl-SK (BArch DO 1/11, Nr. 955, Bl. 58-65, hier Bl. 62). Zu den Grenzgängern und ihren wirtschaftlichen Vorteilen vgl. Schütrumpf, Grenzgängerproblem (1984) sowie die kurzen Hinweise bei Major, TorschluBpanik (2000), S. 229 f.

sy Da zahlreiche Autos aus der Bundesrepublik eingeführt wurden, aber nicht angemeldet werden durften, wies die HA PM sogar auf die Gefahrdung der DDR durch die in Garagen abgestellten Autos hin, da sie zu öffentlichen Diskussionen über den Reiz von Republikfluchten führten (vgl. Dok. 27).
} 
Zu den gut ausgebildeten Fachleuten zählten die Berichte neben Medizinern, Ingenieuren, Lehrern und anderen Akademikern auch zahlreiche Fachkräfte und Spezialisten vorwiegend aus technischen Berufen, die mal unter der Rubrik „Intelligenz“, teilweise aber auch separat als ${ }_{n}$ Facharbeiter" Berücksichtigung fanden. Im ganzen bildeten diese Fachleute und Akademiker zwar nur einen kleinen Teil aller Republikflūchtigen, ${ }^{\text {N+ }}$ aufgrund ihrer sozial und ökonomisch hervorgehobenen Stellung und der von ihnen besetzten Leitungspositionen wurden Republikfluchten aus ihren Reihen jedoch mit besonderer Aufmerksamkeit registriert. Die "Flucht des Geistes aus der DDR ${ }^{485}$ hatte verschiedene Ursachen, unter denen die berufliche Situation eine besonders wichtige Rolle spielte. Aufgrund der traditionell sehr hohen beruflichen und geographischen Mobilitāt dieser Bevölkerungsgruppe scheint diesen Menschen der Weggang zudem vor allem im Vergleich zu den erwāhnten Handwerkern und landbesitzenden Bauern hãufig leichter gefallen zu sein.

Allgemein zusammengefaßt werden die meisten Fluchtgründe wohl am besten unter dem Gefühl der Benachteiligung, das die meisten gut ausgebildeten Menschen in der DDR umtrieb. Zum einen bildete der Abbau sozialer Privilegien einen zentralen Drehund Angelpunkt der Politik und Ideologie der SED, der traditionell überdurchschnittlich bezahlte Berufsgruppen schon in der Zusammenbruchsgesellschaft der frühen Nachkriegszeit als deutliche Bedrohung erschienen waren. Zum zweiten wußten alle Fachkräfte, da $B$ ihnen der Westen attraktive berufliche Alternativen bot. Vor allem seit der Konsolidierung der westdeutschen Prosperităt Mitte der fünfziger Jahre stieg die Sicherheit, im Westen eigenen Wohlstand aufbauen zu kōnnen.

Ähnlich wie viele Arbeiter beurteilten auch zahlreiche Akademiker und Spezialisten die finanzielle Entlohnung für ihre Arbeit als besonders offensichtliche Benachteiligung. ${ }^{\text {(4i }}$ Da der Weg in den Sozialismus zum Ende sozialer Privilegien einzelner Berufsgruppen führen sollte, gab es in der DDR keine so großen Einkommensspannen wie in der Zeit vor 1945 und in Westdeutschland. Im Laufe der fünfziger Jahre wurde der Unterschied zum Westen immer deutlicher sichtbar. Fast alle Arbeitskräfte konnten sich in der Bundesrepublik einen erheblich größeren Wohlstand ermöglichen als ihre Kollegen in der DDR. ${ }^{x}$; Die weiterhin bestehenden privaten und beruflichen Kontakte ermöglichten den meisten Akademikern zudem einen leichten Vergleich zwischen ihrem Verdienst und dem ihrer Studien- und Berufskollegen im Westen. Deutliche Spannen zwischen Ost und West zeigten sich nicht nur bei Medizinern oder Spitzenwissenschaftlern, sondern in fast allen Berufen, etwa bei Lehrern, deren Gehälter im Westen an allen Schultypen „bedeutend“

\footnotetext{
s4 Ihr Anteil schwankte nach Angaben der ZV für Statistik zwischen zwei und dreieinhalb Prozent, wobei nicht sicher ist, inwiefern Facharbeiter dazugezāhlt wurden, da nicht ermittelt werden kann, was genau sich hinter der Kategorie „Ingenieure, Techniker, Chemiker" verbirgt. Vgl. Tabelle 3.

ks So der Titel eines Sonderdrucks aus dem Bulletin des Presse- und Informationsamtes der Bundesregierung, Nr. 199 und 214/1960.

${ }^{86}$ "Die Hauptmethoden [der Abwerbung] waren die Formen des Versprechens, indem Spezialisten und Intelligenzlern besser bezahlte Stellungen in Westdeutschland angeboten wurden“ (HVDVP HA K am 16.4. 1955: „Analyse über die Feststellungen von Abwerbern“, BArch DO 1/11, Nr. 708, BI. 10-13, hier Bl. 11).

${ }^{87}$ Dabei kam zuweilen auch eine unkritische Sicht auf den Westen zum Tragen, so daß nicht wenige enttäuschte Zuwanderer und sogar das Hilfswerk der Evangelischen Kirche Deutschlands etwa den RIAS kritisierten, dessen Sendungen von vielen DDR-Bürgern als offizielle Verlautbarungen Bonns und als Einladungen in den Westen mißverstanden würden (Ackermann, Der „echte “ Flüchtling [1995]. S. 103).
} 
hōher waren. ${ }^{88}$ Auch die westdeutsche Industrie zahlte vor allem seit dem chronischen Mangel an qualifizierten Arbeitskräften erheblich mehr als volkseigene Betriebe oder die verbliebenen selbstāndigen mittelständischen Unternehmen in der DDR. Neben den hōheren Gehältern bestand im Westen auch die Möglichkeit zu selbstāndiger Arbeit, ein Wunsch, der beispielsweise bei Juristen verbreitet war, vor allem aber bei zahlreichen Medizinern. Für den Wunsch, eine eigene Firma, Kanzlei oder Arztpraxis in der DDR zu eröffnen, gab es in der DDR aber nur sehr geringe Realisierungschancen, worüber sich viele Ärzte - nicht zuletzt mit Blick auf die schlechte Organisation des öffentlichen Gesundheitswesens - beschwerten. ${ }^{89}$

Das MiBtrauen der Betroffenen rührte aber nicht nur aus den widersprüchlichen Aktivitäten von SED und Regierung, sondern mehr noch aus der eigenen Anschauung in den Nachbarlāndern. Ein Bericht an das Sekretariat der SED über die Parteiarbeit und Republikfluchten im Bezirk Halle faBte das verbreitete MiBtrauen präzise zusammen: „Nach wie vor ist bei einem Teil der Ärzte die Frage des Vertrauens das wichtigste Problem. Sie glauben nicht an die Ehrlichkeit und Beständigkeit der Intelligenzpolitik der Partei.“ Unbehagen lösten vor allem die seit Ende der fünfziger Jahre verstärkten Forderungen nach einem Friedensvertrag und die damit zusammenhängende Berlinkrise aus. Viele Fachkräfte in der DDR fürchteten sich vor den Konsequenzen einer noch grōßeren Annāherung der DDR an die sozialistischen ,Bruderstaaten', da "dort die Ärzte wie durchschnittliche Facharbeiter bezahlt werden“ ${ }^{40}$ Ähnlich äußerten sich die Chefärzte im Kreis Senftenberg bei einer Aussprache im Februar 1961: „Der Arzt in den Volksdemokratien verdient nicht mehr als ein guter Facharbeiter. Es wird allgemein angenommen, daß die Stellung der Ãrzte revidiert wird, sobald die Westberlin-Frage zur Zufriedenheit der DDR geklärt wird. “91

Die Frage des Verdienstes wurde in ministeriellen und anderen Beratungen über die Flucht zwar wiederholt angesprochen, aber meistens herrschte die Einschātzung vor, daß andere als finanzielle Gründe vorherrschend sein müBten: „Gen. Oberst Kotulan (BDVP [Bezirksbehörde der Deutschen Volkspolizei] Frankfurt) erklärte ebenso wie der Gen. Oberst Knōpke, daß finanzielle Schwierigkeiten der Ärzte nicht der Grund einer R[epublik]-Flucht sein kōnnen. Ein gewisser Dr. Frank kam 1955 nach Frankfurt und hatte monatlich ca. 4000 DM Gehalt. Frank hat bei seiner R[epublik]-Flucht eine gut eingerichtete Wohnung mit allem Komfort unberührt verlassen." Auf der gleichen ${ }_{n}$ Cheftagung ${ }^{4}$ des

* Bericht über die Republikflucht von Lehrern vom 2. 12.1958 (Dok. 18).

"9 Vgl. z.B. BArch DO 1/34, Nr. 21719: Leiter der HA K der HVDVP, Odpadlik, am 15. 4. 1959: Bericht Analyse der Republikfluchten von Personen der Intelligenz"; Bericht der HA PM an ZK der SED vom 25. 1. 1958 über die Republikflucht von Ärzten (Dok. 19); „2. Bericht über die Reaktion der medizinischen Intelligenz auf das Kommunique des Politbüros [... $]^{\star}$, BStU ZA, MfS-HA XX/AKG, Nr. 1048, Bl. 307. Im Politbüro wurde am 2.9. 1958 über ${ }_{n} \mathrm{MaBnahmen}$ zur Veränderung der Lage der medizinischen Intelligenz" debattiert und unter anderem erwogen, für Ärte einen "unnormierten Arbeitstag* einzuführen, womit ihr Angestelltenstatus wenigstens teilweise abgemildert wurde (SAPMO-BArch DY $30 /$ J IV 2/2/608, Bl. 18).

90 SAPMO-BArch DY 30/J IV 2/3-740, Bl. 60-83, hier Bl. $77 \mathrm{f}$.

91 Bericht vom 13.2. 1961, BArch DO 1/11, Nr. 967, Bl. 37-60, hier Bl. 44. Āhnlich: Dombrowsky, Generalmajor der Volkspolizei, HVDVP, Der Leiter, am 10.9. 1958 an die HA Innere Angelegenheiten über Gen. Staatssekretār Grünstein (BArch DO 1/34, Nr. 21725); Abschiedsbrief eines Arztes vom 29.5. 1959: ${ }_{n} \mathrm{MaBgebend}$ für meine Entscheidung [zur Flucht] ist [...], daß ich vielleicht in 10 Jahren auf der Höhe meines Könnens wieder so viel verdiene wie ein Facharbeiter, so wie es uns aus der CSR bekannt ist." (Dok. 30). 
Innenministeriums im Oktober 1958 äußerte sich ein Genosse aus Neubrandenburg: „Fest steht, daß kein Arzt aus finanziellen Gründen unsere Republik verlāßt. ${ }^{-92}$ Offensichtlich machten sich schon Mitte der fünfziger Jahre zahlreiche Funktionāre keine Vorstellung mehr davon, wie groB die Verdienstunterschiede zwischen Ost und West sein konnten. Selbst in der Chemiekaderkommission der Staatlichen Plankommission herrschten Vorstellungen von Wohlstand, die keinem Besuch in einem der Villenvororte von West-Berlin Anfang der sechziger Jahre standgehalten hātten: „Fast alle Wūnsche der Intelligenz aus den Großbetrieben werden erfült. [...] Der Kauf von Autos wurde bisher realisiert. Dabei tauchte als neues Problem die Beschaffung von Garagen auf. Dieses ist im Moment in Zeitz [Bezirk Halle] sehr akut. Bōhlen [Bezirk Leipzig] hat sich insofern geholfen, daß sie ein Freigelānde zur Verfügung gestellt haben und die Intelligenz zusammen mit den Maurern in Gemeinschaftsarbeit Garagen bauen. ${ }^{\text {"9s }}$ Als Maßstab zur Beurteilung der finanziellen Bedürfnisse vor allem hochqualifizierter Fachkräfte und Wissenschaftler hatten die Staats- und Parteifunktionäre ausschlieBlich die eigene Gesellschaft im Blick, nicht aber Westdeutschland oder die Situation in Deutschland vor dem Krieg. Damit entsprachen sie den politischen Vorgaben, die vor allem Funktionären fast jeden Kontakt in den Westen untersagten $^{\text {rt }}$ und die gesamte jüngere deutsche Vergangenheit mit antifaschistisch-antikapitalistischen Rundumschlãgen desavouierten. Die Folge dieser politischen Linientreue war aber eine Blindheit für die sozialen Maßstäbe und Bedürfnisse von zahlreichen Menschen in der DDR, also eine selbstgewāhlte Unfāhigkeit, die Mehrheit der eigenen Bevōlkerung zu verstehen und sich mit ihr ernsthaft auseinanderzusetzen.

\subsection{Weitere Fluchtgrunde}

Selbst wenn ihre Gehālter in Ost und West gleich hoch gewesen wãren, hātten die matcriellen Lebensbedingungen von Akademikern und anderen Fachkräften in Ost- und Westdeutschland deutlich für den Umzug in die Bundesrepublik gesprochen. Dies zeigt die lange Liste von systematischen Fluchtgründen, die keiner bestimmten Berufsgruppe zuzuordnen sind. Diese Motive waren vorrangig für die privilegierten Berufsgruppen ausschlaggebend, da diese das eigene Leben vor 1945 und die Situation der Kollegen im Westen als Maßstab für ihren jetzigen Lebensstandard nahmen. ${ }^{95}$ Daher lösten die folgen-

92 BArch DO 1/11, Nr. 79, Bl. 134-167, hier Bl. 135, $139 \mathrm{f}$. Der geflohene Arzt hatte seine Wohnungseinrichtung sicherlich nicht aus Desinteresse an den Einrichtungsgegenstānden „unberūhrt“ zurūckgelassen. Ende der fünfziger Jahre flohen die meisten Menschen ohne Gepäck, weil sie sich sonst auf dem Weg nach Berlin verdãchtig gemacht hätten. Eine regelrechte Wohnungsauflösung führte hãufig zu Nachfragen der ABV oder Polizei. Ähnlich pauschal - und fehlerhaft - urteilte auch der Bezirksarzt Dr. Papsdorf am 30. 7. 1958 gegenūber dem Ministerium für Gesundheitswesen: „Erwāhnt werden muB, $\mathrm{da}$ wirtschaftliche Gesichtspunkte oder ein Nicht-vorwãrts-kommen als Grund keine Rolle spielen. Hervorgehoben werden muß, daß Ärzte, die nach Westdeutschland gehen, kein materielles Opfer scheuen. um ihr Ziel durchzusetzen. Sie trennen sich mit Leichtigkeit von ihrer vielfach sehr gut eingerichteten Wohnung sowie auch von ihrem Kraftfahrzeug" (BArch DO 1/34, Nr. 21719).

93 SPK, Chemiekaderkommission, am 28. 7. 1960 (BArch DO 1/34, Nr. 21725).

9 Vgl. den Schriftwechsel zwischen dem Minister für Kohle und Energie, Goschũtz und Innenminister Maron, 16./ 30.8. 1957 in BArch DO 1/11, Nr. 964, Bl. 142 ff.

${ }_{95}$ So schreibt eine republikflūchtige Angestellte aus dem DLA Chemie in ihrem Abschiedsbrief an die Mutter: „Wir werden monatlich ca. 450-500 Westmark sparen kōnnen, ohne dabei knapp zu leben. So 
den Gründe v.a. bei denjenigen Republikflucht aus, die im Westen die besten Aussichten auf eine Besserung der Lage hatten.

Zu den am meisten beklagten konkreten Măngeln gehörte zweifellos die Unterbringung in unzureichenden Wohnungen. ${ }^{96}$ Anders als bei den finanziellen Ansprüchen leugnete niemand in der DDR das Problem des Wohnraummangels, über das sich beinahe die gesamte Bevölkerung beschwerte, nicht nur Akademiker und Spezialisten. Angesichts des in ganz Deutschland verbreiteten Problems, die Altbevölkerung und die Millionen Flüchtlinge aus den ehemaligen deutschen Ostgebieten in den häufig kriegsbeschādigten Städten und Häusern unterzubringen, gingen viele Angehörige ehemals stark bevorzugter Berufsgruppen stillschweigend davon aus, eine bessere Unterbringung zu verdienen als die Bevôlkerungsmehrheit. Obwohl die SED dem nicht immer gerecht werden konnte, teilte sie diese Ansicht, weshalb sich etwa das Sekretariat des ZK schon früh um eine privilegierte Unterbringung der Intelligenz bemūhte. ${ }^{97}$ Die guten Absichten reichten aber nicht aus, so daB das Problem bestehen blieb und einige Jahre lang auch die mit der Republikflucht befa\&ten Funktionäre beschäftigte. 1955 klagte etwa der Leiter der Hauptabteilung Kriminalpolizei in der HVDVP über das mangelhafte Engagement verschiedener Bürokraten und nahm dabei auch die Wohnungsämter ins Visier: Ein Ingenieur aus Ost-Berlin sei geflohen, nachdem er zweieinhalb Jahre mit seiner vierköpfigen Familie in einem Zimmer "hauste“, ohne daB ihnen eine Wohnung zugewiesen worden sei. ${ }^{80}$ Noch Anfang der sechziger Jahre war die Wohnungsfrage selbst in großen Betrieben „ein weiteres schwieriges Problem beim Kampf gegen die Auswanderung: 53 Intelligenzler der Farbenfabrik Wolfen sind ohne Wohnung [...]. Es gibt solche Fälle, daß ein Intelligenzler seit 4 Jahren auf der Couch in der Küche seiner Eltern schläft. Trotz Vorstellungen und Einschaltung des Staatsapparates ist dieses Problem nicht zu lösen. "Einzelne Lösungsvorschläge der Wohnungsämter bewiesen wieder das geringe Fingerspitzengefühl staatlicher Ämter im Umgang mit für die Volkswirtschaft wichtigen Personen und verstärkten bei manchem standesbewußten Akademiker die Gedanken an Auswanderung wohl eher, als daB sie sie vertrieben: „Die AWG [Arbeiterwohnungsbaugenossenschaft] wird dagegen von den Intelligenzlern sehr wenig in Anspruch genommen, weil nur zwei Zimmer und Küche in dieser gebaut werden. [...] Außerdem wollen sie den körperlichen Einsatz in der AWG nicht leisten, sie sind gewillt, diese als NAW [Nationales Aufbauwerk] Stunden im Werk abzuleisten. ${ }^{\text {q9 }}$

\footnotetext{
kann ich in 2 Monaten eine erstklassige Schlafzimmereinrichtung oder 4 Kühlschränke kaufen. Kann man das bei uns?" (Abschrift des Abschiedsbriefes vom 28. 7. 1956, BStU ZA. MfS-AS, Nr. 26/59, Bl. 30). Offen bleibt dabei, was die Schreiberin mit vier Kühlschränken anfangen wollte.

96 Zu Wohnungsnot, beengten Wohnverhältnissen in der DDR vgl. Jenkis, Wohnungswirtschaft (1976), v.a. S. 173-199; Hoffmann, Wohnungspolitik (1972); Faber, Wohnungswirtschaft (1953); Zimmermann, Wohnung (1995), S. 75-114.

97 Vgl. z. B. den Tagesordnungspunkt „Wohnungsbauten für die technische Intelligenz" auf der Sitzung des Sekretariats des ZK am 20.12. 1951 (SAPMO-BArch DY 30/J IV 2/3-256, B1. 2).

94 "Kriminalpolizeiliche Analyse über Republikfluchten, Rückkehrer und Neuzugānge" vom 13.7. 1955 (BArch DO 1/11, Nr. 708, B1. 18-34, hier Bl. 20).

99 SPK, Chemiekaderkommission, am 28.7.1960 (BArch DO 1/34, Nr. 21725). Jessen, Akademische Elite (1999), S. 424 f., nennt einige besonders drastische Berichte von 1955 über die Wohnungsnot von Universitātsangehörigen, die zu Nervenzusammenbrūchen, doppelseitiger Lungenentzūndung und der Erfrierung beider Wangen eines Kindes führte. In allen Akten zur Republikflucht finden sich zahlreiche weitere Hinweise auf die Wohnungsprobleme, z.B.: „Analyse über die Entwicklung der Republikflucht in den Jahren 1954-1955 u. 1956." vom 3.5. 1956 (BArch DO 1/34, Nr. 21723a).
} 
Gerade solch konkrete Probleme wie die Wohnungsfragen gaben hāufig den Ausschlag zum Weggang. ${ }^{100}$ Lōsungen hätten die Auswanderung deutlich einschrānken kōnnen, da die (MiB-)Erfolge der DDR-Bauwirtschaft fast zu einem Symbol für die Leistungsfāhigkeit der gesamten DDR-Wirtschaft und Bürokratie wurden. Daran erinnerte das Innenministerium die Leiterin der Hauptabteilung Arbeitskräfte, Dr. Hildegard Heinze, im DDRMinisterium für Arbeit und Berufsausbildung, die den Brief auf einer Arbeitstagung an Mitarbeiter der Abteilung Wohnraumlenkung im Dezember 1957 bekanntgab: Es kōnne „nicht nur Aufgabe der Abt. Innere Angelegenheiten sein [...], unsere Bürger, die nach Westdeutschland verziehen wollen, von der Perspektive, die sie in unserem Arbeiter- und Bauernstaat hatten [!], zu überzeugen. Auch die Fachgebiete Wohnraumlenkung bei den örtlichen Rāten haben durch eine ordnungsgemāße Wohnungspolitik dafür zu sorgen, daß unsere Bürger erkennen, in welchem Maße sich stāndig der Aufbau des Sozialismus bei uns durch die Verbesserung auch ihres persōnlichen Lebens auswirkt. Gerade mit Hilfe der Wohnraumlenkung [...], können die dafür zuständigen Mitarbeiter dazu beitragen, daß die Republikflucht weiter nachlāßt und darüber hinaus diejenigen Familienangehörigen, die bereits nach Westdeutschland verzogen sind, wieder hierher zurückkehren. ${ }^{\text {"101 }}$ Die Wohnungssituation im Westen wurde ein immer deutlicherer Beleg für dessen Leistungsfāhigkeit und Attraktivităt, zumal dort nicht nur begehrte Fachkräfte ausreichend große Wohnungen fanden, sondern selbst junge ungelernte Arbeiter aus der DDR beneidenswerte Zustände schilderten: „Mir geht es glānzend. Ich habe eine große Wohnung für mich, auch Platz für Dich, verdiene sehr gut. [...] Du bist doch schon 18 Jahre. Schmeiß doch Deine Lehre ins Wasser. Ich verdiene auch ohne meinen Beruf [...] mein gutes Geld. ${ }^{{ }_{102}}$ Am Wohnungsproblem orientierten sich auch Versuche westlicher Firmen, qualifizierte Mitarbeiter aus der DDR zu gewinnen. Wiederholt stellten Polizei- und ZK-Berichte fest, daß westliche Firmen in Grenznāhe oder West-Berlin mit neuen Fertigungsstãtten gleich neue Wohnanlagen für ihre Mitarbeiter bauten. Eine entsprechende Warnung kam aus dem Funkwerk Kōpenick: „Die AEG soll in Gesundbrunnen [West-Berlin] ein neues Werk errichten und vor allen Dingen Wohnungen dazu bauen, so daß bei Fertigstellung mit weiteren Abwerbungen zu rechnen ist. ${ }^{\text {"103 }}$

Die angestrebten Erfolge der DDR-Bauwirtschaft kamen nicht zustande und die Verteilung des vorhandenen Wohnraums blieb nicht nur individuell, sondern auch politisch unzufriedenstellend. Der allgemeine Unmut in der Bevölkerung nahm zu und richtete sich

\footnotetext{
100 Als Beispiel vgl. VKH Deutscher Innen- und Außenhandel an Ministerium für Außenhandel und Innerdeutschen Handel, Kaderabteilung: „Meldung über ungesetzliche Verānderung des Wohnsitzes (R.-Flucht)", 17.6. 1958 (BStU ZA, MfS-AS, Nr. 26/59, Bl. 56 ff.).

101 Heinze an den Rat des Bezirkes Dresden, Abt. Arbeit und Berufsausbildung, Dezember 1957 (BArch DO 1/34, Nr. 21725).

102 Dok. 34.

103 BArch DO 1/34, Nr. 11803. Ebd. auch Hinweise auf Wohnraumprobleme von Lehrern. Am 19.11. 1957 wurde im Mdl darauf hingewiesen, da B im Kunstseidenwerk Bremnitz Kataloge von gleichartigen westdeutschen Betrieben kursierten, in der u.a. Wohnungen angeboten wurden. (Mdl, HA Innere Angelegenheiten, Abt. I an BA Betriebsschutz, BArch DO 1/34, Nr. 21725). Noch 1960 enthielt eine Aufstellung der "Methoden der Abwerbung von Bürgern der DDR" āhnliche Hinweise, dieses mal über die Allianz-Versicherung, die in Berlin Tiergarten und Tempelhof eigene Wohnkomplexe einrichte (BArch DO $1 / 34$, Nr. 21724).
} 
sogar gegen die - nirgends sonderlich zahlreichen ${ }^{104}$ - Zuwanderer aus dem Westen, ${ }^{105}$ um die sich die Regierung der DDR in der ersten Hälfte der fünfziger Jahre noch recht eifrig bemühte. So ging im Sachsenwerk Niedersedlitz in Dresden unter den $\mathbf{3 0 0}$ Mitarbeitern, die ndringend einer Wohnung bedürfen", ein einfacher Ratschlag um: „,Wir werden erst republikflüchtig werden, und man wird uns nach unserer Rūckkehr schon eine Wohnung geben. ${ }^{\prime \prime}{ }^{106}$ Die tatsāchliche Behandlung der Zuziehenden und Rückkehrer weckt allerdings Zweifel daran, ob dieser Weg zum Erfolg geführt hätte, denn die ehemaligen Bewohner der Bundesrepublik standen nicht nur unter dem Generalverdacht der politischen Unzuverlāssigkeit, sondern erhielten auch nur selten die vollmundig versprochenen Integrationsleistungen wie Wohnungen und adāquate Arbeitsplätze. ${ }^{107}$ So wuBte nicht nur die Polizei von dem Schicksal eines Ingenieurs und seiner Familie, die Anfang 1955 aus Westdeutschland nach Jena zurückgekehrt waren: Die Zeitungen hatten über die Rūckkehrer "viel geschrieben und positiv diskutiert" und der Familie war "dabei schnellstens eine Wohnung zugesagt [worden]. Die fünkōpfige Familie wurde vorlāufig in ein Zimmer eingewiesen und befindet sich jetzt, nach einem halben Jahr, noch immer in dieser Behelfswohnung. Aus dem Bericht geht hervor, daB sich die Bevōlkerung über den Fall lustig macht ${ }^{{ }^{108}}$ Neben dem angesprochenen öffentlichen Prestigeverlust verursachte der Wohnraummangel zahlreiche familiäre Probleme.

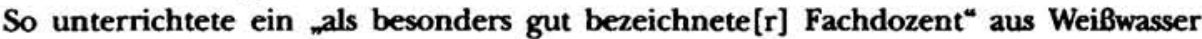
(Sachsen) bereits vier Jahre an der etwa 130 Kilometer entfernten Ingenieur-Schule ,Fritz Selbmann' in Mittweida, ${ }_{n}$ ohne daß ihm die Möglichkeit gegeben werden konnte, eine Wohnung zu erhalten. Seine Familie wohnt noch in WeiBwasser, er kommt nur alle 4-6 Wochen dazu, nach Hause zu fahren. ${ }^{109}$ Da die gemeinsame Wohnung der Familie eine Werkswohnung gewesen war, hatte die Familie sie zwischenzeitlich auch noch räumen müssen, wodurch nicht nur der Lehrer, sondern auch seine Frau und Kinder nicht mehr in den eigenen Mōbeln leben konnten. Solche monate, zum Teil sogar jahrelangen Tren-

104 Wiederholt ergingen Anweisungen, „Konzentrationen“ von Rückkehrern und Zuziehenden in einzelnen Orten und Betrieben zu vermeiden. Vgl. z.B. „Vorlage für die Leitung der HVDVP über MaBnahmen zur Verbesserung der Aufnahme und Behandlung von Rückkehrern und Erstzuziehenden" (BArch DO 1/11, Nr. 93, Bl. 129-136, hier Bl. 133); Bericht über Rūckkehrer und Erstzuzūge im 1. Halbjahr 1958, o.D. (BArch DO 1/11, Nr. 79, Bl. 100); Staatssekretär Grünstein am 5.3.1958 an Minister Gen. Steinwand, Ministerium für Berg- und Hüttenwesen: Die Einstellung von Erstzuziehenden im Stahl-und Walzwerk Brandenburg sei "möglichst zu unterbinden“, da dort bereits 129 Rūckkehrer und Erstzuziehende beschäftigt seien (BArch DO 1/34, Nr. 21725).

$105 \mathrm{Vgl}$. Schmelz, West-Ost-Migranten (1999), S. 90-94.

106 "Bericht über die illegalen Abwanderungen aus der Deutschen Demokratischen Republik und den Kampf gegen die Republikflucht im Jahre 1954" (SAPMO-BArch DY 30/J IV 2/3 A-455; der Bericht wurde am 23. 3. 1955 dem Sekretariat des ZK vorgelegt, SAPMO-BArch DY 30/J IV 2/3-463, B1. 2).

$107 \mathrm{Zu}$ den Schwierigkeiten bei der Versorgung der Rūckkehrer und Zuziehenden mit Wohnungen und Arbeit vgl. Schmelz, West-Ost-Migranten (1999), S. 98 ff., sowie die unzāhligen Hinweise in den einschlāgigen Akten.

108 Dok. 15.

109 BArch DO 1/34, Nr. 11803. Weniger wichtigen Mitarbeitern wurde dagegen kaum Verstāndnis für unzumutbare Wohnungsverhāltnisse zuteil: $\mathrm{Zu}$ einem flüchtigen Sektionsgehilfen der Universitātsklinik Greifswald, der in seinem Abschiedsbrief das Scheitern seiner Ehe infolge von Wohnungsschwierigkeiten als Fluchtgrund angegeben hatte, heißt es lapidar, dies sei „nur ein vorgeschobener Grund“. MfS, Kaderarbeiter Meissner [A]: Meldung über Republikflucht von Heinz B. (BStU ZA, MfS-AS, Nr. 2453/67, Bl. 2 ff., Zitat Bl. 2). 
nungen von ihren Familien verstärkten nicht nur bei vielen Akademikern den Eindruck, für ihre qualifizierte Arbeit ungenügend entlohnt zu werden, sondern riefen auch die Empörung staatlicher Funktionăre hervor, die den Wert der Familie zumindest ideologisch sehr hoch ansiedelten.

Während der Wohnungsmangel und die damit verbundenen Probleme allgemein anerkannt waren und offen angesprochen werden konnten, galten die zahlreichen weiteren materiellen Versongungsengpässe von Kleidung und Schmuck über besondere Lebensmittel bis zu Autos in den offiziellen Berichten als Nebensāchlichkeiten. Entsprechenden Klagen gingen die DDR-Organe gewöhnlich nicht nāher nach, sondern erklärten sie zu Zeugnissen von mangelhafter ,Aufgeklärtheit' oder politischer Unreife, weshalb die - zumeist mānnlichen - Berichterstatter die Unzufriedenheit darüber nicht zufāllig meistens bei Frauen verorteten, vor allem bei nicht-berufstātigen Ehefrauen: „Außerdem werden die Intelligenzler in den Buna-Werken von ihren Ehefrauen negativ beeinflußt, in dem [sic!] sie ihnen nach Feierabend von dem Fehlen der sogenannten , 1000 kleinen Dinge* erzāhlen. ${ }^{\text {"10 }}$ In der Vorstellung der Partei- und Staatsfunktionāre stellten sich die Geschlechterverhältnisse recht einfach dar: Die Mãnner engagierten sich für den Aufbau, ihre Ehefrauen aber ,arbeiten meistens nicht, sondern sitzen zu Hause. Sie wirken ständig auf ihre Männer ein und sagen ihnen, daß man in Westdeutschland weit besser leben kōnnte." Daher spiele „die Frage der Ehefrauen der Ärzte [...] eine große Rolle" bei der Bekämpfung der unerwūnschten Auswanderung. ${ }^{11}$ Beinahe erschien es so, als befänden sich die vom Sozialismus überzeugten Mãnner gemeinsam mit ,ihrer' DDR in einem schweren Abwehrkampf gegen die Konsumabhāngigkeit ihrer Ehefrauen: „Man hat nicht selten den Eindruck, als ob Ärzte, die vielfach zunächst die Absicht haben, in der DDR zu bleiben, schließlich den fortgesetzten Angriffen ihrer Frauen erliegen. Hierbei sind es oft ganz āußerliche Gesichtspunkte, die zugrunde liegen, z. B. Bekleidungsfragen, luxuriōses Leben, Reisen ins Ausland usw. ${ }^{\text {"112 }}$ Anstatt sich aber über die ungenügende Versorgung und die dafür mitverantwortlichen Produktionsausfälle Gedanken zu machen, interpretierten Genossen selbst dieses Problem unter der Überschrift „Methoden der Abwerbung von Bürgern der DDR“ zu einem Akt westlicher Aggressivităt: „Im September diesen Jahres 1960 soll die Jahresvollversammlung des Weltārztebundes in Verbindung mit dem 63. deutschen Ärztetag stattfinden. In dem Programm, daß auch an Ärzte in der DDR verschickt wurde, sind u. a. Veranstaltungen für die Ehefrauen der Ärzte vorgesehen, die durch die pharmazeutischen Fabriken organisiert und finanziert werden. ${ }^{" 113}$

\footnotetext{
110 SPK, Chemiekaderkommission, am 28. 7. 1960 (BArch DO 1/34, Nr. 21725); dazu ãhnlich: Ernst, Prophylaxe (1997), S. 67.

II' HVDVP, Sekretariat, Unterschrift Glāser, Major der VP, am 6. 10. 1958: Protokoll einer 8-stūndigen (!) Cheftagung vom 3. 10. 1958 mit Minister Maron, Seifert, Wenzel u.a.: _Tagesordnung: Beratung über die Fragen, die sich aus dem Kommuniqué des Politbüros zum Gesundheitswesen und der medizinischen Intelligenz ergeben" (BArch DO 1/11, Nr. 79, Bl. 134-167, hier Bl. 153).

"12 Bezirksarzt Dr. Papsdorf (.VI/I/Ro.") am 30.7.1958 an das Ministerium für Gesundheitswesen (BArch DO 1/34, Nr. 21719). Diese Abhāngigkeit wurde als generationenunabhāngig dargestellt: _Rückkehrende jugendliche Mädchen lassen erkennen, daß sie sich bei Besuchen in Westdeutschland oder Westberlin von den angeblich besseren und eleganteren Waren blüffen [!] ließen; daß man, um diese angeblich besseren Waren zu kaufen, auch Geld benötigt, spürten sie erst, als sie sich unter sehr schlechten Arbeitsbedingungen [...] verkaufen muBten." (Dok. 15).

113 BArch DO 1/34, Nr. 21724.
} 
Durch die anhaltend hohen Fluchtzahlen geriet im Laufe der Jahre fast jeder Kontakt mit dem Westen in den Verdacht politischer Unzuverlāssigkeit. In der frühen Nachkriegszeit hatten dabei noch im engeren Sinn sicherheitspolitische Bedenken im Vordergrund gestanden. Mit der wachsenden Attraktivitāt des Westens, die fast nur denjenigen DDRBürgern verborgen blieb, die nichts davon wissen wollten, mißtrauten Regierung und SED aber fast allen persōnlichen Kontakten zwischen Ost- und Westdeutschland. Die wirksamste Einflußnahme des Westens sah man dabei in der persōnlichen Kontaktaufnahme und -pflege bei Westreisen, weshalb diese ein dauerhaftes Thema bei der Beobachtung und Bekāmpfung der Auswanderung aus der DDR waren. Immer wieder flohen Bürger der DDR, die bereits über Kontakte in den Westen verfügten oder ihren Neuanfang im Westen bei genehmigten Besuchen dort vorbereitet hatten. Eine kriminalpolizeiliche „Analyse der Republikfluchten von Personen der Intelligenz" vom 15. April 1959 bemerkte, daB fünf von achtzig geflohenen Ärzten zuvor mit offizieller Erlaubnis Kongresse im Westen besucht hatten. ${ }^{114}$ Bei zahlreichen weiteren Fluchten stellten die Untersuchungsorgane schon länger bestehende Verbindungen in die Bundesrepublik fest, meistens zu Verwandten oder ehemaligen Kollegen, die häufig selbst aus der DDR weggegangen waren. Allerdings muBten die Berichterstatter erkennen, daB nicht nur Westreisen die Auswanderung verstärkten, sondern daB es genauso fluchtfordernd sein konnte, wenn die offiziellen Reisegenehmigungen, die begehrten PM 12a, nicht erteilt wurden. „So erklärte der Bauingenieur Lebus aus Meiningen vor seiner Republikflucht, daB er gezwungen sei, republikflūchtig zu werden, da er keine Genehmigung zum Besuch seiner im Jahre 1955 republikflūchtig gewordenen Eltern erhalte. Ingenieur Lebus wurde in fachlicher und gesellschaftlicher Hinsicht gut beurteilt." ${ }^{315}$ Āhnlich schrieb eine Lehrerin in ihrem Abschiedsbrief nach der Republikflucht, daB sie "niemals auf den Gedanken gekommen wäre, für immer von hier fortzugehen, wenn sie die Möglichkeit gehabt hãtte, jedes Jahr in ihrem Urlaub zu ihren Angehörigen nach Westdeutschland zu reisen. "I16 Von einem Arzt wußte die Kriminalpolizei, daß er nicht von der Gnade und Willkür der Volkspolizei abhängig sein" wollte, "wenn er seine engsten Verwandten in Westdeutschland besuchen will“, und ein junger Ingenieur begründete seinem Werksleiter im VEB Harzer-Eisenerzgruben den Weggang damit, daß er nach zwei Kurzaufenthalten von insgesamt acht Tagen für seinen Jahresurlaub keine Reisegenehmigung mehr in die nahegelegene Bundesrepublik erhalten habe, obwohl dort "meine Braut, meine Eltern und meine Geschwister $^{\text {" }}$ wohnten. ${ }^{117}$ Gleiches berichtete das Transportpolizeiamt Wittenberge über eine Frau, deren Verwandte alle in der Bundesrepublik lebten und die nicht einmal mehr ihre Geschwister besuchen durfte, seitdem ihre Mutter gestorben war. Wie in zahlreichen anderen Fãllen wurde auch diese Flüchtige von ihrem direkten Vorgesetzten so eingeschãtzt, daß sie nie geflohen wãre, wenn sie jāhrlich eine Reiseerlaubnis erhalten

\footnotetext{
I" BArch DO 1/34, Nr. 21719: Leiter der HA K der HVDVP, Odpadlik, am 15.4. 1959.

115 Dieser und die beiden folgenden Fälle ebd.

$116 \mathrm{Vgl}$. auch den Abschiedsbrief (20.4. 1959) einer Krankenschwester an ihren ehemaligen Chef: „Die Veranlassung zu meiner Reise gab mir Herr [Name von der BStU geschwãrt], er hãtte mir meine Bescheinigung für den Interzonenpaß nicht verweigern sollen, dann wäre ich gar nicht auf den Gedanken gekommen, Rostock zu verlassen." (BStU ZA, MfS-AS, Nr. 2453/67, Bl. 101).

i17 BArch DO 1/11, Nr. 965, Bl. 7-13, hier Bl. 9 f. Leiter der HVDVP, Generalmajor der VP, Dombrowsky, am 8. 1. 1958 an ZK, Gen. Borning; MfS, Gen. Szinda; Innere Angelegenheiten u. weitere Abteilungen der VP.
} 
hãtte. ${ }^{118}$ Angesichts der zahlreichen familiären, freundschaftlichen und beruflichen Beziehungen zwischen Ost und West sahen die meisten Betroffenen die Reisebeschränkungen - die auch für die an westlichen Universitāten immatrikulierten Kinder von Akademikern in der DDR galten ${ }^{119}$ - „als eine unerträgliche Einschränkung ihrer persönlichen Freiheit an ${ }^{\prime 120}$. Diese Einschätzung war in der ganzen Bevōlkerung und selbst in der Volkspolizei weit verbreitet: Zahlreiche unklare, verzōgerte oder vertröstende Antworten von Polizeiämtern gegenüber den Antragstellern zeigen, daß die Ende 1957 wieder verschärften Reiseverbote ${ }^{121}$ auch innerhalb der offiziellen Stellen nicht unumstritten waren und nach außen nur schwer vertreten werden konnten: „Bei Beantragung von Interzonenpāssen ist man in Leipzig zu feige, den Intelligenzlern eine klare ablehnende Antwort zu geben, sondern läßt sie wochenlang warten. ${ }^{\text {} 122} \mathrm{DaB}$ in Karl-Marx-Stadt seit Anfang 1958 nkeine Anträge für illegal abgewanderte Personen mehr entgegengenommen“ wurden, führte zu einer mgroßen politisch-ideologischen Auseinandersetzung vor allem auf der Gemeinde- und Kreisebene. [...] Das Ausweichen vor offenen und ehrlichen Auseinandersetzungen mit Betriebsangehörigen über Reisen in die NATO-Staaten gibt Anlaß zu berechtigten Verärgerungen der Antragsteller. ${ }^{{ }^{123}}$ Mit einem āhnlichen Anliegen wandte sich Hauptreferent Wilke der Hauptabteilung Innere Angelegenheiten im MdI am 6. Mai 1958 an die Präsidialkanzlei: Personen, denen die Ausreise verweigert worden sei, seien nicht mehr auf eine spātere Liberalisierung hin zu vertrōsten. "Wir möchten hierzu bemerken, daß eine derartige Argumentation nicht der gegenwärtigen Situation entspricht. Sie ruft bei den Antragstellern Hoffnungen hervor, die in der Tat nicht Wirklichkeit werden können. Man sollte deshalb [...] zukūnftig auf einer anderen Ebene argumentieren und den Antragstellern offen zu verstehen geben, daB es gegenwärtig keine Genehmigung zur Übersiedlung gibt und warum es auch keine gibt. Für einen offenen klaren Bescheid werden unsere Bürger mehr Verstāndnis entgegenbringen als für Versprechungen. die in der Tat nicht realisiert werden können. ${ }^{\text {"124 }}$

Die Bestimmungen gegen einen freizügigen Reiseverkehr galten - außer in den kurzen Perioden grōßerer Liberalitãt - in beide Richtungen und wurden von den Polizeidienststellen schematisch angewandt. So begründete ein Arzt aus Sonneberg (Thüringen) seine Republikflucht mit dem besonders scharfen Besuchsverbot in der Sperrzone im Westen der DDR, wodurch ihn seine vor fünf Jahren geflohenen Kinder nicht mehr besuchen konnten. ${ }^{125}$ Als Anfang 1959 ein Gemeindebürgermeister „und bewährtes Mitglied unserer Partei“ im Kreis Kōnigs Wusterhausen starb, wurde nicht einmal ndem Wunsch seiner

\footnotetext{
${ }^{11}$ LAS Trapo Schwerin 28, Nr. 79, Bl. 31-35: „Abschrift. Transportpolizei-Amt, Abt. Kriminalpolizei W'ittenberge" am 12.11.1960.

119 Vgl. BArch DO 1/11, Nr. 960, Bl. 65 f.

120 BArch DO 1/34, Nr. 21719: Bezirksarzt Dr. Papsdorf am 30.7. 1958 an das Ministerium für Gesundheitswesen.

121 In Karl-Marx-Stadt wurden z.B. im ersten Quartal 195736000 Anträge auf PM 12a gestellt und nur 54 abgelehnt, im ersten Quartal 1958 dagegen 12763 Antrāge auf PM 12a gestellt und 7341 abgelehn (BArch DO 1/34, Nr. 21725); dies galt auch für die DDR insgesamt, vgl. z.B. die Genehmigung fast aller Anträge für PM 12a 1957 und die zahlreichen Ablehnungen 1958 (BArch DO 1/11, Nr. 79, Bl. 101).

${ }_{192}$ Rat des Bezirkes Halle, Abt. Innere Abgelegenheiten am 6. 10. 1958 an MdI, HA Innere Angelegenheiten (BArch DO 1/34, Nr. 21725).

123 Ratsvorlage vom 31.5. 1958 in Karl-Marx-Stadt (BArch DO 1/34, Nr. 21725).

124 BArch DO 1/34, Nr. 21725.

125 Leiter der HA K der HVDVP, Odpadlik, am 15.4. 1959 (BArch DO 1/34, Nr. 21719).
} 
Verwandten, seine Schwester aus Westberlin, die positiv unserer Republik gegenūber steht, an den Trauerfeierlichkeiten teilnehmen zu lassen, [...] von der Passierscheinstelle [...] entsprochen. ${ }^{\text {"}}{ }^{26}$ Verschiedene Dienststellen kritisierten wiederholt, daß die lokalen Polizeidienststellen bei der Vergabe von Reisegenehmigungen zu rigoros verfuhren. Nicht selten wurden gerade Akademiker von den Polizisten in rūder Art abgewiesen: Einem Oberarzt, der eine Reisegenehmigung zu seinem schwerkranken Vater nach Westdeutschland beantragt hatte, entgegnete der Mitarbeiter des Volkspolizeikreisamts: „Warten Sie doch lieber, bis Ihr Vater gestorben ist, denn zweimal bekommen Sie die Genehmigung nicht." Daraufhin floh der Arzt in den Westen. ${ }^{127}$ Da sie die von zentralen SED- und Regierungsstellen für Akademiker gewährten Freizügigkeitsregelungen nicht anwandten, erwartete die Hauptabteilung Kriminalpolizei eine „bessere Kontrolle der von Partei und Regierung erlassenen Beschlūsse und Gesetze über die Arbeit mit der Intelligenz, besonders durch die zuständigen staatlichen und gesellschaftlichen Institutionen. ${ }^{\text {I28 }}$ Solche Vorschläge zeitigten letztlich aber durch das Zusammenspiel von zentralen und lokalen Dienststellen fast keine Folgen, weil Kritik und Ursachenanalyse niemals eindeutig formuliert und die liberaleren Anweisungen aus Berlin nur selten langfristig gültig waren. So blieben auch die auf höchster Ebene formulierten Vorhaben weitgehend wirkungslos, etwa wenn Innenminister Maron Anfang Oktober 1958 die „sture und schematische Anwendung " von Verordnungen sowie "Überspitzungen und Verzerrungen“ bei der Vergabe von Reisegenehmigungen kritisierte: ${ }_{n}$ s darf auch keinen Wettbewerb geben, wer am meisten ablehnt. [...] Wir kōnnen doch kein Verbot zum Heiraten oder Getrenntleben aussprechen. ${ }^{\text {"29 }}$ Die Regierung befand sich gegenūber ihrer Bevōlkerung ganz offensichtlich in einem Dilemma: Erlaubte Westreisen wurden zur Republikflucht genutzt, untersagte Reisen aber konnten ebenso zum $A$ nla $B$ werden. In dieser ausweglosen Situation ãnderten SED und Regierung die Genehmigungsverfahren in den letzten Jahren vor dem Mauerbau nicht mehr nennenswert. Dies zeitigte verheerende Folgen, denn viele Menschen verstanden die Reisebeschrānkungen im Kontext der Berlinkrise als Vorboten einer völligen Grenzschließung und gingen gerade aufgrund der Furcht, daß bald auch das Schlupfloch Berlin geschlossen würde: „Ich nehme für mich und meine Familie, solange es irgend geht, das Recht auf Selbstbestimmung in Anspruch, das heute jedem Afrikaner zugestanden und von der Sowjetunion propagiert wird! ${ }^{{ }^{130}}$

Besonderen Ärger verursachten die Reiseverbote, wenn es um Tagungen oder Kongresse im Westen ging, die in erster Linie der Weiterbildung dienten, aber auch die beruflichen und privaten Kontakte zwischen Ost und West stärkten. Fast kein Bericht über die Flucht von Akademikern läßt Probleme wegen solcher Tagungen in westlichen Ländern

\footnotetext{
126 „Zusammenfassung der von den 1.Stellvertretern gegebenen Informationen für den Monat März 1959" (BArch DO 1/11, Nr. 19, Bl. 149-162, hier Bl. 158).

127 „Beispiele sektiererischen Verhaltens gegenüber der Intelligenz“, o.V., 1. 11. 1960, BStU ZA, MfS.SdM, Nr. 1228, Bl. 285.

${ }_{128}$ BArch DO 1/34, Nr. 21719: Leiter der HA K der HVDVP, Odpadlik, am 15.4. 1959. In vorsichtiger Form wurde auch vorgeschlagen $„$ zu prüfen, inwieweit es ratsam erscheint, bei der Ausgabe von PM 12a an die gesamte Intelligenz großzügiger zu verfahren".

1.29 BArch DO 1/11, Nr. 79, Bl. 134-167, hier Bl. 155: HVDVP, Sekretariat, Unterschrift Gläser, Major der VP, vom 6. 10. 1958.

${ }^{190}$ Abschiedsbrief eines Arztes vom 29.8.1960 aus Wiesbaden an den Pfarrer an seinem bisherigen Wohnort Lehnin (BArch DO 1/34, Nr. 21724).
} 
unerwähnt, denn wohl kaum zu Unrecht vermuteten die Behörden dahinter häufig die Absicht, sich durch die Kontakte zu ehemaligen Studienfreunden und Kollegen eine Fluchtmöglichkeit aus der DDR offen zu halten. Dieses Mißtrauen verschärfte sich dadurch, daß solche fachspezifischen Zusammenkünfte auch unabhängig vom politischen Systemgegensatz traditionell der Stellenvermittlung dienten, die von den DDR-Organen aber nie anders denn als feindliche Abwerbung verstanden werden konnte. ${ }^{191}$ Der Sektor Kader im Sekretariat für das Hoch- und Fachschulwesen stellte in seiner Analyse über die Fluchten im ersten Quartal 1961 fest, daB die teilweise mit der Devisenknappheit der DDR begründeten Verbote von "Tagungs-, KongreB- und Studienreisen" in verschiedenen Fāllen „zu großen persönlichen Verärgerungen“ führten sowie zu „Drohungen, daß sie ihre gefertigten wissenschaftlichen Arbeiten in Westdeutschland verlegen werden, um in den

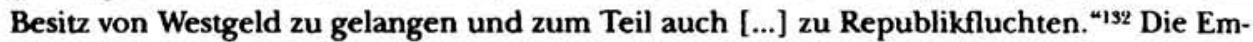
pörung sei groß und selbst der Teil der Ärzte, der „Verstāndnis für diese Schwierigkeiten“ habe, nverlangt aber, daB wir ihnen vertrauen und mit ihnen offen über diese Schwierigkeiten sprechen. ${ }^{13 s}$

Auch für dieses Problem gab es von staatlicher Seite keine realistischen Lösungsvorschläge. Das Vorhaben, die eigenen Akademiker häufiger ins östliche Ausland reisen zu lassen, war nur für eine kleine Minderheit attraktiv, da den meisten Kandidaten die Sprachkenntnisse fehlten und sie nicht an irgendwelchen Weiterbildungen interessiert waren, sondern an der Pflege jahrzehntelang gewachsener und bewăhrter Netzwerke und Diskussionszusammenhänge. ${ }^{194}$ Darüber hinaus verstärkten die Reisen zu Kollegen ins osteuropäische Ausland bei vielen Akademikern die Sorge davor, daß sich die Verhāltnisse in der DDR diesen ,Vorbildern' noch weiter annähern könnten.

Als ebenso wenig tragbar wie die Verbote, sich im Westen weiterzubilden, empfanden die meisten Mitglieder akademischer Berufe den stark beschränkten Zugang zum Studium für ihre Kinder. Abgesehen von Ausnahmen ${ }^{1.5}$ gehörte es zum bildungspolitischen Pro-

131 Entsprechende Kritik am Besuch von Fachtagungen im Westen in: Unterlagen über die Flucht von Chemikern aus Halle (Saale) (BArch DO 1/34, Nr. 21725); „Methoden der Abwerbung von Bürgern der DDR“ (BArch DO 1/34, Nr. 21724); Hinweis auf Grūne Woche, Kongresse für ãrztliche Fortbildung u.a. Veranstaltungen in West-Berlin, um „Kontakte mit Bürgern der DDR aufzunehmen." (Bericht vom 13.2. 1961, BArch DO 1/11, Nr. 967, Bl. 37-60, hier Bl. 41); „Entwurf. Argumentation über die Probleme der Republikfluchten und des Reiseverkehrs" (BArch DO 1/34, Nr. 21724).

132 Weitere Beispiele für die Androhung von Republikflucht bei Ross, .....sonst sehe ich mich veranlasst. auch nach dem Westen zu ziehen" (2001). S. 622-626.

139 BArch DO 1/34. Nr. 21721 (11.4.1961).

19 So nahm die westdeutsche Vereinigung .Deutsche Gesellschaft für Chirurgie' allein im Jahr 1957 34 neue Mitglieder aus der DDR in ihre Reihen auf und zāhlıe Anfang 1959401 DDR-Bürger zu ihren Mitgliedern. Die Gesellschaft pflegte rege grenzüberschreitende Aktivitãten wie Referentenvermittlung oder den Versand von Fachpublikationen. Der von Innenminister Maron an das MfS und verschiedcne andere Ministerien versandte Bericht vom 21.1. 1959 sah darin vor allem „Gefahren der feindlichen Beeinflussung“ (BArch DO 1/11, Nr. 966, Bl. 3 ff.).

135 Die am 23. 7. 1953 von der Regierung der DDR erlassene „Verordinung über die Neuregelung des Abschlusses von Einzelverträgen mit Angehörigen der Intelligenz in der DDR" führte neben anderen

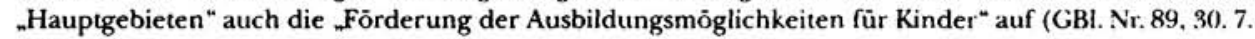
1953, S. 897-901, hier S. 899). Diese Regelungen hatten allerdings auch zahlreiche Probleme bei der Auslegung entsprechender Vereinbarungen zur Folge. Konflikte tauchten vor allem dann auf, wenn die schulischen Leistungen der Akademikerkinder als unzureichend eingeschãtzı wurden (vgl. den Fall von Dr. Gründel im Bericht vom 6. 10. 1958, BArch DO 1/34, Nr. 21725: Hinweise auch bei Jessen, Vom Ordinarius [1996], S. 80; vgl. auch die Verordnung vom 12. 7. 1951, in: (BBI. 1951, S. 681). 
gramm der DDR, „Kinder von Angehörigen der Intelligenz und des Kleinbürgertums [...] aufgrund des festgelegten Planes ungeachtet vorhandener Leistungen nicht zum Studium an Ober-, Fach- und Hochschulen in der DDR" zuzulassen. ${ }^{136}$ Verschärft wurde diese soziale und politische Auswahl noch dadurch, daB sich jedes Jahr mehr Abiturienten zum Studium bewarben, als überhaupt zugelassen wurden. ${ }^{137}$ Dies führte dazu, daB viele Akademiker wie ein führender Chemiker der Farbenfabrik Wolfen zu der Überzeugung kamen, daß ${ }_{n}$ Nichtarbeiterkinder [...] keine Perspektive in der DDR“ hatten und ihren Weggang in den Westen mit den eingeschränkten Zukunftschancen ihrer Kinder begründeten. ${ }^{138}$ Im gleichen Kontext erwähnten die Berichte gewöhnlich auch die sozialistische Schulerziehung, die vorwiegend bürgerliche Eltern wegen der politischen Bekenntnisse, der mangelhaften Qualităt in der Lehre und vor allem der antireligiōsen StoBrichtung kritisierten: „So verlieB der Zahnarzt Dr. W. O. aus Magdeburg die DDR deshalb, weil er nicht wollte, daB seine Kinder in der Schule im atheistischen Sinne erzogen werden. Dr. O. war streng katholisch. "199

Nicht selten führten auch Überforderung am Arbeitsplatz oder Arbeitsüberlastung zur Republikflucht. Hinter diesen Fluchtmotiven stecken zwei strukturelle Gründe: zum einen der Einsatz sehr junger, häufig ungenügend qualifizierter Menschen in leitenden Positionen. So wurde der "tatsāchliche Grund“ der Republikflucht des Brigadeleiters eines VEB darin gesehen, daB ihm ,auf Grund seiner Schwächen in organisatorischen Fragen die Dinge über den Kopf gewachsen sind ${ }^{\text {“ }}$ und er ${ }_{n}$ Schwierigkeiten in der Anleitung seiner Mitarbeiter" hatte; ${ }^{140}$ der Betriebsleiter eines VEB wurde republikflūchtig, weil er nden Aufgaben nicht gewachsen “ war und er "Angst [hatte], daB er nochmals zur Verantwortung gezogen wird “. ${ }^{141} \mathrm{DaB}$ solche Probleme weit verbreitet waren, zeigt der Brief eines DDR-Bürgers an das ZK der SED, in dem er dieses über die tatsächlichen Ursachen der Republikflucht aufklären will, in dem es u. a. heißt: „In vielen Fällen liegt ein reines Versagen der Nerven zugrunde. Meiner Ansicht nach geben wir den jungen Menschen heute

136 Analyse über die Entwicklung der Republikflucht in den Jahren 1954-1955 u. 1956“ vom 3.5. 1956 (BArch DO 1/34, Nr. 21723a). Zur Zulassung von Schülern zu hōherer Bildung vgl. auch GeiBler, Geschichte des Schulwesens (2000), S. 320-324.

1371954 bewarben sich in der DDR 25000 Abiturienten, aber nur 20000 konnten berücksichtigt werden. Wie Abteilungsleiter Kiehl vom Staatssekretariat für Hochschulfragen, Abt. Studentenangelegenheiten, am 5. 1. 1955 gegenüber der HA PM mitteilte, sei bei der Auswahl einerseits „die soziale Struktur unseres Volkes berücksichtigt “ worden, andererseits wären „nur fachlich gute und politisch aufgeschlossene junge Menschen immatrikuliert" worden (BArch DO 1/11, Nr. 962, Bl. 229 f.).

iss Rat des Bezirkes Halle, Abt. Innere Abgelegenheiten, am 6. 10. 1958 an das MdI, HA Innere Angelegenheiten, Gen. Meyer: Bericht über die Flucht von drei führenden Chemikern der Farbenfabrik Wolfen (BArch DO 1/34, Nr. 21725); vgl. auch Bericht der HA PM an ZK der SED vom 25. 1.1958 mit Fallbeispielen zur Republikflucht von Ärzten, in dem u.a. Studienbeschränkungen für Kinder genannt werden (Dok. 19); Bezirksarzt Dr. Papsdorf schreibt am 30.7.1958 an das Ministerium für Gesundheitswesen, daß die Ärzte als Grund für Republikflucht „[i]n erster Linie“ die „ungerechtfertigten Ablehnungen für den Besuch der Oberschule oder der Universität" für ihre Kinder angeben (BArch DO 1/34, Nr. 21719). 139 Leiter der HA K der HVDVP, Odpadlik, am 15.4. 1959 (BArch DO 1/34, Nr. 21719). Vgl. auch die in der vorhergehenden Anmerkung angeführten Berichte.

140 "Einzel-Information über die Ergebnisse der Überprüfung der von dem Ingenieur [anonym] in seinem Brief an den Ministerpräsidenten Gen. Otto Grotewohl dargelegten Grūnde seiner Republikflucht“, 9. 3. 1961. BStU ZA, MfS-ZAJG, Nr. 391, Bl, 1-5, hier Bl. 4.

141 Staatssekretariat für Staatssicherheit, Wollweber, an Ministerpräsident Grotewohl, 16. 8. 1954: „Auszüge aus Berichten einiger Bezirksverwaltungen über Tendenzen und Schwerpunkte der DDR-Flucht", 7. 8. 1954, BStU ZA, MFSSdM, Nr. 1200, Bl. 105-113, hier Bl. 111. 
schon viel zu frūh verantwortungsvolle Posten, zu denen auf die Dauer die Nerven nicht ausreichen. [...] Verstândnisvolle Hilfe fehlt nur zu oft. Und dann: Die überbeanspruchten Nerven halten nicht mehr Stand, enttāuscht suchen die jungen Menschen anderswo ihr Glūck. ${ }^{\text {"142 }}$ Zum anderen lag die Ursache in der Republikflucht selbst, die gerade in Berufen, in denen ohnehin Personalmangel bestand, wie bei Ärzten und Lehrern, das ndagebliebene" Personal zusātzlich belastete und dadurch eine Art Teufelskreis auslōste. Je mehr Kräfte flohen, desto höher wurde die Arbeitsbelastung für den einzelnen, was wiederum zu verstärkten Fluchttendenzen führte: „Eine andere Erscheinung, die Ursache zur Republikflucht von Ärzten werden kann, ist die Tatsache, daß durch die vielen, mitunter sehr konzentriert erfolgten Abgānge, bei den in der DDR verbliebenen Ārzten Arbeitsüberlastung eintritt ${ }^{\text {"143 }}$. So klagte beispielsweise eine Ärztin: „Wir sind hier am Ort nur noch zwei Ärzte, gegenüber fünf vor 12 Jahren. Ich habe so leidenschaftlich Praxis gemacht, aber jetzt - diese Massen - mir graut jeden Tag vor der Sprechstunde. ${ }^{{ }^{144} \text { Eine }}$ Krankenschwester begründete ihre Republikflucht in einem Brief an ehemalige Kollegen folgendermaßen: „Ich konnte die Nachtdienste nicht mehr machen [...] Ich wäre bald durch die Arbeitszeit ins Irrenhaus gegangen. ${ }^{{ }_{145}}$ Bei Lehrern waren es oft zusātzliche gesellschaftspolitische Aufgaben, die zur Arbeitsüberlastung und schließlich zur Republikflucht führten. ${ }^{146}$

Zahlreiche Berichte beschreiben die Reisebeschrānkungen, die Wohnungsprobleme und selbst die höheren Gehaltsansprüche mit vielen facettenreichen und illustrierenden Beispielen. Einige Aspekte und Fluchtgründe blieben hingegen farblos und schematisch. Dazu zāhlen vor allem das religiöse Bekenntnis und die Kirchenzugehörigkeit. In unzāhligen Berichten wird zwar der kirchliche Hintergrund und zuweilen auch das ehrenamtliche Engagement in Kirchengemeinden erwāhnt, aber fast nirgends konkretisieren sich kausale Zusammenhänge zwischen privatem religiösen Bekenntnis, kirchlichem Engagement, der religionsfeindlichen Haltung von Staat und SED und der Republikflucht. Recht nebulōs wird von "kirchlichem Einfluß" berichtet, als hātten die Amtskirchen ein Interesse am Weggang ihrer Gemeindemitglieder in den Westen, ${ }^{14 \overline{7}}$ obwohl offizielle Verlautbarungen der Kirchenleitungen wiederholt zum Verbleib in der DDR aufriefen. ${ }^{1+8}$ Eine gewisse Aus-

142 Anonymisiertes Schreiben an das ZK der SED, Politbūro, 27. 11.1957 (Dok. 35).

143 MrS, Abt. Information, Information Nr. 23/58, 8.4. 1958: „Illegales Verlassen der DDR durch Ärzte. Zahnärzte und medizinisches Pflegepersonal“, BStU ZA, MfS-ZAIG, Nr. 97, Bl. 1-8, hier BI. 5.

144 BStU ZA, MfS-ZAIG, Nr. 97, BI. 6.

145 BStU ZA, MfS-ZAIG, Nr. 97, BI. 7.

146 "Bericht über die Gründe und Entwicklung der Republikflucht bei Lehrern“, BStU ZA. MrS-ZAIG, Nr. 139, Bl. 1-4, hier Bl. 2.

147 „Die klerikal-militaristischen Kräfte der katholischen und evangelischen Kirche haben eine Reihe von Maßnahmen getroffen, wie 2.B. die Verkūndigung des Fastenhirtenbriefes der ostdeutschen Bischofskonferenz der katholischen Kirche sowie die verschiedensten Kanzelabkündigungen zur sozialistischen Umgestaltung der Landwirtschaft, die die Christen in Gewissenskonflikte brachten und als Ausweg nur die Republikflucht offenließen“ (Bericht vom 13.2. 1961, BArch DO 1/11, Nr. 967, Bl. 37-60, hier Bl. 41). Unter der Überschrift ${ }_{n}$ Zur Beeinflussung durch die Kirche ${ }^{*}$ werden beispielsweise einige Pfarrer genannt, die zur Ausreise animiert haben sollen und deren Fälle tcilweise an das MfS übergeben wurden ( Bericht über die Republikflucht [...] für die Zeit vom 1.1.1954 bis 31.12.1955“. BArch DO 1/11. Nr. 963, Bl. 100-130, hier Bl. 122 f.).

148 Beispielhaft für die Verlautbarungen, in denen vor zu schnellen und rein eigennüuigen Entscheidungen zur Auswanderung gewarnt wird, ist die Stellungnahme der Synode der evangelischen Kirche der Union vom November 1960 (SAPMO-BArch DY 30/J IV 2/3-714, B1. 8; Dok. 25; Dok. 26) und die Pre- 
nahme bildeten Hinweise auf die Junge Gemeinde, die wesentlich konkreter ausfielen. Wahrscheinlich war sie infolge der Anschuldigungen von Staat und SED auch in den Kreisen der Parteibürokratie und Volkspolizei bekannt. So hie $B$ es beispielsweise 1955, daß Mitglieder der Jungen Gemeinde „auf Anraten der Kirche die DDR verlassen“ hātten, statt zur KVP zu gehen, ${ }^{149}$ und 1958 berichtete die Polizei von der Kinderklinik der Karl-MarxUniversitāt Leipzig, daß Lehrlinge dort bei ihrer Einstellung noch das FDJ-Abzeichen tragen würden, 14 Tage spãter aber schon das Kreuz der Jungen Gemeinde. Die Kirche würde von dort aus republikflüchtige Schwestern in kirchliche Krankenhäuser in Westdeutschland und ins westeuropäische Ausland vermitteln. ${ }^{150}$ Den fortgesetzten EinfluB der Kirchen beklagte das Innenministerium auch am 22. Oktober 1960 in einem Bericht über Probleme im Zusammenhang mit der Republikflucht von Jugendlichen: In Halle trete "die Kirche bei der Beeinflussung der jungen Intelligenz sehr stark in Erscheinung " und führe mit ihnen beispielsweise "Rüstzeiten" durch. ${ }^{151}$ Trotz dieser Detailbeobachtungen waren die Berichte ūber den mōglichen Einfluß der Kirchen auf die illegale Auswanderung aus der DDR in erster Linie von Ressentiments und allgemeiner politischer Ablehnung geprägt, ${ }^{152}$ die sich etwa in der Verärgerung über Pakete zeigte, die westdeutsche Kirchenkreise in die DDR schickten: „Diese ganze Aktion läuft auf eine Diskriminierung unseres Arbeiter- und Bauernstaates hinaus und führt zur Verherrlichung des Bonner Staates in den Kōpfen einzelner solcher Empfänger. " ${ }^{\text {"15s }}$ Ein deutlicher Hinweis auf den geringen Kenntnisstand oder das nachgeordnete Interesse an religiösen Fragen ist die ,Monopolstellung' der christlichen Konfessionen in den offiziellen Berichten: Das Judentum findet überhaupt keine Erwähnung, obwohl viele ostdeutsche Juden und vor allem zahlreiche Rabbiner vor den antisemitischen Gefährdungen im gesamten sowjetischen Einflußbereich in den fünfziger Jahren aus der DDR flohen. ${ }^{154}$

Hâufig rief der offizielle Atheismus der DDR-Regierung und ihrer Verwaltung weniger Probleme hervor als die alltăgliche religionsfeindliche Atmosphäre an Arbeitsplātzen, in Schulen oder Nachbarschaften. Beispielhaft zeigt sich dies an der Republikflucht des katholischen Diplomingenieurs Hans Büttner aus dem Zentralen Konstruktionsbüro für metallurgische Industrie in Leipzig im August 1954, einer "Kapazitāt“ auf dem Gebiet der Energieeinsparung. In den Berichten über seine Flucht wird eine subalterne Genossin in der Personalabteilung kritisiert, die den Wissenschaftler wiederholt ohne AnlaB als reak-

digt des Bischofs von Meißen, Otto Spülbeck, vom 31.12. 1960 (Pilvousek, Kirchliches Leben [1994], S. 158-167, besonders S. 162 ff.). Hohmann, Lehrerflucht (2000), S. 33, zitiert entsprechende Ratschlāge der "katholischen [...] wie der evangelischen Geistlichkeit" aus dem Brief eines katholischen Grundschullehrers: „Wenn Ihr geht, kommen Kommunisten an Eure Stelle.“

149 Dok. 15.

150 BArch DO 1/11, Nr. 965, Bl. 32 ff.: Leiter der HVDVP, Generalmajor der VP, Dombrowsky, am 7. 2. 1958 an ZK, Gen. Borning u.a.

151 Dok. 20.

152 Vgl. zum Beispiel das Protokoll vom 6.9.1958 über die Cheftagung mit den 1.Stellvertretern der Vorsitzenden der Räte der Bezirke und den Chefs der BDVP am 4. 9. 1958: „Republikfluchten der Intelligenz mit auf Wühlarbeit der Kirche zurūckzuführen. Ideologie gegen Staat und Partei“ (BArch DO 1/11, Nr. 66. Bl. 1-5, hier Bl. 4 f.).

159 „Die Rolle der Kreisparteiorganisation Heiligenstadt bei der Lōsung der politisch-ideologischen und wirtschaftlichen Aufgaben in ihrem Gebiet" von 1957 (SAPMO-BArch DY 30/J IV 2/3 A-564).

154 Nach Angabe von KeBler, Die SED und die Juden (1995), S. 101, verließen allein im Januar 1953400 Juden die DDR gen Westen; vgl. auch ebd., S. 99-105; KeBler, Zwischen Repression und Toleranz (1993). 
tionãr beschimpft habe und seinen Glauben und seinen bürgerlichen Lebensstil nicht tolerieren wollte: „Die Familie Büttner gehört dem katholischen Glaubensbekenntnis an und keiner staatsfeindlichen Sekte. ${ }^{1155}$ Das unhöfliche und religionsfeindliche Verhalten war für alle dienstlichen Belange bedeutungslos, brachte den Ingenieur aber in einen nicht unerheblichen Konflikt, weil die bloß zwischenmenschliche Dimension durch die ,politischen' Rahmenbedingungen überlagert wurde: Erst durch die Anwürfe der Personalsachbearbeiterin sah sich der Ingenieur zu einem Loyalitātsbekenntnis zugunsten der DDR genötigt, das er aufgrund seiner Religionszugehōrigkeit vermeiden wollte. Sobald der Konflikt eskaliert war, überragte er die zwischenmenschliche und betriebsinterne Ebene, weil sich die Mitarbeiterin der Kaderabteilung auf ihre Partei berufen konnte, der man Mitte der fünfziger Jahre nur dann widersprechen sollte, wenn ein Interesse an weiteren Konflikten bestand. ${ }^{156}$ Auch ein Polizeibericht vom Juni 1958 zeigt, daß der christliche Glaube aus eher alltäglichen und aus politisch-ideologischen Gründen zur Flucht führen konnte: So äußerte ein aus Gera geflohener Konstrukteur katholischer Konfession, $\mathrm{daB}$ er "kein Interesse" mehr daran habe, ,seinen Glauben von einigen Menschen als Aberglauben [ab]stempeln zu lassen. ${ }^{157}$ Seltener als aufgrund solch alltäglicher Konflikte, wie sie auch in den genannten Hirtenworten beider Konfessionen beschrieben wurden, flohen Menschen wegen eines direkten Bekenntniszwangs. Darauf bestanden die Kommunisten vor allem in den Bereichen, die sie als wichtigste Missionsfelder ihrer privilegierten Welterkenntnis ansahen. So floh eine Geschichtsprofessorin aus Jena mit ihren Eltern in den Westen, weil sie den ,fachlichen 'Anforderungen der SED nicht gerecht werden wollte und es daher unterlieB, ${ }_{n}$ sich mit dem historischen und dialektischen Materialismus vertraut zu machen. Von ihr wurde die Meinung vertreten, da $\beta$ sie das mit ihrer Religion nicht vereinbaren kann. ${ }^{{ }^{158}}$

In vielen der religiōs motivierten Konflikte scheint die seit Bestehen der DDR von der SEDSpitze beklagte intelligenzfeindliche Haltung ihrer eigenen Mitglieder durch, ${ }^{159}$ dic als klassischer sozialer Konflikt keineswegs nur aus sozialistischen Gesellschaften bekannt ist. Obwohl die DDR auf die Fachkräfte angewiesen war, prägte die SED letztlich eine antielitäre Grundhaltung, die neben der politischen Macht auch auf der vermeintlichen Überlegenheit ihrer, wissenschaftlichen' Weltanschauung beruhte. Dadurch galten nur diejenigen, die sich der Partei unterwarfen, als gleichwertige Partner, alle anderen aber als Feinde oder Zielobjekte politisch-pãdagogischer Betreuung: „Für uns als Genossen der Partei ist es doch klar, daß die Intelligenz eine schwankende Haltung einnimmt, sie wird bei Erfolgen, die die Arbeiterklasse hat, die Arbeiterklasse in der Erfüllung ihrer Aufga-

1 ss BArch DO 1/34, Nr. 11800.

156 Eine āhnliche Situation zeigt die etwa zeitgleiche Flucht des Ingenieurs W'illi Richter, dessen Begründung „wir kehren nicht mehr zurück, so bitter es ist, aber der bösen Machı muß ich weichen *, sich nichı gegen die SED, sondern gegen intrigante, aber durch ihre SED-Mitgliedschaft unangreifbare Kollegen richtete (BArch DO 1/34, Nr. 11800).

157 Ein weiteres Beispiel für die Politisierung von Privatem ist die Reaktion der Berichterstatter aus der Abt. Innere Angelegenheiten, die dem Leiter der Abt. Arbeit in Montagewerk Halle „erhebliche ideologische Unklarheiten" vorwarfen, weil er den Weggang der Jugendlichen auch als „Modekrankheit" bezeichnete, bei der sie „sich nun einmal die Hörner abstoßen müssen“ (Dok. 20).

158 Dombrowsky, Generalmajor der Volkspolizei, HVDVP, Der Leiter, am 16.6. 1958 an Abt. Innere Angelegenheiten über Gen. Staatssekretār Grünstein (BArch DO 1/34, Nr. 21725).

159 Als frūhe Beispiele vgl. die Sitzungen des Sekretariats des ZK am 10. 12. 1951 (SAPMO-BArch DY30/J IV 2/3-253, BI. 3) und am 8. 12. 1952 (SAPMO-BArch DY 30/J IV 2/3/346 BI. 10 f.). 
ben unterstūtzen, ebenso gut wird die Intelligenz aber bei Krisen bzw. bei weniger Erfolgen eine abwartende und zurückhaltende Stellung einnehmen. ${ }^{160}$ Entsprechend vermißte eine „kriminalpolizeiliche Analyse über Republikfluchten, Rūckkehrer und Neuzugānge" bei vielen DDR-Bürgern - gemeint waren wohl insbesondere die Mitglieder der SED - das „richtige Verhāltnis“ zur Intelligenz, da sie „nicht die notwendige Geduld zur Umerziehung dieser Menschen an den Tag ${ }^{4}$ legten. ${ }^{161}$ Die hohen Fluchtzahlen und die wirtschaftliche Abhängigkeit von den auch im Westen begehrten Fachleuten machten einen rücksichtsvollen Umgang mit ihnen notwendig, weshalb ein zu negatives, arrogantes oder ausgrenzendes Verhalten wiederholt als „sektiererisch ${ }^{{ }^{162}}$ kritisiert wurde. Da SED und Staatsapparat es jedoch vermieden, das Verhältnis zwischen der Partei mit ihrer vermeintlichen Erkenntnisprivilegierung und den Akademikern samt ihrer fachlichen Fähigkeiten und privaten Überzeugungen zu klären, waren Konflikte unausweichlich. Es blieb bei kosmetischen Korrekturen in dem hierarchisch gedachten Verhältnis zwischen Partei und Akademikern. ${ }^{16 s}$

Die Folge dieser politisch motivierten Haltung gegenüber Spezialisten, die häufig kein Interesse an Politik zeigten und in erster Linie nur ihre beruflichen Aufgaben erfüllen wollten, war zunehmende Sprachlosigkeit. Ein Brigadebericht in Buna stellte fest, daB "die Angehörigen der Intelligenz des Werkes [Wolfen] bevormundet “ worden seien und daher „keine offene und ehrliche Atmosphäre herrschen konnte." Die Erfahrungen hätten aber gezeigt, „wie wichtig es ist, mit den Intelligenzlern zu sprechen, denn die Intelligenzler warten darauf, daB man sich mit ihnen unterhält. ${ }^{\text {} 164}$ Wie unkommunikativ das Verhältnis zwischen Parteivertretern und Akademikern zuweilen war, demonstrierte die „ZK-Brigade Bitterfeld“ im März 1961 unfreiwillig, als sie zusammenfaßte, daß die SEDLeitung im VEB Farbenfabrik Wolfen ihr Vertrauensverhältnis zu den Angehörigen der Intelligenz bedeutend [!] verbessert [habe], indem sie aufmerksam ihre Meinungen anhört, sich mit ihnen berät" und keine „überspitzte[n] Anforderungen hinsichtlich ihrer Bewußtseinsbildung " mehr stellte. Die Abgründe der SED-eigenen Arroganz ahnend, fügte die Brigade noch warnend hinzu, für solche Verbesserungen wsei es nicht ausreichend, [...] mit der Intelligenz lediglich eine Tonart höflicher zu reden “. ${ }^{165}$ Die stereotyp wiederholten Forderungen nach einem offeneren Verhältnis zwischen Partei und Spezialisten

\footnotetext{
160 Leiter des VPKA Brandenburg/Havel, Major der VP, Passenheim, Protokoll der Bürositzung der Kreisleitung-Stadt am 1.10.1957 betr. „Ursachenerforschung der Republikfluchten im Stahl- und Walzwerk Brandenburg", 3. 10. 1957, BArch DO 1/34, Nr. 21725.

161 BArch DO 1/11, Nr. 708, Bl. 18-34, hier Bl. 21 f.: Dombrowsky HVDVP, Leiter der HA K am 13.7. 1955.

162 Vgl. zum Beispiel „Informationsbericht ūber die Bevölkerungsbewegung für das Jahr 1959 einschließlich der legalen Verzüge nach Westdeutschland“ vom 26. 1. 1960: Wichtiger Fluchtgrund der technischen Intelligenz auch ${ }_{n}$ das oft noch sektiererische Verhalten von Staats- und Wirtschaftsfunktionären" (SAPMO-BArch DY 30/J IV 2/3 A-695).

16s $\mathrm{DaB}$ die Korrekturen bloß oberflāchlich sein soliten, schloß nicht aus, daß einzelne SED-Funktionāre gerade wegen dieses Verhaltens gerügt, aus der Partei ausgeschlossen und teilweise sogar kriminalisiert wurden: Ein Fall von sektiererische[m] Verhalten der Parteileitung [...] gegenüber der Intelligenz“ im Werk Wolfen, der durch einen Korruptionsfall verschärft wurde, endete mit der Verhaftung des bisherigen 1.Sekretärs der BPO, des Arbeitsdirektors, seines Stellvertreters und des persönlichen Referenten des Werksdirektors (SPK, Chemiekaderkommission, am 28. 7. 1960, BArch DO 1/34, Nr. 21725).

164 SPK, Chemiekaderkommission, am 28. 7. 1960, BArch DO 1/34, Nr. 21725.

165 SAPMO-BArch DY 30/J IV 2/3 A-775.
} 
blieben allerdings hãufig fruchtlos, so daß zum Teil selbst dann, wenn Fluchtplāne von Akademikern bekannt waren, ${ }_{n}$ niemand mit ihnen [sprach], um in diese Menschen einzudringen und sie gründlich kennenzulernen und wenn erforderlich, bestimmte Mängel. die sie unzufrieden werden lassen, zu beseitigen. ${ }^{\text {} 166}$

Fast alle Akademiker und Spezialisten, die keine überzeugten SED-Anhānger waren, sahen ihre berufliche Lage stārker von den politischen Rahmenbedingungen als von ihrer beruflichen Leistung abhängig. EinfluBreiche und inkompetente Leiter, vor allem aber die Betriebsparteiorganisationen konnten die Arbeit schwer machen und Karrieren verhindern. Im August 1960 kritisierte Abteilungsleiter Bergmann (Hauptabteilung Innere Angelegenheiten) gegenüber der Kaderabteilung der Staatlichen Plankommission, $\mathrm{daB}$ "bei leitenden Ingenieuren" noch immer nicht die Überzeugung ausgerāumt sei, ${ }_{n} \mathrm{daB}$ sie als Parteilose oder Blockfreunde in der DDR keine Perspektive haben und über kurz oder lang durch Mitglieder der Sozialistischen Einheitspartei Deutschlands ersetzt werden. [...] So wurde beispielsweise dem inzwischen republikflüchtigen Ingenieur M., Leiter der Abt. Forschung und Entwicklung beim VEB Braunkohlenbohrungen und Schachtbau in Welzow zu verstehen gegeben, daB er ohne Parteizugehörigkeit und aktive gesellschaftliche Arbeit nur solange in seiner Position bleiben kann, bis geeigneter Ersatz vorhanden ist. Der flüchtige Abteilungsleiter für Strahlenchemie vom Institut für angewandte Physik der Reinstoffe in Dresden, Dipl.-Physiker G., gibt in einem hinterlassenen Brief an, daß die politische Qualifikation über die fachliche gestellt wird. ${ }^{4167}$ Das Gefühl der Benachteiligung, daß die meisten Fachkräfte im Blick auf den Westen hatten, verstärkte sich angesichts solcher antiakademischen und arbeitshemmenden Zustānde in den eigenen Betrieben.

Die SED vertrat ihren antiakademischen Kurs vor allem aufgrund ihrer Ressentiments gegen alle Eliten der Zeit bis 1945 und in der Hoffnung, die ,alte Intelligenz' so schnell wie möglich durch ihre in der DDR ausgebildete ersetzen zu können. Der Nachwuchs von den DDR-Hochschulen brachte aber nicht die erhoffte Entlastung, denn die jungen Mediziner, Ingenieure, Wissenschaftler und Lehrer waren, āhnlich wie andere besonders qualifizierte Berufsgruppen, nicht weniger fluchtanfällig als ihre âlteren Kollegen. ${ }^{168}$ Auch ihnen blieb die Attraktivităt des Westens nicht verborgen, dessen berufliche Angebote sich

166 BArch DO 1/34, Nr. 11803. Ein weiterer Hinweis auf die gestörte Kommunikation zwischen den versierten Fachleuten und den politisch überzeugten Genossen ist der Ratschlag, bei „persōnliche[n] Aussprachen [...], besondere [n] Wert darauf zu legen [...], daß mit Angehôrigen der Intelligenz solche Gen. Gespräche führen, die ein ebenbürtiges fachliches Niveau haben." (BArch DO 1/34, Nr. 11803) Zu dem häufig unhōflichen Ton von Funktionären und Polizisten vgl. auch BArch DO 1/11, Nr. 79. Bl. 159.

167 BArch DO 1/34, Nr. 21725.

168 Unter den Geflohenen waren 1960301 leitende Angestellte und 1051 Angehörige der Intelligenz, von denen 914 nach 1945 ausgebildet worden waren. ( Stand und Entwicklung der Bevölkerungsbewegung im Jahre 1960" vom 13. 2. 1961, BArch DO 1/11, Nr. 967, Bl. 37-60, hier Bl. 38). Von den zwischen 1948 und September 1958 geflüchteten Lehrern waren 1341 nach und nur 315 vor 1945 ausgebildet (Analyse über die Republikfluchten der Lehrer von den Grund-, Mittel- und Oberschulen sowie Sonderschulen, o.V., o.D.: BArch DO 1/34, Nr. 21720). Bci den Medizinern gab es in den Jahren 1953 bis 1959 überdies selten mehr als doppelt so viele neu ausgebildete Ärzte wie Geflüchtete; 1958 lag die Anzahl der Geflüchteten mit 1269 sogar deutlich höher als die der Absolventen mit 1080 (Aktenvermerk vom 13.2. 1960 aus Dresden, o.V.: Republikflucht von Ärzten und Zahnärzten und die Zahl der "Absolventen“: BArch DO 1/34, Nr. 21719). Zum Verhältnis zwischen vor und nach 1945 ausgebildeten Akademikern vgl. auch Jessen, Akademische Elite (1999), S. 48; Ernst, Prophylaxe (1997), S. 58 f. 
auch an die Absolventen der DDR-Hochschulen richteten. Abgesehen von der westlichen Anziehungskraft verhinderten vor allem vier Gründe, daB sich die in der DDR ausgebildeten Menschen mit einer größeren Loyalitāt bedankten: Zum ersten waren sie mit den Betrieben weniger verbunden als die älteren Kollegen, die dort schon lange gearbeitet und hāufig den Neuaufbau nach den Kriegszerstörungen mitgetragen hatten. ${ }^{169}$ Zum zweiten machten die "sektiererische[n] Tendenzen“ vieler Genossen und Arbeiter auch vor den Jungakademikern nicht halt, selbst wenn sie der SED angehörten und keine politisch ab-

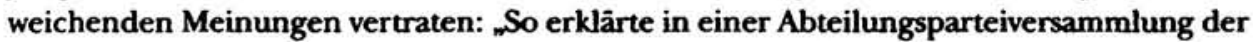
Zündkerzenabteilung ein junger Ingenieur, wenn er gewußt hätte, welchen ungerechtfertigten Anwürfen er von Arbeitern ausgesetzt würde, hătte er als Arbeiterjunge nie studiert. ${ }^{-170}$ Zum dritten litt die Arbeit vieler Fachkräfte unabhängig von ihrem Alter und Ausbildungsort an den zumeist hausgemachten politischen, administrativen und arbeitstechnischen Schwierigkeiten in den Betrieben der DDR.

Viertens kam hinzu, daß weder die jungen noch die alten Fachkräfte angesichts der auch hinsichtlich der Freizeitmōglichkeiten attraktiveren Angebote des Westens die kulturrelle Langeweile der DDR vor allem auf dem Land ertragen wollten. Die entsprechenden Klagen und von verschiedenen Berichterstattern und Brigaden formulierten SchluBfolgerungen wiesen immer wieder auf den Mangel an Theatern, Bibliotheken, Restaurants, Cafés und Kinos in fast allen Kreisen der DDR hin. Mit Blick auf die Auswanderungswelle wurde immer wieder Abhilfe gefordert und Beschlüsse gefaßt wie der des Sekretariats des ZK vom 30. Mărz 1953, ,in allen Orten, vor allem in solchen, wo GroBbetriebe und Hochschulen sind, [...] Klub- und Kulturräume für die Intelligenz zu schaffen und besondere Veranstaltungen durchzuführen. ${ }^{\text {"171 }}$ Besonders drastisch spürbar waren die kulturellen Defizite vor allem dort, wo es durch den forcierten Aufbau der Industrie sowieso an fast allem, vor allem auch an geeignetem Wohnraum, mangelte. So beriet das Sekretariat des ZK am 26. April 1961 ,SchluBfolgerungen zum Bericht der Arbeitsgruppe des Zentralkomitees, die im Kreis Bitterfeld tātig war ${ }^{4},{ }^{172}$ dem „bedeutendste[n] Kreis des Bezirkes Halle und eine [m] der bedeutendsten Kreise der DDR überhaupt“, in dem besonders viele Mitglieder der wissenschaftlich-technischen Intelligenz lebten. Nach deutlicher Kritik am baulichen Zustand, an den wenigen Freizeitmöglichkeiten, den schlechten Verkehrsverhältnissen, dem Mangel an Kinos, Theatern, Kulturhāusern, Hotels, Bãdern, Sporteinrichtungen und Grünanlagen und an der Stadtreinigung, die "trotz des sehr hohen Staubgehaltes der Luft [...] keinerlei besondere Maßnahmen" ergriffen habe, wodurch "die Stadt regelrecht verdreckt" sei, verlangte die Parteispitze einen umfassenden Plan zur drastischen Verbesserung der Lebensqualitāt in Bitterfeld, der bis zum 31. August 1961 vorzulegen war. Der Plan sollte fast alle Lebensbereiche umfassen, wie Kultur, Wohnungsbau, Schulen, Gesundheitswesen, Stadtverschönerung und nicht zuletzt auch die Arbeit mit den Akademikern „auf eine[r] wesentlich höhere[n] Stufe“ als bisher. Da nicht nur die tatsāchlichen Verbesserungen, sondern schon die Erstellung des Plans vom Mauerbau ein-

\footnotetext{
169 SPK, Chemiekaderkommission, am 28. 7. 1960: „Die alte Intelligenz im Werk hãngt sehr an ihrer Arbeit und arbeitet sehr hãufig bis über den Feierabend hinaus" (BArch DO 1/34, Nr. 21725).

170 SAPMO-BArch DY 30/J IV 2/3 A-635 (Sekretariat des ZK am 29. 10. 1958: Organisationsabteilung des ZK am 2. 10. 1958).

171 SAPMO-BArch DY 30/J IV 2/3-373, Bl. 3.

172 SAPMO-BArch DY 30/J IV 2/3 A-775.
} 
geholt wurde, konnte die Anweisung ihre Wirkung zur Verhinderung der Auswanderung nicht mehr entfalten. Häufig reichten aber auch einfachere und nicht vom ZK angeordnete MaBnahmen, um die kulturelle Enge in der DDR etwas zu erweitern. So wußte ein Jugendlicher aus dem Randgebiet von Berlin, welche Ereignisse nicht nur den Akademikern, sondern der überwiegenden Mehrheit der Bevōlkerung zugute kamen: „Hoffentlich ist in Westberlin bald wieder ein Revanchistentreffen oder eine Ausstellung, dann gibt es bei uns auch wieder Tanz und andere kulturelle Veranstaltungen. "173 Zahlreiche Klagen über die kulturelle Langeweile in der DDR finden sich in den offiziellen Berichten über die Attraktivitāt westlicher Musik, Literatur, Mode, Rundfunksender und Kinos, die vor allem in West-Berlin besorgt bzw. erlebt werden konnten. So wurde in einem „Bericht der Brigade des Sekretariats des Zentralkomitees an das Politbüro“ vom 2. Oktober 1958 mit Bezug auf die Situation in der Gemeinde Liebau (Kreis Sonnenberg), die am 10-m-Streifen liegt, kritisiert, daB der Rat des Bezirkes nicht dafür sorge, ${ }_{n}$ daB es in dieser Gemeinde die notwendige kulturelle Entwicklung gibt, um den Menschen das Gefühl der Seßhaftigkeit zu geben“. Außer einer 14tägigen Kinovorstellung gäbe es "kein kulturelles Leben“,

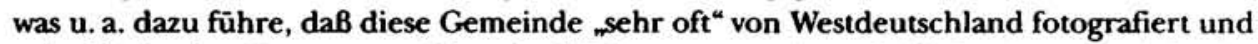
${ }_{n}$ als Objekt der Hetze gegenüber der DDR ausgenutzt " werde. ${ }^{174}$ In einem Bericht der ${ }_{n}$ Kommission zu Fragen der Republikflucht" beim Politbūro vom 25. Mai 1956 wird u.a. folgendes vorgeschlagen: „Besserer Ausbau der Freizeitgestaltung, insbesondere durch stärkere Ausnutzung von Stadien und Sportplätzen für künstlerische Großveranstaltungen, für Zwecke des Tanzes, Kinovorführungen im Freien“. ${ }^{175}$

Die lange Liste von Vorhaben zur Verbesserung der Lebensumstānde in Bitterfeld ist ein Spiegel der Ursachen der verbreiteten Unzufriedenheit und Republikflucht. Durch die Betriebs- und Berufszentrierung wurden nicht alle Facetten erfaßt, weshalb die Berichterstatter einzelne Aspekte zum Teil nur am Rande ansprachen oder in fast allen gleichermaßen erwähnten. Dabei ging es vor allem um private, hāufig familiāre Lebensentscheidungen, um den Einfluß weltpolitischer Entwicklungen auf die Auswanderung. um die größere Mobilitãt der Mitte der vierziger Jahre aus den ehemaligen deutschen Ostgebieten geflohenen Menschen und um die starke Machtkonzentration in bürokratischen Apparaten, die im SED-jargon als ,Bürokratismus' kritisiert wurde. Auch in diesen Bereichen bot der Weggang in den Westen den Bürgern der DDR eine Möglichkeit, Probleme konfliktfrei zu lōsen oder ihnen auszuweichen, unabhãngig davon, ob es sich um eher individuelle Fragen handelte oder um Verantwortungsbereiche, in denen die - wenig entwickelte - Problemlōsungskompetenz der SED gefragt gewesen wäre.

Die Problemlōsung mit Hilfe der offenen Westgrenze der DDR nutzten zahlreiche Menschen auch in privaten Angelegenheiten: Vor allem in den ersten Jahren nach dem Krieg ging es hảufig um die Zusammenführung von Familien, deren Angehörige im Osten und im Westen lebten: Von den 854 Personen, gegen die zwischen dem 13. Dezember 1957 und dem 13. Februar 1958 - also nach Änderung des Paßgesetzes - wegen "vorbereitetem und

173 Stand und Entwicklung der Bevölkerungsbewegung im Jahre 1960“ vom 13.2.1961 (BArch DO 1/ 11, Nr.967, Bl. 37-60, hier Bl. 49). Nach Major, Vor und nach dem 13. August (1999), S. 330, 340, hatte die DDR-Regierung ein solches Treffen in der West-Berliner Waldbūhne im September 1960 allerdings dazu genutzt, eine kurzfristige GrenzschlieBung nach West-Berlin zu begründen.

174 SAPMO-BArch DY 30/J IV 2/3 A-635.

1 is Dok. 16. 
versuchtem illegalen Verlassen der DDR “ Ermittlungsverfahren eingeleitet wurden, gaben die meisten (21 Prozent) als Motiv „Zusammenleben mit Familienangehörigen und Verwandten" an. ${ }^{176}$ Spāter kamen als Gründe neue oder gescheiterte Ehen und Liebesbeziehungen ${ }^{177}$ und die Flucht vor Vaterschaftspflichten, Familienstreitigkeiten ${ }^{178}$ oder strafrechtlicher Verfolgung ${ }^{179}$ hāufiger hinzu. In den Akten der staatlichen Behōrden und der SED finden sich nur verhältnismäBig wenig Unterlagen zu Fragen der persōnlichen Lebensführung. Die SED stand diesen Lebensbereichen keineswegs indifferent gegenüber: So verhandelte und entschied sie in ihren obersten SED-Gremien, dem Politbüro und dem Sekretariat des ZK, regelmäßig über private Lebensentscheidungen von Parteimitgliedern, die heiraten, sich verloben, umziehen oder eine Kur antreten wollten. ${ }^{180}$ Da es sich dabei um Kader handelte, deren gehorsame Verfügbarkeit zu den Grundlagen der kommunistischen Partei gehörte, unterstand auch ihr Privatleben unter deren politischer Verfügungsgewalt. Anders lagen die Dinge bei den Republikflüchtigen, die sich ja ausdrücklich der Verfügungsgewalt der SED und ihres Staates entzogen. Bei ihnen schienen

176 Bericht über Anwendung und Auswirkung des PaBānderungsgesetzes, 19. 2. 1958, BArch DO 1/11, Nr. 780, Bl. 32-40, hier Bl. 34. Der Wunsch, zu Verwandten in den Westen zu ziehen, konnte jedoch hâufig auch ohne Republikflucht erfullt werden, da zu diesem Zweck Ausreisegenehmigungen erteilt wurden, eine Praxis, die im Laufe der Jahre jedoch immer restriktiver gehandhabt wurde: Bereits Ende 1952 heißt es in einem Bericht: „Wo Personen aufgrund der landjährigen [sicl] Trennung wieder mit ihren Angehörigen zusammensein wollen, sind diese zu bewegen, ihre Angehörigen nach hier zu holen." (Bericht von Ende 1952, o.V., o.D., BArch DO 1/11, Nr. 780, Bl. 6-19, hier Bl. 8); seit August 1953 war die Erteilung zur Ausreise in den Westen zwecks Familienzusammenführung nur noch zu erteilen, "sofern die Angehörigen nicht republikflüchtig geworden waren" (Generalinspekteur der VP, Maron, an MdI, Minister Stoph, BArch DO 1/11, Nr. 963, Bl. 7); in einem „Protokoll der Arbeitsbesprechung mit den Referatsleitern Bévölkerungspolitik der Abt. Innere Angelegenheiten der Räte der Bezirke“ vom 16. 4. 1957 heißt es, daß Familienzusammenführungen ,nur in sehr stark begründeten Fällen“ zu genehmigen seien (BArch DO 1/34, Nr. 21725).

177 Sekretariat für das Hoch- und Fachschulwesen, Sektor Kader am 11.4. 1961: „Quartalsanalysen der Republikfluchten I. Quartal 1961“: „Des weiteren ist erkenntlich, daB eine Reihe von Personen ihre zerrütteten Eheverhältnisse und Ehestreitigkeiten dadurch zu klären versuchen, indem sie die Republik verlassen." (BArch DO 1/34, Nr. 21721) In einer Informationsmeldung zur Republikflucht im VEB ,Henry Pels' (Erfurt) vom 25. 10. 1957 weist der Beaufuragte der Zentralen Kommission für Staatliche Kontrolle (ZKSK), Wessel, u.a. auf schwierige[] Familienverhãltnisse“ und „Liebesverhältnisse“ hin (BArch DO 1/34, Nr. 21725).

${ }_{178}$ Vgl. z.B. die Vorgānge um die Flucht eines 17 jährigen, der bei Onkel und Tante lebte, da der Vater ihn finanziell ausnutzte und schlug, während seine Mutter im Westen war und zum Zeitpunkt der Scheidung keine Unterkunft hatte. Bei einem Besuch mit Onkel und Tante im Westen blieb er bei seiner Mutter, weshalb der Vater nun Onkel und Tante wegen Abwerbung bestrafen lassen will. (BArch DO 1/34, Nr. 21725: Rat des Kreises Borna, Abc. Innere Angelegenheiten an die HA Innere Angelegenheiten, Abt. Bevōlkerungsbewegung, 19.6. 1957).

179 Ein anscheinend für die sowjetische Besatzungsmacht bestimmter Bericht von 1954 über „Personen, die wegen krimineller Delikte oder Steuerhinterziehung republikflüchtig wurden " zāhlt eine zwischen 1949 und 1952 von 341 auf 3160 jāhrlich ansteigende Zahl solcher Fluchtfâlle. 1953 schnellte die Zahl auf 13060 hoch, auch deshalb, weil die HA PM erst zu diesem Zeitpunkt mit der systematischen Erfassung anfing und für die Jahre zuvor auf Recherchen der Kriminalpolizei zurückgreifen mußte (BArch DO 1/11, Nr. 962, Bl. 159). Vgl. einen Fall von Körperverletzung aus dem Kreis Ludwigslust in: LAS RdB Schwerin, Nr. 258, Bl. 25.

16w So verlangte z.B. das ZKSekr am 23.4.1953 eine Charakteristik über den Verlobten einer Genossin, wegen dem sie in den Westen wollte (SAPMO-BArch DY 30/J IV 2/3-378, B1.6). Ähnlich erging es am 17. 10. 1949 Jürgen Kuczynski, als das ,Kleine Sekretariat' sein Treffen mit Familienangehörigen aus London in Prag vorab prüfte (SAPMO-BArch DY 30/J IV 2/3-57, B1. 7). 
die offiziellen Erklārungsmuster hãufig nicht mit der Beobachtung und Bewertung ihres Privatlebens kompatibel zu sein, so daB die offiziellen Berichte es meistens nur denkbar knapp abhandelten.

Die Unfāhigkeit der SED, die Fluchtmotive vieler Menschen zu erfassen, zeigt auch das fast völlige Fehlen von allgemeinpolitischen Erklärungen von Auswanderern. So führten die Berichte nur äußerst selten welipolitische Gründe als Ursache für den Weggang an. ${ }^{181}$ Explizite Bezugnahmen wie die des Leiters der zahnärztlichen Klinik in Halle blieben Ausnahmen: „Der Zahnarzt Dr. Heinrich Hansmann aus Halle ãußerte sich dahingehend, daß er nicht lānger auf der Naht zwischen zwei Machtblöcken leben kann, da es auf die Dauer zwischen den beiden gröBten Mächten kaum so ruhig zugehen wird wie bisher. ${ }^{182}$ In den letzten beiden Jahren vor dem Mauerbau nahm der Einfluß der internationalen Politik stark zu. Die weltpolitische Lage und die zunehmende Republikflucht während dieser zweiten Berlinkrise beunruhigte nicht nur die Bevölkerung, sondern auch die loyalen Funktionsträger der DDR. Einer von ihnen stellte im Februar 1961 fest, daß „ein weiterer Höhepunkt der Hetze und eine damit verbundene Steigerung der Republikfluchten [...] zum Zeitpunkt des Scheiterns der Gipfelkonferenz zu verzeichnen " gewesen sei: „Ein groBer Teil der Flüchtigen schenkte den Hetzparolen Gehör, daß mit der Schaffung der freien Stadt Westberlin die verwandtschaftlichen Bindungen mit Angehōrigen in Westdeutschland unterbunden werden. ${ }^{{ }^{183}}$ Am 31. Mai 1961 wurde dem Sekretariat des ZK aus Halle berichtet, daß der Kampf gegen die Auswanderung "nach der Torpedierung der Gipfelkonferenz in Paris durch den USA-Imperialismus “ und durch die verstärkte ,ideologische Diversion gegen die DDR ${ }^{4}$ schwieriger geworden sei. ${ }^{184}$ In einem Informationsbericht des CDU-Kreisverbands Wolmistedt an die Parteileitung von Ende Juli 1961 wird neben der wachsenden Kriegsfurcht in der Bevōlkerung auch eine Einstellung erwāhnt, „die unter Jugendlichen sehr stark verbreitet ist: Jetzt ist noch Zeit, nachher sind die Grenzen dicht. So wird ganz offen über das evtl. Verlassen der DDR gesprochen "IR5 Trotz der Berlinkrise und der verbreiteten Kriegsangst verdrängte die Weltpolitik die alltäglichen Sorgen aber niemals vom ersten Rang des individuellen Interesses, so daß beispielsweise die Aufmerksamkeit für das Gipfeltreffen zwischen Kennedy und Chruschtschow in Wien „durch die starken Diskussionen über Versorgungsfragen unter[ging] “. ${ }^{\text {1 }}$ "

$\mathrm{Zu}$ den Menschen, die infolge weltpolitischer Verānderungen aus Deutschland flohen, gehörten auch die zahlreichen Vertriebenen, die bis 1945 in den ehemaligen Ostgebieten des Deutschen Reiches gewohnt hatten. Bereits Anfang der fünfziger Jahre hatten die DDR-Behōrden die besondere politische Behandlung dieser Bevōlkerungsgruppe been-

\footnotetext{
181 Zur beinahe entgegengesetzten Wahrnehmung im Westen vgl. Heidemeyer, Flucht und Zuwanderung (1994), S. 60 ff., der die politischen und weltpolitischen Gründe für die Flucht sehr hoch veranschlagt.

182 Leiter der HA K der HVDVP, Odpadlik, am 15.4. 1959: „Analyse der Republikfluchten von Personen der Intelligenz" (BArch DO 1/34, Nr. 21719).

183 Bericht vom 13.2. 1961 (BArch DO 1/11, Nr.967, Bl.37-60, hier Bl. 39 f.). Dem Sekretariat des ZK wurde am 31.5. 1961 aus Halle berichtet, daB der Kampf gegen die Auswanderung nach der Torpedicrung der Gipfelkonferenz in Paris durch den USA-Imperialismus" und durch die verstärkte "ideologische Diversion gegen die DDR" schwieriger geworden sei (SAPMO-BArch DY 30/J IV 2/3-740, BI. 4-82, hier Bl. 62).

184 SAPMO-BArch DY 30/J IV 2/3-740, Bl. 4-82, hier Bl. 62.

185 ACDP VII-011, Nr. AI117.

186 Bericht aus Suhl vom 13. 6. 1961, SAPMO-BArch DY $30 /$ IV 2/9.02/50, BI. 3-7.
} 
det, weil sie die etwa 4,3 Millionen Menschen ${ }^{187}$ inzwischen für erfolgreich in die Gesellschaft der DDR integriert hielten. ${ }^{188}$ Eine Folge davon war, daß sie nicht mehr als eigene Bevölkerungsgruppe gezāhlt wurden und in den verschiedenen Statistiken keine eigene Kategorie mehr bildeten. ${ }^{189}$ Dies verhindert auch eine wenigstens annāhernde Quantifizierung ihres Anteils an den Republikflūchtigen. Dennoch wird bis 1961 immer wieder davon berichtet, daß die „Umsiedler" hãufiger in den Westen gingen als der Rest der Bevōlkerung der DDR. ${ }^{190}$ Dies schien den Berichterstattern von SED und Polizei vor allem drei Umständen geschuldet zu sein: Zum ersten waren die Zugezogenen in ihren Städten und Kreisen weniger verwurzelt als die Altbevölkerung. Als weiterer Grund wurden oft Organisations- und Kommunikationsnetze der Vertriebenen erwähnt. Neben den in Ost und West verstreuten Familien tauchen in diesem Zusammenhang vor allem Kirchengemeinden auf, die in der DDR als Knoten in den informellen Umsiedlernetzwerken wirkten, sowie die westdeutschen Landsmannschaften, deren Aktivitāten in der DDR zwar untersagt waren, aber nicht vollständig unterbunden werden konnten. ${ }^{191}$ Zum dritten belegte die Weiterwanderung der "Umsiedler" in den Augen der Berichterstatter den starken EinfluB der westdeutschen Politik: Vor allem die Bonner Lastenausgleichsgesetzgebung entfaltete eine starke Sogwirkung auf die „ehemaligen Umsiedler" und wurde immer wieder als Beleg für die staatlich organisierte Abwerbung angeführt ${ }^{192}$ Eine weitere Personengruppe, die fluchtanfälliger erschien als der Bevōlkerungsdurchschnitt, waren die Rūckkehrer aus Westdeutschland, die ebenfalls hãufig ihre alten heimatlichen Wurzeln verloren hatten. Viele von ihnen wurden bis 1961 weder in Ost- noch in Westdeutschland langfristig ansässig, sondern wechselten wiederholt ihre Wohnorte und gerieten als unberechenbare GrōBe in Ost wie West hâufig in den Verdacht, asozial oder kriminell zu sein. ${ }^{193}$

187 Zahl der bis Oktober 1948 in die SBZ gekommenen Vertriebenen nach Wille, Die Vertriebenen (2000), S. 203.

In* Vgl. dazu Wille, SED und „Umsiedler" (1999); Schwartz, Vertriebene (2004).

t*9 In der Bundesrepublik stellte sich die Frage, ob die Menschen, die nach 1945 nur einige Jahre in der DDR gewohnt haben, zu den Auswanderern gezāhlt werden sollten (Heidemeyer, Flucht und Zuwanderung [1994], S. 41 f.). Auch in der DDR wurden natürlich diejenigen nicht mitgezählt, die sich - etwa nach der Kriegsgefangenschaft in der UdSSR oder als Spätaussiedler - aus Osteuropa auf dem Landweg durch die SBZ/DDR direkt in die Bundesrepublik begaben bzw. von den SBZ-Organen sofort dorthin weitergeleitet wurden. Zur Weiterwanderung von Vertriebenen vgl. Heidemeyer, Vertriebene als Sowjetflüchtlinge (2000); Zank, Wirtschaft und Arbeit (1987), S. 150 f.

190 Vgl. z.B. BArch DO 1/11, Nr. 962, Bl. 137 ff., hier Bl. 139; BArch DO 1/11, Nr. 963, Bl. 100-130, hier Bl. 122; BArch DO 1/11, Nr. 967, Bl. 37-60, hier B1. 39 f.; BArch DO 1/11, Nr. 967, Bl. 37-60, hier Bl. 42; "Methoden der Abwerbung von Bürgern der DDR" (BArch DO 1/34, Nr. 21724); MdI HA Innere Angelegenheiten, Analyse der Republikfluchten in der Landwirtschaft, 12.5. 1960, „Vertrauliche Dienstsache Nr. 41/60" (BArch DO 1/34, Nr. 21718).

$191 \mathrm{Zu}$ Kirchen und Landsmannschaften: BArch DO 1/34 Nr. 21724: „Methoden der Abwerbung von Bürgern der DDR“; Bericht über die Republikflucht aus der Deutschen Demokratischen Republik für die Zeit vom 1. 1. 1954 bis 31.12. 1955“, BArch DO 1/11 Nr.963, Bl. 100-130, hier Bl. 122; „Thesen zur Analyse über Rückkehrer und Zuziehende aus Westdeutschland und Westberlin“ von Anfang 1961, o.D., BArch DO 1/11 Nr. 967, Bl. 26-33, hier Bl. 32; Informationsbericht über die Republikflucht der Lehrer im Monat August 1960" (BArch DO 1/34, Nr. 21720); MdI HA Innere Angelegenheiten, Analyse der Republikfluchten in der Landwirtschaft, 12.5. 1960 (BArch DO 1/34, Nr. 21718).

192 Zum Lastenausgleich vgl. neben den o.g. Dokumenten den Bericht vom 13. 2. 1961 (BArch DO 1/11 Nr. 967, Bl. 37-60, hier Bl. 39 f.); Heidemeyer, Flucht und Zuwanderung (1994), S. 262 ff.

19: Vgl. beispielhaft MdI HA Innere Angelegenheiten, Analyse der Republikfluchten in der Landwirtschaft, 12.5. 1960 (wie oben); Schmelz, West-Ost-Migranten (1999), S. 101-104. Zum Kriminalitātsvorwurf an Rückkehrer und Zuziehende vgl. auch Rōhlke, Entscheidung (2005), S. 108 f. 


\subsection{Erklarungen}

Die Analyse der Fluchtgrũnde beschränkte sich in den meisten offiziellen Berichten auf phānomenologische Beschreibungen. Nur selten thematisierten oder konkretisierten sie die Verantwortung für einzelne Fluchten oder für den Anstieg der gesamten Abwanderung. Statt dessen reproduzierten alle SED-nahen Berichte zwei immer wiederkehrende Erklärungsmodelle, die in die allgemeinen Schemata der politischen Rhetorik in der DDR paßten. Sie lieferten scheinbar vollstāndige Erklārungen für das existenzbedrohende Problem der DDR, ohne dabei zur Sprache zu bringen, daß erst nennenswerte Verānderungen der gesellschaftspolitischen Grundlagen der DDR und eine starke Beschränkung der SED-Herrschaft dem Problem hātten Einhalt bieten können: Mit dem ersten Schlagwort "Bürokratismus" individualisierten die Berichterstatter die Verantwortung für die Fluchtbewegung, indem sie das Fehlverhalten einzelner Funktionāre überbetonten, wăhrend sie beim zweiten die Schuld in den Westen externalisierten, dessen wichtigstes Kampfmittel gegen die DDR die systematische Abwerbung von Arbeitskräften sei.

Das Schlagwort des "Bürokratismus" führten Parteivertreter bereits seit den vierziger Jahren im Mund, wobei die StoBrichtung der Kritik variierte. Fast immer richtete sie sich gegen administrative Tãtigkeiten, die als zu eigenständig empfunden wurden, weil sie sich an verwaltungstechnischen Regeln orientierten, die dem aktuellen politischen Interesse der SED zuwiderliefen. Das Schlagwort diente - wie bereits in der NS-Zeit - vorwiegend als Chiffre für die ungenügende Anpassung von Verwaltungsstellen an die politischen Autoritāten und ihre tagesaktuellen Forderungen, die einem verwaltungstechnisch korrekten Ablauf widersprachen. Im Rahmen der Bekämpfung der Republikflucht äußerten die ebenfalls in bürokratischen Apparaten angesiedelten - Berichterstatter ihren Unmut über

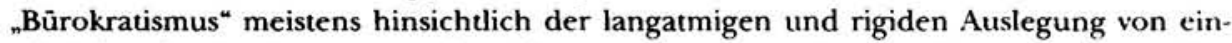
schränkenden Bestimmungen, die sich zuungunsten von Antragstellern auswirkten. Das beliebteste Adjektiv, um diese Kritik zusammenzufassen, war „herzlos”. In unzãhligen Berichten taucht es als Vorwurf gegen Mitarbeiter auf, die nicht ausreichend auf die Belange der Antrag- und Bittsteller eingegangen seien und diese zum Teil erst dadurch in den Westen getrieben hătten: So gebe es ${ }_{n}$ zwischen unserem volksdemokratischen Staat und seiner Politik und den Bürgern" zwar "keinen Widerspruch, [...] durch überhebliches, bürokratisches und herzloses Verhalten von Staats- und Wirtschaftsorganen " sei das Verhältnis aber gestört. ${ }^{194}$ Das Sekretariat des ZK kritisierte am 31. Mai 1961 „Überspitzungen und herzloses Verhalten gegenüber den Menschen "195 und auch das Politbüro stieß im Juni 1961 bei der Suche nach den Hauptursachen für die Republikflucht auf das „herzlose[]. bürokratische [] Verhalten einzelner Funktionäre im Staatsapparat ${ }^{\text {"1.\$ }}$ Um die Individualisierung dieser Fehler zu unterstreichen und um zu zeigen, daß die zu formale Arbeitsweise nichts mit den politischen Entscheidungszentren und den seit 1945 geschaffenen gesellschaftlichen Strukturen zu tun hatte, formulierten die entsprechenden Berichte hāufig auch deutliche persōnliche Vorwūrfe gegen die einzelnen Mitarbeiter, sich etwa als

\footnotetext{
194 Einsatzplan der Brigade im Bezirk Halle von 1961 (SAPMO-BArch DY 30/IV' 2/13/169, B1. 1-8, hicr Bl. 2).

195 SAPMO-BArch DY 30/J IV 2/3-740, Bl. 4-82, hier Bl. 63, 71 f.

196 SAPMO-BArch DY 30/J IV 2/2/775, Bl. 12-98, hier Bl. 49.
} 
„kluge Lehrmeister“ oder ,als ,Chefs“ auf[zu]spielen“ und „ein spießerhaftes Leben [zu] führen“.197

$\mathrm{Da}$ die Regierung zu verschiedenen Zeiten aber unterschiedliche Maße an politischer Großzūgigkeit zulieB, hatten die kritisierten Verwaltungsmitarbeiter der Polizei und der Abteilungen für Innere Angelegenheiten wechselhaften Anforderungen zu entsprechen, die nur selten präzise formuliert waren. So wirkte die Kritik an ihrer zu pedantischen Arbeitsweise hāufig vorgeschoben, da sie den Individuen eine viel größere Kompetenz und Verantwortung unterstellte, als ihnen im politisch-administrativen Apparat der DDR zukam. In den Zeiten der Liberalisierung konnten zwar eindeutige Forderungen formuliert werden - so wies die Bezirkspolizeibehörde Schwerin ihre nachgeordneten Ãmter etwa im Sommer 1953 angesichts des ,Neuen Kurses` an, die „schleppend[en] “ Verfahren bei der Ausgabe von Interzonenpãssen zu beschleunigen und dabei "unbürokratisch vorzugehen ${ }^{{ }_{1} 98}$ - sobald aber restriktivere Bestimmungen erlassen wurden, verlangten die übergeordneten Instanzen von den zuvor als ${ }_{n}$ herzlos“ beschimpften Mitarbeitern die Durchsetzung der harten Linie, ohne aber die daraus folgenden Konflikte vor Ort zu berücksichtigen. So mußten die Behördenmitarbeiter gegenüber der Bevölkerung für Entscheidungen eintreten, die sie nicht selbst beeinflussen konnten. Als die Regierung in Ost-Berlin beispielsweise kurz vor der Weihnachtsreisezeit Ende 1957 das $\mathrm{PaBgesetz}$ verschärfte und die Reisemōglichkeiten radikal einschränkte, wurde von vielen Behördenmitarbeitern „bemāngelt, daß eine Aufklärung in der Presse nicht erfolgt ist. [...] Nach Angaben der Referatsleiterin sollen solche Diskussionen aufgetreten sein, daß, wenn diese MaBnahmen beibehalten werden, es bald einen zweiten ,17. Juni' geben wird. Teilweise nehmen die Besucher - je nach Temperament - eine aggressive Haltung ein, indem sie mit Stühlen und Krückstöcken die Mitarbeiter bedrohen, bzw. ihre eigenen Stūcke vor Wut zerschlagen. Zusammenfassend muß gesagt werden, daß die Arbeit für die einzelnen Mitarbeiter außerordentich schwierig ist, da sie nicht die Zeit haben, sich individuell mit jedem Besucher zu beschäftigen und ihnen den Sinn auseinander setzen können. Im Prinzip sind die Mitarbeiter froh, wenn sich ein Besucher recht schnell zufrieden gibt und den Raum verlãßt. ${ }^{\prime 199}$ Auch in Karl-Marx-Stadt wünschte sich die Abteilung Innere Angelegenheiten „eine offensive Auseinandersetzung über die Verwerflichkeit von Reisen in die NATOStaaten", denn "das Ausweichen vor offenen und ehrlichen Auseinandersetzungen mit Betriebsangehōrigen über Reisen in die NATO-Staaten gibt Anlaß zu berechtigten Verärgerungen der Antragsteller. ${ }^{400}$ In vergleichbare Situationen wie die Verwaltungsmitarbeiter gerieten auch politisch übereifrige Genossen durch die Ost-Berliner Grenz- und Reisepolitik, wenn sie bei Diskussionen den Ärger von Betroffenen auf sich zogen: ${ }_{n}$ In einem anderen Falle führte ein Radarspezialist in einer politischen Diskussion Zitate von Schopen-

\footnotetext{
197 PB-BeschluB vom 18.12.1956 über Parteiarbeit im Kreis Magdeburg (SAPMO-BArch DY 30/ J IV 2/2/519, Bl. 32-37).

196 Im gleichen Fernschreiben vom 3.7.1953 teilte die BDVP Schwerin allen VPKÄ-Leitern noch verschiedene Richtlinien für einen freundlicheren und hilfsbereiten Umgang mit den Antragstellern mit (LAS BDVP Schwerin 13, Nr. 85, Bl. 3).

199 "Aktenvermerk. Bei der Abteilung Innere Angelegenheiten des Rates der Stadt Weimar ist besonders zu den Weihnachtsfeiertagen seit Mitte November ein sehr starker Andrang von Besuchern zu verzeichnen" (BArch DO 1/34, Nr. 21725).

${ }^{200}$ Rat des Bezirkes Karl-Marx-Stadt, Abt. für Innere Angelegenheiten, Strobel, Leiter der Abteilung am 31.5. 1958: „Ratsvorlage zum Tagesordnungspunkt 4 der Ratssitzung vom 4.6. 1958“ (BArch DO 1/34, Nr. 21725).
} 
hauer an. Ihm wurde hierzu erwidert, daß Meinungen solcher Reaktionäre keine Gültigkeit hătten. Der Intelligenzler darüber in Wut geraten, bezeichnete daraufhin den Genossen als , plattfüssigen Judenlümmel " und verließ die Deutsche Demokratische Republik. "'20!

Trotz der häufig unberechtigten Kritik an "herzlosen "Behördenmitarbeitern traf der Vorwurf des Bürokratismus auf viele Ämter der DDR zu, in denen die Bürger in obrigkeitsstaatlicher Manier abgefertigt wurden, ohne beispielsweise Erklärungen für ablehnende Bescheide zu erhalten. Darin glich die Kritik am Bürokratismus den dauernden Behauptungen von der westlichen Abwerbung in den Berichten der DDR-Organe: So wie es tatsāchlich schikanöse Behördenmitarbeiter gab, so leugnete auch niemand die zahlreichen westlichen Versuche, Bürger der DDR zum Umzug in die Bundesrepublik zu animieren. ${ }^{202}$ Zahlreiche Faktoren spielten bei den Abwerbungen eine Rolle, wobei sie zunehmend leichter fielen, je mehr die Spanne zwischen west- und ostdeutscher Prosperitāt anwuchs. Im Schriftgut der DDR-Behörden zur Republikflucht bildet die Abwerbung durch den Westen eine der am häufigsten verwendeten ErkJärungen. Das stärkste Argument für den Weg in den Westen, seine wirtschaftliche Überlegenheit, blieb dagegen fast immer unerwähnt. Statt dessen konstruierten die Behördenschriftsteller zum Teil phantastisch anmutende Erklärungsmuster zum Thema Abwerbung, in denen selbst die offensichtlichsten Tatsachen nur noch schwer wiederzuerkennen waren.

Berufswechsel und geographische Mobilität waren seit vielen Jahrhunderten feste Bestandteile der europäischen Gesellschaften. In zahlreichen Berufssparten organisierte sich der fachspezifische Arbeitsmarkt überregional. Dies galt besonders für die Tãtigkeiten, die eine akademische Ausbildung oder anderweitige Spezialkenntnisse voraussetzten, die nicht in allen Orten erlernt werden konnten. Aber auch für durchschnittlich qualifizierte Handwerker, Arbeiter und Angestellte war es in Deutschland seit langem denkbar, für eine neue Anstellung aus Rostock oder Hamburg nach München, Köln oder Dresden umzuziehen. Die eingeschränkte Mobilität nach Kriegsende und die Demarkationslinie zwischen der Ost- und den Westzonen schränkte solche Berufswechsel zwar ein, ānderte aber nichts grundlegendes an der individuellen und kollektiven Wahrnehmung des gemeinsamen Arbeitsmarktes in ganz Deutschland westlich der Oder ${ }^{203}$ Trotz aller politischen Schwierigkeiten blieb dieser gesamtdeutsche Arbeitsmarkt tatsächlich bis 1961 bestehen.

Seit den ersten Vertreibungen und Enteignungen in der SBZ hatten sich Industrielle und andere Arbeitgeber erfolgreich darum bemūht, ihre Betriebe in einem westdeutschen Bundesland wiederaufzubauen. Dabei griffen sie häufig auf leitende Mitarbeiter und Spezialisten ihrer alten Firmen zurück. ${ }^{204}$ Den Behörden der DDR waren solche Fālle

201 Dombrowsky HVDVP, Leiter der HA K, am 13. 7. 1955: ${ }_{n}$ Kriminalpolizeiliche Analyse über Republikfluchten, Rückkehrer und Neuzugänge" (BArch DO 1/11, Nr. 708, Bl. 18-34, hier Bl. 21). Wie sich solche Auseinandersetzungen bis zur Westflucht steigern konnten, zeigt auch der Fall des Dekans der veterinărmedizinischen Fakultãt der Karl-Marx-Universitãt Leipzig und Nationalpreisträgers Prof. Dr. Dedié (BArch DO 1/11, Nr. 964, Bl. 231).

${ }^{202}$ Für realistische und relativ glaubwürdige Beispiele solcher „Abwerbungen“ vgl. BStU ZA, MfS-ZAIG, Nr. 161 und Nr. 431 (Ärzte).

${ }^{20}$ So war für die meisten DDR-Bürger Republikflucht auch „kein Verrat an der DDR, sondern nur ein geographischer Arbeitsplatzwechsel“ (Ideologische Probleme und Argumente unter den Angehörigen der Intelligenz, o.V., 1. 11. 1960, BStU ZA, MfSSdM, Nr. 1228, Bl. 280).

${ }^{204}$ Hefele, Die Verlagerung (1998). Nach Chefinspekteur der VP Seifert unternahmen „die ehemaligen Besitzer unserer volkseigenen Betriebe, die größtenteils in Westdeutschland wieder gleichartige Betriebe besitzen, alles [...], um Fachkrãfte abzuwerben" (am 6. 7.1956 an das ZK, Dok. 17). 
zum Teil namentlich bekannt. So wies die Hauptabteilung für Innere Angelegenheiten die Hauptabteilung Betriebsschutz 1957 auf einen Fall aus Karl-Marx-Stadt hin, wo westdeutsche Besucher ihre ehemaligen Kollegen aus der Textilindustrie abwarben: Der ehemalige Unternehmer B. habe in Lörrach eine neue Weberei aufgebaut und drei Jahre zuvor "etliche Meister" aus den Betrieben der ,Palla', einem Textilbetrieb in St. Egidien zwi-

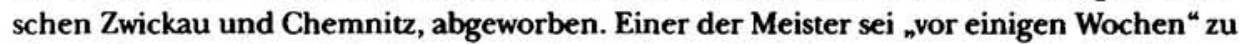
einem lāngeren Besuch in Meerane, einem Ort bei Zwickau gewesen und habe Arbeiter privat zu seinen Eltern eingeladen. Daraufhin hätten zwei der besten Arbeiterinnen ihren Urlaub in Lörrach verbracht und seien nicht zurückzukommen, sondern arbeiteten nun bei B. ${ }^{205}$ Es wurde auch über Briefe, Geschenkpakete und Empfehlungsschreiben an Spezialisten mit dem gleichen Ziel, kompetente Arbeiter in den Westen zu holen, berichtet, die zum Teil recht erfolgreich gewesen sein müssen: „Im Kreise Forst, Bezirk Cottbus, hat der ehemalige Tuchfabrikant Hentzschke nach seinem jetzigen Betrieb in Iserlohn ${ }^{206}$ schon so viele Arbeiter abgezogen, daB man dort, wenn man von Iserlohn spricht, dieses Klein-Forst nennt. " ${ }^{207}$ Zahlreiche dieser Abwerbungsgeschichten beziehen sich auf Fälle aus großen Konzernen, deren westliche Produktionsstandorte für viele Mitarbeiter bald attraktiver wirkten als die in Ostdeutschland: So litt zum Beispiel in Jena der VEB Zeiß darunter, daB ,in Westdeutschland im Pseudo-Betrieb [!] ZeiB viele Automatendreher gesucht werden “. ${ }^{208}$ Eine besonders große Anziehungskraft entfalteten die Firmen und Behörden, die ehemaligen Mitarbeitern ihre schon vor 1945 erworbenen Sonderrechte anerkannten. Dazu zāhlte die Wiederverwendung von ehemaligen Beamten der Deutschen Post und der Reichs- bzw. Bundesbahn mitsamt der im Artikel 131 des Grundgesetzes geregelten Großzügigkeit gegenūber ehemaligen NSDAP-Mitgliedern und der Fortbestand von "vor 1945 entstandenen Versorgungsansprüchen" und die Gültigkeit von "mit dem Zusammenbruch erloschene[n] Lebensversicherungen“. Zur Begründung seines Ausreiseantrages und in Erwartung entsprechender Leistungen legte ein ehemaliger Eisenbahner den Behörden in Luckau sogar das entsprechende ${ }_{n}$ Merkblatt über den Versorgungsanspruch von Angehörigen der Deutschen Reichsbahn bzw. früheren Beamten “ vor. ${ }^{209}$

Die Grundlage dieser Berufswechsel bildeten meistens normale freundschaftliche, familiäre oder kollegiale Kontakte, über die entsprechende Informationen weitergegeben wurden. Solche Netzwerke bestanden seit langem unabhãngig von politischen Anschauungen oder wurden zur Linderung der Kriegsfolgen geknüpft. Zum Beispiel bemūhten sich ehemalige Bürger von Demmin darum, ein Adressenverzeichnis aller ehemaligen Schūler der hōheren Schule Demmins zusammenzustellen, wozu sie auch Briefe in die

${ }^{205}$ MdI, HA Innere Angelegenheiten, Abt. I am 15.11.1957 an BA Betriebsschutz (BArch DO 1/34, Nr. 21725).

${ }^{206}$ Gemeint ist die Firma Henschke und Co. (heute Hãnsel Textil), die 1947 nach Iserlohn im Sauerland (Nordrhein-Westfalen) übersiedelte. Für diesen Hinweis danke ich Tim Peters.

${ }^{207}$ Aus einem Bericht von 1955 über die Republikflucht (Dok. 15). Dort werden noch weitere Fälle aus verschiedenen Branchen aufgezählt: „Das sind die Beispiele, wie sie sich in allen Bezirken mehr oder weniger bemerkbar machen, nur zum Teil noch nicht bekannt sind."

${ }_{208}$ VP Seifert am 6. 7. 1956 an das ZK (Dok. 17). Anschaulich auch der Fall der drei führenden Chemiker der Wofatit-Forschung aus Wolfen, die zu Bayer-Leverkusen gegangen sein sollen (BArch DO 1/34, Nr. 21725) und der Wechsel von zahlreichen Mitarbeitern der Fernmeldeämter in Leipzig zum „Siemens \& Schuckert Konzern“ (BArch DO 1/34, Nr. 21724: „Methoden der Abwerbung von Bürgern der DDR“ von etwa 1960/61).

${ }^{209}$ BArch DO 1/34, Nr. 21724: „Methoden der Abwerbung von Bürgern der DDR“ von etwa 1960/61. 
DDR verschickten und am 31. Januar 1959 einen Artikel in der ,Pommerschen Zeitung. abdruckten. ${ }^{210}$ So wie das ZK solche Aktivitāten gegenüber dem Chef der Deutschen Volkspolizei (DVP), Maron, als Abwerbung interpretierte, so verstand auch die Polizei selbst ein einfaches Fußballturnier in Westdeutschland, in dessen Folge drei Mitarbeiter republikflüchtig wurden, als Angriff auf die DDR, weil ein mittelständischer Unternehmer die ostdeutsche Delegation aus dem alten Betrieb in der DDR durch „hohe Geld- und Sachspenden" beeinfluBt habe. ${ }^{211}$ Ähnlich interpretierten die Berichterstatter alle weiteren deutsch-deutschen Kontakte, egal ob es sich um familiäre oder freundschaftliche Privatbesuche, um Treffen mit ehemaligen Kollegen, um den Besuch von Fachtagungen, um Briefkontakte oder einfach nur um Urlaubsgrüße auf Postkarten handelte ${ }^{212}$ oder um öffentliche Veranstaltungen wie die ,Grüne Woche' in Berlin, um ,illegal eingeschleuste Schundliteratur" oder um den westlichen Rundfunk, wobei die "Schlagerparade“ von "Radio Luxemburg eine besondere Rolle spielt $[\mathrm{e}]^{4}{ }^{4}{ }^{219}$

Tatsāchlich verfügten die meisten Flüchtlinge vor ihrem Weggang schon über Informationen aus dem Westen und über Kontakte dorthin, die ihren Neuanfang erleichterten. ${ }^{214}$ Trotz der zunehmenden Hindernisse und Verbote in der deutsch-deutschen Kommunikation konnten die DDR-Organe den Austausch solcher Informationen nicht stoppen. Angesichts ihrer Hilflosigkeit entwickelten sie - im internen Schriftgut ebenso wie in den Medien - ein rhetorisches Feuerwerk gegen die allgegenwärtige "Abwerbung “, das den Westen so darstellte, als existiere er einzig dazu, um der DDR ihre Bürger abspenstig zu machen. „Die Republikflucht wird von Bonner Stellen planmäßig organisiert und von ihnen als ein wesentliches Mittel zur Weiterführung des ,kalten Krieges' betrachtet. “ Das „Kaiserministerium ${ }^{4}$ arbeite ${ }_{n}$ mit den verschiedenen Ost- und Spionagebüros nach einem einheitlichen Plan" und betrachte "als das Hauptmittel die Ausnutzung der gegenwãrtigen Wirtschaftskonjunktur in Westdeutschland". ${ }^{215}$ Aufgrund der erwāhnten Erklārungsnot

${ }^{200}$ MdI HA Innere Angelegenheiten, Analyse der Republikfluchten in der Landwirtschaft, 12.5. 1960. „Vertrauliche Dienstsache Nr. 41/60“ (BArch DO 1/34, Nr. 21718).

211 BArch DO 1/11, Nr. 962, Bl. $161 \mathrm{f}$.

${ }^{212}$ Vgl. z.B. BArch DO 1/11, Nr. 964, Bl.91; MdI, HA Innere Angelegenheiten, Abt. I am 15. 11. 1957 an BA Betriebsschutz (BArch DO 1/34, Nr. 21725); der Leiter der HA Innere Angelegenheiten im Mdl kritisierte am 21. 1. 1958, daß im Obertrikotagenwerk Eichsfeld im Zimmer des Kaderleiters und an vielen anderen Stellen für jedermann zugänglich Postkarten von Republikflüchtigen hingen (BArch DO 1/34, Nr. 21725). 19 "Methoden der Abwerbung von Bürgern der DDR" (BArch DO 1/34, Nr. 21724). Der Werbewirksamkeit eingeführter Westautos gleich verurteilte die Polizei es auch, wenn sich jugendliche Republikflüchtige mit ihrem Motorrad vor ihren ehemaligen Betrieben zeigten (Dok. 17).

214 Zahlreiche Hinweise hierzu finden sich in den Akten von HVDVP und MdI. Vgl. z.B. „Information:bericht über die Republikflucht der Lehrer im Monat August 1960 (BArch DO 1/34, Nr. 27120), in der darauf hingewiesen wird, daß $[\mathrm{f}]$ ast alle der flüchtigen Lehrer $[\ldots]$ in Westdeutschland Verwandte baw. Bekannte [hatten], die zum großen Teil vorher republikflüchtig wurden“. Bei einer flüchtigen Lehrerin wurde der Brief einer zuvor republikflüchtig gewordenen Kollegin gefunden, in dem Fluchtweg und Notaufnahmeverfahren erlāutert wurden; HA Schutzpolizei, Strieder. berichtet an 3. 4. 1958 an HVDVP (Dombrowsky) von mehreren Fällen, bei denen Studenten, von denen Angehörige republikflūchtig geworden waren, diesen spāter nachfolgten (BArch DO 1/11, Nr. 403, B1. 84). Hāufig wurden Ehefrauen für die Vorbereitung von Republikfluchten verantwortlich gemacht: Die ZKSK (Trotz) berichtete am 17. 10. 1960 an den Stellvertreter des Ministers des Innern, Grünstein, von 56 Familien, die im 1. Halbjahr 1960 aus dem Kreis Borna geflüchtet waren, wobei in diesen Fällen die Fratuen meist die Vorbereitungen getroffen haben. Sie waren vorher ein-bis zweimal in Westdeutschland zu Besuch und konnten somit die Flucht systematisch vorbereiten." (BArch DO 1/34, Nr. 21725).

21 Politbüro des Zentralkomitees am 19.6. 1956 (Dok. 16). 
vieler Behördenmitarbeiter gegenūber reise- und ausreisewilligen Bürgern entwarf das Innenministerium Anfang der sechziger Jahre eine "Argumentation über die Probleme der Republikfluchten und des Reiseverkehrs", in der NATO, Bundesrepublik und USA für die Auswanderung aus der DDR verantwortlich gemacht und die Flūchtlinge als Lückenfüller für die westlichen Spionageorganisationen dargestellt wurden, weshalb die Notaufnahmestelle in Berlin-Marienfelde "heute kein Flüchtlingslager mehr [sei], sondern eine große im Rahmen des Kalten Krieges raffiniert aufgezogene Spionagezentrale“. Fast alle westlichen Medien, vor allem aber der RIAS, mutierten zu „Agentenzentralen“ und Bonn zum Zentrum der ${ }_{\text {Menschenhāndler }}{ }^{2}{ }^{216} \mathrm{Jeder}$ westdeutsche EinfluB auf die DDR, egal ob konkrete Stellenangebote westdeutscher Firmen an Bürger der DDR oder Bonner Gesetze, die ohne Rücksichtnahme auf den kleineren deutschen Staat erlassen worden waren, diente angeblich nur einem Zweck, nämlich der Abwerbung zur Destabilisierung der DDR. Anders als die Bevōlkerung, die noch stark in nationalen, nämlich gesamtdeutschen Kategorien dachte, ${ }^{217}$ orientierten sich die offiziellen Berichte immer stärker an der Systemloyalitāt. Dadurch gerieten im Laufe der fünfziger Jahre selbst Besuche von Familienangehörigen im Westen immer stärker in den Verdacht, keine verwandtschaftlichen, sondern verdeckte politische Ziele zu verfolgen: ${ }_{n} \mathrm{DaB}$ heiBt, daB [...] eine Reise nach Westdeutschland heute oft mehr einer westlichen Orientierung wegen geschieht und allgemein gar nichts mehr mit der Aufrechterhaltung normaler verwandtschaftlicher Beziehungen zu tun hat. ${ }^{-218}$

Tatsāchlich konnten die Polizei und andere DDR-Behörden ihre vehemente Rhetorik gegen die Abwerbung, die sie mit zum Teil drastischen und offentlichkeitswirksam inszenierten Strafprozessen unterstrichen, ${ }^{219}$ nur āußerst selten mit konkreten und glaubhaften Beispielen belegen. Interne Berichte nannten nur sehr geringe Zahlen direkter Abwerbung ${ }^{220}$ und gaben zuweilen sogar - wie etwa für das Farben-Werk in Wolfen - offen zu: ${ }_{\text {„Konkrete Fălle der Abwerbung sind nicht bekannt geworden. " }}$ "21

Die Hilflosigkeit der DDR-Organe im Kampf gegen den Massenexodus korrespondierte mit der oberflāchlichen Wahrnehmung des Phänomens in den offiziellen Berichten. Neben der Individualisierung der Verantwortung für die Republikflucht im Fehlverhalten einzelner Funktionsträger in Staat und Partei verdichtete die SED ihre ,Erklārung' der Republikflucht - und all ihre Aversionen gegen den Westen - in dem Begriff der Abwerbung. Damit externalisierte sie die Verantwortung für die Republikflucht und nahm die gesamte Bundesrepublik als monolithisch geschlossenen Block wahr. Wie die SED ihre Kompetenzkompetenz für praktisch alle Lebensbereiche in der DDR reklamierte, so stell-

\footnotetext{
216 BArch DO 1/34, Nr. 21724.

217 Entsprechende Zitate aus dem letzten Jahr vor dem Bau der Mauer bei: Major, Torschlußpanik (2000), S. $233 \mathrm{f}$.

218 „Die Aufgaben der Volkspolizei im Kampf gegen die Republikflucht, bei der Regelung des innerdeutschen Reiseverkehrs und der Überwachung der Rückkehrer und Zuzüge" von Ende 1957 (BArch DO 1/11, Nr. 558, Bl. 78-101, hier Bl. 80).

${ }^{219}$ „Bericht über die Republikflucht aus der Deutschen Demokratischen Republik für die Zeit vom 1. 1. 1954 bis 31. 12. 1955" (BArch DO 1/11, Nr. 963, Bl. 100-130, hier Bl. 114-118): Seit Ende 1955 auch verstärkter Kampf gegen Abwerbung: Mehr strafrechtliche Verfahren: „Im IV. Quartal 1955 stiegen durch die Durchsetzung des Befehls 59/55 des Chefs der DVP die Verfahren gegen Abwerber auf 349 an, nachdem es in den ersten drei Quartalen des Jahres 1955 nur 59 waren."

220 BArch DO 1/11, Nr. 708, Bl. 10-13.

221 SPK, Chemiekaderkommission, am 28. 7. 1960 (BArch DO 1/34, Nr. 21725).
} 
te sie sich auch den Westen vor. Die nur begrenzte Durchdringung der westdeutschen Gesellschaft durch die Bonner Politik und die Eigenstāndigkeit verschiedener gesellschaftlicher Subsysteme, allen voran der Wirtschaft und der Wissenschaft, die besonders viele Menschen in den Westen zogen, paßten nicht in das kommunistische Bild von der Welt und ihren Gesetzen.

Zusammenfassend lãßt sich feststellen, daß die offizielle Ost-Berliner Wahrnehmung der Republikflucht zwar den kontinuierlichen Schwund der öffentlichen Akzeptanz feststellte, sich dabei aber weitestgehend auf die individuellen Motive konzentrierte. Die von der SED verantworteten politischen und wirtschaftlichen Strukturen fanden dagegen wenig Beachtung, weil die Berichterstatter es vermieden, die Grundlagen der sowjetisch gestūtzten SED-Herrschaft als Ursache für die in der DDR-Bevōlkerung verbreitete Unzufriedenheit zu thematisieren. Die Archivbestānde von CDU und LDPD zeigen die gleiche Tendenz: Obwohl beide Parteien ảußerst genau darüber Buch führten, wann welche ihrer Mitglieder die DDR verließen, finden sich - abgesehen von wenigen Ausnahmen ${ }^{222}$ - keine qualifizierenden Berichte und Analysen über den Massenexodus. Die bürgerlichen Parteien vermieden das Thema, da die Ursachen sowieso klar waren, eine eingehende Beratung und Erlãuterung aber ihr Verhältnis zur hegemonialen Partei belastet hätte. Damit umgingen sie es, sich für die Konfrontation mit der Partei- und Regierungsspitze oder für politisch linientreue, aber analytisch fehlerhafte Berichte entscheiden zu müssen.

Damit einher ging ein zweifaches systematisches Desinteresse der gleichen Institutionen: Obwohl die SED mit dem Bau der Berliner Mauer - trotz aller Rhetorik über ihre angebliche Schutzwallfunktion - die existentielle Bedrohung der DDR durch den Exodus eingestanden hatte, fehlen bis zu dieser Zeit eingehende Analysen über die Auswirkung der Fluchtbewegung auf die Gesellschaft der DDR. Für einzelne Berufsfelder wurden die personellen Verluste zwar aufgezählt, die Bedeutung für die gesamte DDR, vor allem aber die volkswirtschaftlichen Verluste wurden in den Führungsgremien von Partei und Staat weitgehend ausgeblendet. Die Hinweise auf die destruktiven Auswirkungen der Abwanderung in einzelnen Branchen faßten weder die Beobachter noch die Entscheidungsträger in Ost-Berlin systematisch zusammen. Die volkswirtschaftliche Bedrohung durch die Fluchtbewegung, die jeder Zukunftsrhetorik den Boden entzog, durfte anscheinend nicht empirisch gestützt untersucht werden. Erst aus den Jahren nach 1961 finden sich Berechnungen über die abwanderungsbedingten Verluste, ${ }^{2 * 3}$ mit denen die Ōkonomen der DDR aber weniger auf die Probleme des Massenexodus als auf die Legitimităt des Mauerbaus hinweisen wollten.

Das zweite Thema, das seitens des Regimes nicht genauer untersucht und erläutert wurde, war das Bedauern, das zahlreiche Flüchtlinge über ihren Weggang ãußerten. In zahlreichen Abschiedsbriefen, die in die Hände von Mitarbeitern der Polizei und anderer Behörden der DDR gerieten, äußerten Ärzte, Lehrer, Arbeiter, Studenten, Ingenieure und andere Flūchtlinge, daß sie die DDR, ihre Heimatstadt oder -region und vor allem ihren angestammten Arbeitsplať nur ungern verließen. So verließen zahlreiche geflūchtete

\footnotetext{
T22 Eine Ausnahme bildet die Ergānzung zur Sekretariatsvorlage vom 7.11.1960: „Republikflucht aus Kreisen der Intelligenz" (ADL, LDPD, L3-92).

${ }^{223}$ SED-Hausmitteilung Dr. Mittag an Ulbricht: „Einschâtzung der Verluste, die der Volkswirtschaft durch Abwerbung von Arbeitskräften entstanden sind." SAPMO-BArch NY 4182. Nr. 972, Bl. 88-93. Vgl. dazu auch Hoffmann, Lenkung des Arbeitsmarkts (1999), S. 73.
} 
Lehrer die DDR in den Schulferien, um ihren Schülern einen regulären Jahresabschluß zu ermōglichen, ${ }^{224}$ und vor allem Akademiker sahen die Abwanderung häufig nur als „letztes Instrument beruflicher Selbstbehauptung “. ${ }^{225}$ Hãufig versuchten Flūchtlinge mit ihrem Abschied noch Einfluß auf den Arbeitsplatz zu nehmen und gaben Hinweise auf die - in zahlreichen Besprechungen schon erwāhnten - fehlerhaften Strukturen etwa in den Fabriken und Krankenhāusern, in denen sie gearbeitet hatten. Einige bemūhten sich sogar, einen Teil ihres Privatbesitzes zu überschreiben; besonders offenherzig und engagiert zeigte sich dabei ein Kinder-Oberarzt: ${ }^{226}{ }_{n} \mathrm{Ich}$ gehe nicht leicht. Ich verlasse meine Eltern und einen großen Freundeskreis und meinen verehrten Chef, meine mir sehr am Herzen liegende Klinik und nicht zuletzt viele gute Kerle mancherlei Orts. Aber ich habe mich darüber hinweggesetzt, weil ich meine Arbeitskraft nicht sinnlos vergeuden möchte [...]. In diesem Zusammenhang möchte ich Sie, verehrter Herr Kreisarzt, um etwas bitten. Sie kennen die Mōbelnot unserer Klinik. Ich möchte, daß mein Schlafzimmer und mein Herrenzimmer dazu verwendet wird, einige Zimmer einzurichten. [...] Ich habe meinem Chef im gleichen Sinne geschrieben und schenke die Möbel der Klinik aus Dankbarkeit für meine Ausbildungszeit."

Einige Flūchtlinge āußerten sogar ihre Sympathie zum politischen System der DDR und beklagten nur das Fehlverhalten einzelner Vorgesetzter ${ }^{27}$ oder verwahrten sich gegen eine politische Instrumentalisierung in Ost- wie in Westdeutschland: So erklārte z. B. ein Arzt vor seiner Republikflucht, „daß er mit dem Aufbau des Sozialismus nicht mehr zu Recht kommt; da er mit dem System in Westdeutschland nicht einverstanden ist, will er nach Ghana gehen. ${ }^{\text {"228 }}$ In Lehnin verabschiedete sich ein Arzt im August 1960 vom Ortspfarrer mit dem Hinweis, daB er aus seiner Abwanderung in die Bundesrepublik kein ${ }_{\text {po- }}$ litisches Kapital und sonstige Vergünstigungen schlagen“ wolle: „Ich betone, daß uns niemand zwingt, die DDR zu verlassen, ich betone weiterhin, daß ich in der Bundesrepublik lediglich arbeiten und leben will und keinen Tag gesonnen bin, $\mathrm{mir}$ in Verleumdungen gegen die DDR zu gefallen. “229 Wie stark dabei die Grenze zwischen politischen und unpolitischen Fluchtgründen verwischte, zeigt die Klage einer Philosophiestudentin, die im Fach Marxismus-Leninismus öffentlich als ${ }_{n}$ negatives Element" beurteilt worden war. Vor ihrer Flucht hatte sie ihren Antrag auf Exmatrikulation damit begründet, ${ }_{\text {daß }}$ sie den Anforderungen eines sozialistischen Studiums weder physisch noch psychisch gewachsen sei. Es sei ihr unmöglich, in der Atmosphäre des Mißtrauens zu lernen, zu leben und gemeinsam [...] zu studieren [...]. Die Republikflüchtige betont, daß für sie keine andere Mög-

\footnotetext{
${ }_{224}$ Vgl. z.B. Meyer, Mdl HA Innere Angelegenheiten, am 8. 2. 1960 (BArch DO 1/34, Nr. 21720, „Aktenvermerk. Beur.: Ursachen der Republikfluchten der Lehrer im Januar 1960"), der diese saisonalen Aspekte allerdings nur auf die in den Ferienzeiten oberflächlicheren Kontrollen am Ring um Berlin zurückführt.

${ }^{225}$ Augustine, Frustrierte Technokraten (1996), S. 68. Vgl. ähnlich Ernst, Von der bürgerlichen zur sozialistischen Profession (1996), S. 28, und „Informationsbericht über die Republikflucht der Lehrer im Monat August 1960" (BArch DO 1/34, Nr. 21720) mit Hinweisen auf erklärende Briefe, die von Flüchtigen hinterlassen wurden.

${ }_{226}$ Abschiedsbrief des Kinder-Oberarztes Dr. med. Dieter P. vom 19. 10.1960 (Dok. 33).

${ }_{227}$ Vgl. z.B. den Brief von Dr. Siegfried Schöll aus Freiburg/Br. vom 19. 3. 1955 an den Bevollmächtigten des MdI, Herrn Schulz-Bãumler in Naumburg (Saale) (BArch DO 1/34, Nr. 11800).

228 BArch DO 1/11, Nr. 79, Bl. 134-167, hier Bl. 135, 139 f.

${ }_{229}$ 29. 8. 1960: Abschrift eines Abschiedsbriefes aus Wiesbaden von Dr. R.M. an den Pfarrer an seinem bisherigen Wohnort Lehnin (BArch DO 1/34, Nr. 21724).
} 
lichkeit übrig blieb und dieser Schritt für sie keine weltanschauliche Entscheidung bedeute. "230 Ganz offensichtlich fehlte nicht nur den SED-nahen Berichterstattern eine Ahnung von den engen Verbindungen und starken Auswirkungen zwischen Politik und Privatleben, wenn die massive Einschränkung der akademischen Freiheit selbst von einer Studentin als Privatangelegenheit verstanden wurde.

SED und Polizei reagierten auf solche Āußerungen des Bedauerns, die keine generelle Ablehnung der DDR und ihrer Regierung bedeuteten, überhaupt nicht oder nur mit ritualisierten MaBnahmen zur Zurückgewinnung von Flüchtlingen. Diese beschränkten sich gewōhnlich auf Gespräche und Belehrungen sowie auf einzelne Versprechungen und Bekundungen des guten Willens, endeten - wenn einzelne Flüchtlinge tatsāchlich zurūckgekehrt waren - aber immer wieder in polizeilicher Überwachung und systematischem Mißtrauen. So wie viele Flüchtlinge es in Abschiedsbriefen ankündigten, verweigerte die offizielle DDR eine differenzierte Wahrnehmung der meistens vielschichtigen und vordergründig auch unpolitischen Fluchtmotive. Statt dessen bewertete sie jeden Weggang ausschließlich nach ihren antagonistischen Mustern von Gut und Böse bzw. Ost und West. Damit war die Fluchtbewegung aber weder exakt wahrzunehmen noch zu verstehen und schon gar nicht effizient zurückzudrängen. Erst mit ihrem übertriebenen Mißtrauen und ihren dichotomen Kategorien trieb die DDR viele Menschen in den Westen.

230 Sekretariat für das Hoch- und Fachschulwesen, Sektor Kader: „Quartalsanalysen der Republikfluchten I. Quartal 1961“, 11.4. 1961 (BArch DO 1/34, Nr. 21721). 